Portland State University

PDXScholar

Spring 6-12-2015

\title{
Focus on a STEM, Based in Place, Watershed \\ Curriculum: A confluence of stormwater, humans, knowledge, attitudes, and skills
}

Lecia Molineux Schall

Portland State University

Follow this and additional works at: https://pdxscholar.library.pdx.edu/open_access_etds

Part of the Science and Mathematics Education Commons

Let us know how access to this document benefits you.

\section{Recommended Citation}

Schall, Lecia Molineux, "Focus on a STEM, Based in Place, Watershed Curriculum: A confluence of stormwater, humans, knowledge, attitudes, and skills" (2015). Dissertations and Theses. Paper 2352. https://doi.org/10.15760/etd.2349

This Thesis is brought to you for free and open access. It has been accepted for inclusion in Dissertations and Theses by an authorized administrator of PDXScholar. Please contact us if we can make this document more accessible: pdxscholar@pdx.edu. 
Focus On a STEM, Based In Place, Watershed Curriculum:

A Confluence of Stormwater, Humans, Knowledge, Attitudes, and Skills

by

Lecia Molineux Schall

A thesis submitted in partial fulfillment of the requirements for the degree of

\author{
Master of Science \\ in \\ Teaching in General Science
}

Thesis Committee:

Michael Flower, Chair

Stephanie Wagner

Matthew Collins

Portland State University

2015 


\begin{abstract}
This case study investigated the potential of a place-based watershed curriculum, using STEM principles, to increase watershed literacy and knowledge of human impacts on stormwater in the environment. A secondary goal was to examine whether the placebased connection and increased exposure to issues within their local watershed impacted the students' environmental attitudes and sense of place. Over 500 sixth graders participated in this localized curriculum, where they learned the science behind watershed issues on their own school campuses. They focused on ways humans can monitor and mitigate their impacts on stormwater, through engineering investigations. The mixedmethod research study investigated the effectiveness of the OLWEDU curriculum, to address these key questions: 1) To what degree did the OLWEDU increase the students' combined watershed literacy? 2) To what extent did the OLWEDU affect their environmental attitudes? 3) How did using a STEM oriented and place-based curriculum make the learning more relevant? In order to provide a solid triangulation of data, this study used a quasi-experimental design format with multiple measures: a) A Pre-Posttest (PPT), was given to all of the students to gather quantitative changes in knowledge of watershed concepts, stormwater issues related to human impacts on the environment, and engineering techniques; b) A constructed-knowledge questionnaire (CKQ) was used with forty four of the participants, to gather additional quantitative data on the students' local watershed knowledge; c) an environmental attitudes survey (EAS) was included in this sub-sample group; d) interviews were conducted with ten of the students to examine their opinions on the STEM aspects of the curriculum in addition to the place-based
\end{abstract}


connections between the unit and their community. The statistically significant results showed increases in overall watershed literacy, knowledge of human impacts on stormwater, engineering principles, and environmental attitudes. These findings will be used to improve the current curriculum, and have broader implications concerning the benefits of using a formalized middle-school $21^{\text {st }}$ century standards-based curriculum to teach watershed literacy and promote pro-environmental attitudes by using a combination of Science, Technology, Engineering, and Math in a local, place-based context. 


\section{Dedication}

It is with much gratitude that I dedicate this thesis to those who have attempted to integrate geographical and environmental education concepts into existing science programs and curriculums. What seems as a likely blending of knowledge, skills, and attitudes has often resulted in conflicting agendas. I honor those educators and scientists who see the infinite connections and attempt to align the shared outcomes through a Place-based, STEM, and Systems Thinking approach. To that end, I wish to state my admiration for those who acknowledged the need for and designed the O Lake Watershed Engineering Design Unit: The City of Lake O; The O Lake Watershed Council members; The Lake O School District administrators, teachers, and students; Portland State University's Center for Science Education faculty and graduate students. I look forward to sharing my enhanced skills and understanding with the next generation of youth.

In addition, I dedicate the completion of this thesis to my family, whose lives had to be put on the back burner for many months. Thank you all for allowing me to pursue the advancement of my own education. You all know how important education is to me. 


\section{Acknowledgements}

No one can achieve a graduate degree on their own, despite the reality that it is ultimately up to you to make it happen. Consequently I wish to acknowledge my classmates and professors for their part in helping me negotiate the path to a Master's in Teaching Science.

First of all I want to thank Stephanie Wagner for her dedication and support, and especially for bringing PSU's Center for Science Education to my attention. From that first winter term of 2012 in her Connect 2 Science, Connect 2 Water class, she has been

my advisor and guide along the way, through the nested watersheds of misconception and comprehension. I will always admire her ability to know what's happening up stream at every confluence and who to send to investigate it more.

Drawing on another one of earth's elements, I would also like to thank Melissa Potter for her ability to hold your feet to the fire, while also holding your hand. Her enthusiasm can light sparks under a person, and her determination helps you keep the embers glowing.

Being able to bring everything down to earth and simplify research and engineering is Cary Sneider's forte. His reminders to write in a fashion so that "your 
dear old Aunt Zelda" would be able to understand your thesis, was oft remembered. He also shared my beliefs that engineering is a human endeavor, for everyone, and needs to be encouraged within the science curricula at all ages.

In addition, I would like to thank William Becker for keeping his lofty ideals alive. I, too, believe that environmental education and STEM principles can coexist in the $21^{\text {st }}$ Century. In order to encourage knowledgeable and capable citizens a blending of the two is a necessity.

Many thanks to Michael Flower and Matthew Collins for agreeing to sit on my Thesis committee, and for sitting through my melting iceberg of a defense. You both gave me valuable suggestions for improvements on how to move away from the unconventional and towards clarity, while still keeping to my philosophical foundations.

Lastly, I wish to show appreciation for my colleagues in the 2013-2015 cohort. You have all given me wise advice, loads of encouragement, and hours of patience. Thank you. I just wish I had all of your writing and speaking skills. 


\section{Table of Contents}

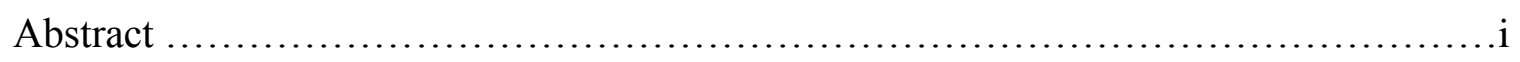

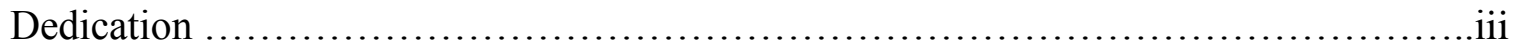

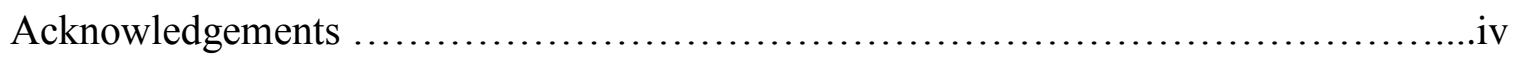

List of Tables............................................................. viii

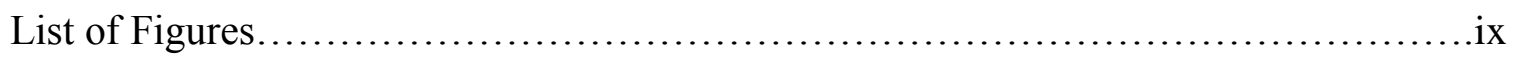

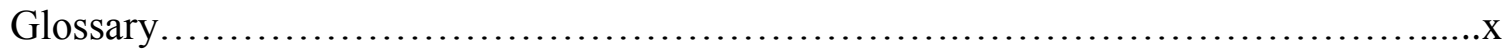

List of Abbreviations.........................................................

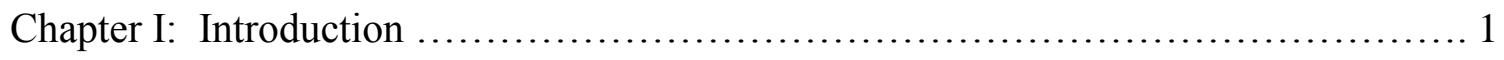

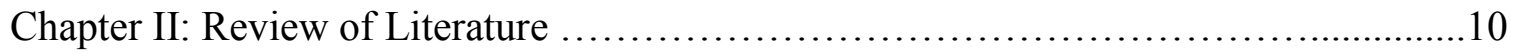

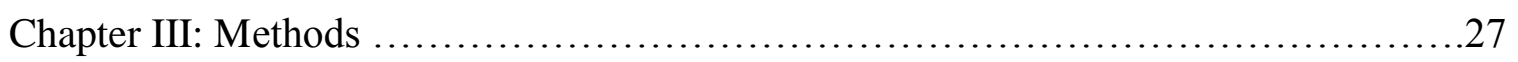

Chapter IV: Results ...................................................50

Chapter V: Discussion ...............................................69

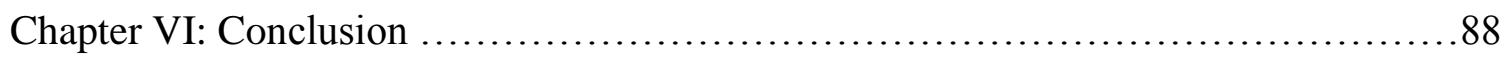

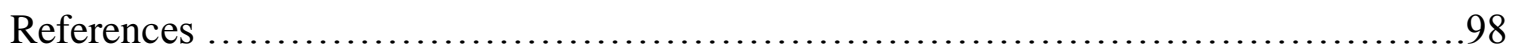

Appendix A: The Owl Lake Watershed \& Engineering Design Unit (OLWEDU) Pre/Posttest (PPT) ......................................... 103

Appendix B: Constructed Knowledge Questionnaire (CKQ) portion......................109

Appendix C: Environmental Attitude Survey (EAS) portion.......................112

Appendix D: Interview script of questions for the OLWEDU....................113

Appendix E: Next Generation Science Standards used in OLWEDU................116

Appendix F: Data Analysis Table of Instruments and Variables.....................117 
Appendix G: Excel Quick Analysis snapshot...................................123

Appendix H: Human Subject Protocol and Consent Forms........................ 124 


\section{List of Tables}

Table 1: Study design chart...............................................29

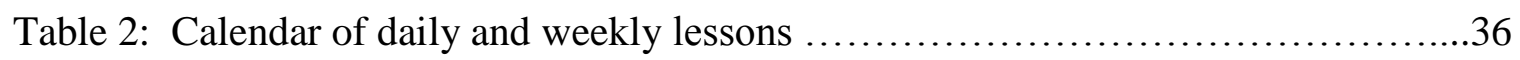

Table 3: Study timeline ................................................... 43

Table 4: Descriptive statistics for Pre/Posttest and Environmental Attitude Survey......51

Table 5: Descriptive data for Posttest and Constructed Knowledge Questionnaire.........54

Table 6: Descriptive statistics for Environmental Attitude Survey..................62

Table 7: Descriptive data for Environmental Attitude Survey .......................64

Table 8: Frequency data for Interview responses .........................................67 


\section{List of Figures}

Figure 1: Scatter plot of Pretest and Posttest (PPT)............................. 52

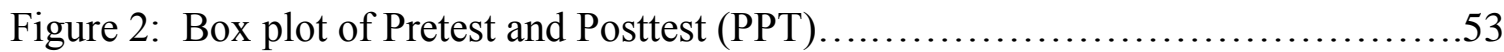

Figure 3: Bar graph of Pretest and Posttest for Watershed Literacy (WSL)............55

Figure 4: Bar graph of Pretest and Posttest for Human Impacts Stormwater (HIS)......56

Figure 5: Bar graph of Pretest and Posttest for Engineering Design Process (EDP).......57

Figure 6: Box plot of Environmental Attitude Survey: Before and After..............62

Figure 7: Cluster graph of Environmental Attitude Survey: Before and After.........63

Figure 8: Box plot of Environmental Attitude Survey questions \# 1-7: Change.........65

Figure 9: Bar graph comparison of PPT and CKQ with EAS Change..................66 
Glossary

Environmental education: (Tidball and Krasny, 2011)

"educational practices that help learners view themselves as part of nature, and that have the potential to contribute as one component of a larger system of practices and policies that positively impact community and environmental well-being."

Environmental literacy: (The Campaign for Environmental Literacy, 2007)

"The capacity of an individual to act successfully in daily life on a broad understanding of how people and societies relate to each other and to natural systems"

1) general awareness: a consciousness about the relationship between the environment and human life

2) knowledge: an orderly comprehension, application, analysis, synthesis, and evaluation of human and natural systems and processes

3) attitudes: process of thinking and acting based on appreciation and concern for the environment

4) critical thinking skills: practical exercises in problem solving and analysis

5) personal and collective action: participation in new behaviors

Place-based education: (Sobel, 1996)

"Place-based education is the process of using the local community and environment as a starting point to teach concepts in language arts, mathematics, social studies, science and other subjects across the curriculum. Emphasizing hands-on, real-world learning experiences..."

Pro-environmental attitudes and behaviors: (Hager, et al., 2013)

An increase in awareness concerning environmental issues surrounding air, water, land, plants, and creatures. Behaviors which support the well-being of the environment and its inhabitants.

Sense of place: (Kudryavtsev, et al., 2012))

A combination of place attachment and place meaning, specifically ecological awareness

Stormwater literacy: (Hager, G., et al., 2013)

- understanding of the natural hydrological cycle and how humans have changed the flow of water

- the difference between pervious and impervious surfaces

- understanding point-source and non-point sources of pollution and their effects on the environment.

- understanding the environmental and economic trade-offs of using Best Management Practices (BMP) to improve environmental quality and quality of life. 
Student outcomes (STEM): (Portland Metro Stem Partnership (PMSP) 2013)

- Academic identity: belonging/relatedness, competence/efficacy, autonomy/ownership, and purpose

- Motivational resilience: academic engagement and constructive coping/persistence.

- Application of conceptual knowledge: tasks requiring students to apply powerful disciplinary ideas and to organize and interpret information

- Higher-order Cognitive Skills: refer to the ability to: Problem solve; Develop an argument based on evidence; Communicate ideas, solutions, arguments, or conclusions in oral and/or written form; Utilize metacognitive skills

Watershed: (Shepardson, D. et al., 2007) (Endreny, 2010)

A watershed is the land area that provides runoff that feeds particular rivers, streams, lakes, ponds, or wetlands; that is, a watershed has a structure (i.e., flowing and still water).

- Watersheds are defined by elevation and relief.

- Watersheds have a structure that includes running water and still water.

- Watersheds consist of biological and physical components.

- Watersheds are changed by natural processes and human activity.

- Watersheds function to transport, store, cycle and transform water and materials.

- Watersheds are polluted by point sources, non-point sources and biological, organic and thermal pollution.

- The water cycle (precipitation, evaporation, condensation, infiltration and run-off) is responsible for the water in the watershed.

- A watershed is any body of water and the land that drains into that body of water.

- Topography defines and separates the watersheds.

- Smaller watersheds connect to each other forming larger more inclusive watersheds.

Watershed literacy: (Zint and Kramer, 2012)

Watershed literate individual should be able to:

- define the term "watershed",

- identify their local watershed(s),

- identify how watersheds are connected to the ocean via streams, rivers, and human-made structures,

- identify the functions that occur in a watershed (transport, store, and cycle water),

- recognize that both natural processes and human activities affect water flow and water quality in watersheds, 
- identify connections between human welfare and water flow and quality,

- identify possible point and non-point sources of water pollution,

- identify actions individuals can engage in to protect/restore water quality in watersheds, and

- identify how humans seek to manage watersheds

Research results categories of significance: (Stern et al. 2013)

- $0=$ Null (or negative) showed no statistical gain in quantitative data, or lack of positive outcomes in the qualitative data;

- $1=$ Mixed (or ambiguous) findings were attributed to statistically significant positive gains in most, but not all of the results. This was also the case for qualitative measures. This rating was also used in descriptive statistics where less than 50\%, but more than $0 \%$ exhibited positive outcomes.

- $2=$ Positive findings were associated with at least $50 \%$ of the participants exhibiting positive outcomes, including statistically significant positive outcomes for inferential statistically tabulated results. In qualitative studies any unusual null or conflicting data was reported as exceptions or outliers. These categories of results will also be used in describing the results of the current study. 


\section{List of Abbreviations}

ACK = application of conceptual knowledge

$\mathrm{BMP}=$ best management practices

$\mathrm{CKQ}=$ constructed knowledge questionnaire

$\mathrm{EAS}=$ environmental attitude survey

$\mathrm{EDP}=$ engineering design process

$\mathrm{EE}=$ environmental education

HIS = human impacts on stormwater

$\mathrm{INT}=$ interviews

$\mathrm{KAQ}=$ knowledge and attitude questionnaire

MWEEs = Meaningful Watershed Education Experiences.

NGSS $=$ Next Generation Science Standards

OLWEDU = Owl (Pseudonym) Lake Watershed Engineering Design Unit

$\mathrm{PBE}=$ Place based education

PEA $=$ pro-environmental attitude

$\mathrm{PPT}=$ pretest/posttest

STEM $=$ Science, Technology, Engineering, Math

$\mathrm{SWMP}=$ stormwater management practices

$\mathrm{WSL}=$ watershed literacy 


\section{Introduction}

As instructional time becomes as valuable as fresh water, it is vital to combine disciplines and apply learning to real-world, place-based applications, such as stormwater issues in a local watershed.

Locally relevant topics are needed to connect concept and skill development across subject areas and grade levels. A study of watersheds can serve this role; everyone on earth lives within a watershed; the quality of life is greatly affected by the condition of the local watershed; and watershed can serve as an instructional focus for active learning in science, mathematics, social studies, environmental education, and other subject areas (Haury, 2000, p.2).

Since the Clean Water Act of the 1970's, and then again in the 1990's in the form of the "National Environmental Education Act", national mandates for watershed education have been handed down from Congress and the US Environmental Protection Agency (EPA) to state and local authorities. (Public Law 101-619Nov.16, 1990). One of the ongoing questions has been under which jurisdiction or discipline watershed education lies. Municipalities have been entrusted in carrying out the mandates, or have left the duty to local watershed councils. Watershed education has often been viewed under a broader environmental education umbrella and left out of standardized science curricula. Consequently it has been a hit or miss proposition for students who might go to Outdoor School, or a local EE camp or nature center. Watershed literacy has also been considered to be an adjunct to studies in Geography (Eflin and Shaeffer, 2006). "Determined by the topography of a region rather than political boundaries, watersheds are areas of land defined by the flow patterns of rainwater or melting snow and ice." 
(Haury, 2000, p.2). This perspective appropriately incorporates the broader impacts of humans' behavior on the environment both near and far. Despite the arguments over which discipline Watershed Education (WE) should be covered, it has most often been included under the guise of Environmental Education (EE) (USDA Forest Service, 1993). As we enter the $21^{\text {st }}$ Century, and water consumption rises, the number of stakeholders is bound to increase. What better place to educate all citizens about watershed functions and related issues, than using the science classrooms of our public schools.

As one aspect of the broader EE umbrella, scientists, watershed education providers and environmental literacy advocates share many goals. Among them is the progression from knowledge and awareness to action (Stern, 2013; Zint, 2012). One of the purposes of educating citizens young and old is to assist them in making informed decisions. The Campaign for Environmental Literacy, established in February 2005, lists five essential components of environmental literacy which can also be correlated to watershed literacy: 1) general awareness, 2) knowledge, 3) attitudes, 4) critical thinking skills, and 5) personal and collective action (The Campaign for Environmental Literacy, 2007). It must be cautioned, however, that these hierarchical steps on the "literacy ladder" are an ideal model and that "literacy alone does not guarantee that the learner will exhibit a specified set of behaviors" (Campaign for Environmental Literacy, 2007). It has been found, however, that when people develop a connection to local natural resources, they do feel a greater responsibility toward their environment, translating into greater responsibility in their daily lives and activities (Vaske \& Kobrim, 2001). One of the key 
focuses of this research study is on how well the Owl Lake Watershed Engineering Design Unit (OLWEDU) addresses many of these important elements in this continuum from increased awareness to collective action, from knowledge and critical thinking skills, to broader attitudes.

Regardless of which discipline claims to be better suited to address watershed issues, a variety of informal and formal institutions have taken on the challenge of providing watershed education (Hager, 2013; Zint \& Kramer, 2012). Informally, local soil and water districts, metropolitan parks systems, and 4-H Extension clubs have produced workshops and camps to promote environmental and watershed ecology health (Hager, 2013; Kudryavtsev, et al., 2012). On the formal side of the equation, many nationally-recognized science institutions such as the National Oceanographic and Atmospheric Administration (NOAA), have funded and supported other Meaningful Watershed Educational Experiences (MWEE) developed to “increase students' and teachers' knowledge, attitudes, and skills so that they will act in ways to protect watersheds and related... ecosystems. “ Zint et al. (2012 p. i). Organizations involved in national science standards also include key aspects of watershed education in their documents (Achieve, 2014; National Research Council, 1996; Next Generation Science Standards Lead States, 2012). In order to further support watershed education, curriculum developers have published and provided curricula and workshops for teachers, such as Bay Watershed Education and Training Program (B-WET) and Project WET (Gruver \& Luloff, 2008; Zint et al., 2012). Unfortunately many of these curriculums, which were originally designed around local watersheds and ecoregions, have been expanded and 
used nationally. Although they have many quality aspects, they lack the necessary local connection to directly impact students' attachments to their own watersheds.

Consequently, some colleges and universities have collaborated with nearby school districts and watershed councils (Austin, 2012; Beatty, 2008; Eflin, 2006; Stagner, 2013) to provide standards-based curricula and assistance, as is the case with the particular construct of this study, the Owl Lake Watershed Engineering Design Unit (OLWEDU) (Gardner, 2013; Meinershagen, 2014). One problem noted of some curricula is the fact that, "school based science education primarily occurs in the classroom without including student experiences in the outdoors, even when its focus is on the natural world" (Carrier, 2013 p. 2060). Several researchers would agree with this statement and the power and necessity of conducting watershed education in a place-based setting rather than as a theoretical exercise (Elfin, 2006; Grunewald, 2003; Kudryavisev, Krasny, Stedman, 2012; Tidball, Krasny, 2011). David Sobel (1996) defines place-based education as:

Place-based education is the process of using the local community and environment as a starting point to teach concepts in language arts, mathematics, social studies, science and other subjects across the curriculum. Emphasizing hands-on, real-world learning experiences, this approach to education increases academic achievement, helps students develop stronger ties to their community, enhances students' appreciation for the natural world, and creates a heightened commitment to serving as active, contributing citizens. Community vitality and environmental quality are improved through the active engagement of local citizens, community organizations, and environmental resources in the life of the school (Sobel, 1996, p.6).

Therefore, in place-based curricula, such as the OLWEDU, the assumption is that students' awareness of the complexity of interactions between humans and their environments will be increased (Santelmann, Gosnell, \& Meyers, 2011). Students will be exposed to other factors in their own community, which affect watershed management, 
such as economic, political, and regional constraints (Santelmann et al.2011). One of the potential benefits of this curriculum is for the students to become aware of how using partnerships among community stakeholders impacts the environment and the community for future generations. As the students investigate and design stormwater solutions, using the same stormwater management practices (SWMP) that city leaders and providers do, they are exposed to real life criteria and constraints. They learn that the proposed solutions can have long-term consequences. Becoming more familiar with their community has the bonus potential of encouraging active civic engagement. Not only is participating in a place-based (PBE) school project potentially rewarding and engaging, having the ability to identify problems and then design solutions for them is one of the empowering aspects of including standards-based engineering in a middle-school science curriculum.

By asking questions and solving meaningful problems through engineering in local contexts (e.g., watershed planning...), diverse students deepen their science knowledge, come to view science as relevant to their lives and future, and engage in science in socially relevant and transformative ways (NGSS Lead States, Volume 2: Appendix I, 2013).

Focusing on real life STEM (science, technology, engineering, and math) practices, such as the engineering design process, has the potential to empower students and help them see themselves as bridging the divide between being helpless children and productive and creative adults in the future.

Consequently, it is my belief that the OLWEDU is a unique and viable method to approach EE, specifically watershed literacy (WSL). Not only is this curriculum authentically place-based, nestled in the familiarity of the students' schools and 
watershed, it is aligned with standards-based STEM (Science, Technology, Engineering, Mathematics) principles including the potential to meet performance expectations in the Next Generation Science Standards (NGSS Lead States, 2013). The use of the engineering design process (EDP) is engaging, and when combined with the focus on human impacts on stormwater (HIS) aspects, can lead to autonomy, purpose, and a relevant application of math and science skills. Using stormwater issues at the school level encourages place-based learning without the hassle, time, and cost of field trips. Sites can be monitored more easily and by more groups (classes). This in turn adds to the potential number of creative solutions which could be proposed. The curriculum presents the science content in a real-life, awareness, knowledge, attitude, skills, action continuum, (Campaign for Environmental Literacy, 2007) to all of the public school students regardless of demographics. Incorporating a place-based element into the watershed curriculum is central to both increased sense of place and ultimately proenvironmental attitudes.

Research Aims

Ultimately, the purpose of this mixed method case study was to assess the strength of the Owl Lake Watershed Engineering Design Unit (OLWEDU) to increase comprehensive watershed literacy in a population of middle school students within the Owl Lake watershed. Quantitative measures were used to determine if increases in watershed literacy relevant to stormwater issues and engineering design practices were statistically significant. Quantitative measures were also used to assess the degree of increase in place-based (PBE) specific knowledge. Pro-environmental attitudes (PEA), 
and intentions to act responsibly were also measured quantitatively. In addition, individual interviews provided qualitative data of the participants' opinions and observations regarding the STEM and place-based components of the curriculum as a whole. The outcomes of these mixed method instruments will be used to improve the OLWEDU and increase its potential for use in other watershed-related environmental programs. In analyzing the data from these instruments the researcher will consult Shepardson et al. (2012) for elements of watershed literacy; Stern and colleagues for their Best Practices (BP) for identifying characteristics of successful environmental programs; Zint and Kramer for their parameters of MWEEs (Stern, Powel, \& Hill, 2013; Zint et al., 2012).

The key questions guiding this study were:

- To what extent does the Owl Lake Watershed Engineering Design Unit increase:

a) The students' watershed literacy, including the ways human monitor and mitigate stormwater impacts on their watersheds?

b) The students' pro-environmental attitudes?

- How does using a place-based, STEM-formatted curriculum add relevancy to the unit?

Based on the aims of the research, the first hypothesis I propose is that students' inclusive watershed literacy will significantly increase as a result of participation in the Owl Lake Watershed \& Engineering Design Unit (OLWEDU). Included in this hypothesis is the confidence that students' comprehension of the structure and function of watersheds will be elevated after their involvement in the curriculum. Also under this watershed literacy umbrella is the conviction that students' understanding of human 
impacts on stormwater systems will be deepened after learning about the science of pervious and impervious surfaces. They will also exhibit an increase in skills surrounding the ability of humans to monitor and mitigate their impacts on stormwater systems.

The second hypothesis is regarding a byproduct of participation in the OLWEDU, and that is the assumption that students' pro-environmental attitudes will improve significantly as a result of involvement in the unit. There is also the underlying assumption that the students' sense of place will be amplified after experiencing the OLWEDU. This hypothesis is built upon the inherent factors of the local and place-based nature of the program. It is my understanding that this place-based nature of the unit will make the curriculum more relevant and give students a local sense of impact.

The third hypothesis will be regarding whether the use of STEM components are made relevant to the students. I expect to show that their awareness of STEM practices, such as the engineering design process, will be heightened after involvement in the OLWEDU. They will exhibit a familiarity with how the engineering design process might be used in real-life situations.

The independent variable of the study was the Owl Lake Watershed \& Engineering Design Unit (OLWEDU) treatment itself. The unit was conducted with approximately 500 students at two suburban middle schools over a five-six week period as part of the regular sixth - grade science instruction. The main dependent variables of the study included: students' watershed literacy (WSL), knowledge of human impacts on stormwater (HIS), and familiarity with the engineering design process (EDP) as measured by an embedded pre-post assessment (PPT) and a constructed knowledge questionnaire 
(CKQ). As a second key dependent variable, the students' pro-environmental attitudes (PEA) were measured using an environmental attitude survey (EAS). The third overarching dependent variable was the students' perceptions of the place-based and STEM design aspects of the unit, measured through individual interviews. The results of the study will be used to improve the featured curriculum, and could have broader $21^{\text {st }}$ Century implications for the development of E-STEM watershed curricula in other regions. 


\section{Review of Literature}

This review of watershed education literature provides both theoretical and empirical background to support the need for continuing research on place-based environmental literacy and formalized K-12 watershed curricula, specifically the Owl Lake Watershed Engineering Design Unit (OLWEDU). The combination of theoretical articles and case studies were chosen to seek clarification as to which institutions have been responsible for watershed education and which collaborations are best suited to educate today's citizens. The research studies range from urban to rural, national to local, and even one international one. It also includes some national reviews which give parameters for evaluating watershed education programs. Each study or report could be considered in one or more of the following sections, the key "element" being water:

- Watershed education as part of the Environmental Education movement

- Human impacts and community stormwater-based watershed education

- Place-based watershed education in both urban and rural settings

- Pro-environmental attitudes as a result of increased environmental literacy

- Formalized watershed education evaluations

- Local watershed education and attitude studies

\section{Watershed Education within Environmental Education}

The realm of environmental education (EE) is broad and difficult to define as Marc Stern and colleagues, Robert Powell, Dawn Hill, found in their review of 66 peerreviewed studies published during the years 1999-2010, entitled Environmental education program evaluation in the new millennium: what do we measure and what have we learned? (Marc J., Stern, Robert B. Powell, \& Dawn Hill, 2013). The authors 
empirically evaluated the outcomes of several environmental education programs to uncover what works and what doesn't, using the 'consensus based best-practices' named in the NAAEE Guidelines for Excellence. For their coding and analysis they identified the most common outcomes reported by the majority of EE programs; these outcomes of interest were: knowledge, awareness, skills, attitudes, intentions, behavior, and enjoyment, which are very similar to those named by the Center for Environmental Literacy (2007). Of particular significance to my evaluation of the OLWEDU was the finding that "Knowledge was the most commonly measured outcome in the review, followed by attitudes.” (Stern et al., 2013 p.8) In general Stern and colleagues found "broad evidence that EE programs can lead to positive changes in student knowledge, awareness, skills, attentions, intentions, and behavior." However they caution that while behavioral change is ultimately the goal of EE, "Decades of research on human behavior broadly recognize that knowledge gain is not typically a direct cause of behavior change." (p.23). The authors go on to examine why, then, the trend seems to be of knowledge being the most commonly measured outcome. This is certainly the case with the OLWEDU, which was not designed to directly illicit a behavioral change, but bring awareness of broader environmental aspects to the students while addressing stormwater issues.

In their academic article, Keith Tidball and Marianne Krasny (2011) evaluated environmental education from both a theoretical and pragmatic point of view. They contrasted traditional environmental education with an ecology of learning model, proposing a broader framework, or socio-ecological system (SES) of environmental 
education, which included ecological literacy. They stated the need to "go beyond factual knowledge, and incorporate understandings of ecological processes, scientific reasoning, and the relationship of individual actions to the larger ecosystem."(p.1) Tidball and Krasny's proposed SES model also addressed the relationships between the nested components of person, social, environmental, and cosmic ecologies. Their ultimate purpose was "to suggest educational practices that help learners view themselves as part of nature, and have the potential to contribute as one component of a larger system of practices and policies that positively impact community and environmental well-being." (p.2). One example of a civic ecology practice the authors mentioned, was a communitybased watershed restoration project, which would have measurable impacts on both the environment and the community. In their model Tidball and Krasny place the civic ecology education of humans as a crucial part of the solution, which enhances the practices of civic ecology and ultimately fosters the positive attributes of socialecological systems. With support from various community organizations, the OLWEDU is well poised to stimulate civic ecology and to teach students about the roles humans have in monitoring and mitigating stormwater issues on their own community, i.e. school campus.

The previous articles point to the complexities of addressing watershed literacy under the all-encompassing umbrella of environmental education, and how watershed literacy is only one aspect of the puzzle. The authors of these studies tend to agree that humans need to understand the overlapping and complicated nature of communities and watershed boundaries. As will be seen in the next section, narrowing the scope of 
watershed education to focus on human impacts on the environment and stormwater issues is one way to bring watershed awareness and literacy to the masses.

\section{Human Impacts and Community Stormwater Education}

In their 2013 report on the revitalization of an urban watershed Guy Hager and his colleagues also discussed the interactions between bio-geophysical dynamics and social actors and institutions. The authors examined the socio-ecological implications of retrofitting aging urban neighborhood stormwater systems using current best management practices (BMPs) in a collaborative approach between the community and the local Public Works. The research was conducted in a sub-watershed, identified as WS263, of the Chesapeake Bay watershed near Baltimore, Maryland during 2004-2009. Many local partners were involved in the project, such as the Baltimore City Department of Public Works, Parks and People, USDA Forest Service, Urban Forestry Work Group, and the National Science Foundation. The purpose was five-fold:

- To model and measure the results of BMP on water quality.

- Determine indicators for assessment of environmental quality and quality of life

- Help citizens apply new ecological concepts to revitalize their communities and watershed

- Determine whether a greening strategy affects the community and increases awareness of water quality issues.

- Develop educational activities associated with the greening of schools.

Using telephone surveys, the study assessed the ramifications of the local upgrades and greening projects. “The survey showed major changes in people's behavior in 
WS263 that may be related to efforts to improve water quality in the watershed." (p.33). One change was the increased participation in outdoor recreational activities, such as walking, biking, canoeing, fishing and motor boating, in relation to other parts of the city and region. The surveys also showed notable improvements in "neighborhood satisfaction" comparatively. Unfortunately, the satisfaction and increased neighborhood activity did not seem to directly transfer to watershed awareness, where there was actually a decline in the results. The Hager study did attribute some marked improvement in environmental science and literacy assessments which were tied to several corresponding school-based partnerships with local informal and formal education groups. During 2004-2009, the educational community collaborated at nearby schools and parks with place-based educational programs including professional development workshops and research. The authors noted the need for further correlational research regarding whether the links to K-12 education programs were significant and acted as a primary factor between ecological and socioeconomic revitalization. As one example of a collaborative effort amongst community and educational partners, a review of the OLWEDU will add to this body of research.

Olivia Odom Green and her colleagues at the US Environmental Protection Agency (EPA) also described a localized study surrounding an alternate approach to manage stormwater runoff and "crumbling water infrastructure" in a Cincinnati, $\mathrm{OH}$ urbanized watershed (2012). One of the goals of the project was to move away from relying on physical capital, such as the actual pipe infrastructure, and towards reducing the stormwater loads by incorporating green infrastructure (GI), like rain gardens. The 
study took place in 2007 and 2008, and involved offering neighbors the opportunity to participate in new stormwater management practices (SWMPs) on their property, namely rain gardens and rain barrels. Through statistical methods based on spatial clustering analyses, the authors Green, Shuster, Rhea, Garmestani, and Thurston analyzed the patterns of the GI confidential reverse-auction construction bids during the project and calculated the significance of human capital and social capital. Human capital was defined as the knowledge, skills and experiences that humans bring to an activity. Social capital was considered to be the combined set of those resources from the relationships among the neighbors, as measured by the patterns of the bids received for the new stormwater features in the neighborhoods. Although the intent was to focus on the human capital element to invoke positive change, by the end of the study, the researchers concluded that it was due to the nature of social capital that the auction bids for SWMPs increased in certain neighborhoods. More than one third of the 350 residential properties were awarded the installation of the 165 rain barrels and 81 rain gardens. The physical capital, or environmental benefits of the retrofits, included the ability to keep a substantial volume of the runoff in place at a much reduced cost than traditional infrastructure upgrades. Not only were the environmental goals met, the social and political ones exceeded expectations, illustrating the potential of this type of collaboration and the relationships among the various types of capitals. This intriguing way of looking at various forms of capital can be helpful when peering deeper into the social and political dynamics of the OLWEDU where students have the ability to bring their human 
capital into the classroom, combine it with their classmates during group projects to form social capital, and extend that social capital into their homes and neighborhoods.

These previous studies illustrate the power of community-based stormwater improvement projects to increase not only the health of the neighborhoods, but also the residents' sense of place and satisfaction. However, it is important to note that this increased satisfaction and involvement did not always result in increased watershed awareness and pro-environmental behavior. There was some encouraging evidence of increased environmental literacy within the educational forums, suggesting the need for further research into the benefits of systematic educational partnerships. The results of the OLWEDU study could certainly add to this body of research. These studies also support another feature of the OLWEDU curriculum, the importance of linking watershed education to a specific place, sometimes known as place-based education.

\section{Place-based Education}

The authors, Alex Kudryavisev, Marianne E. Krasny, and Richard C. Stedman, are members of the Department of Natural Resources at Cornell University, New York. In this study on urban environmental education and its impact on sense of place, the authors distinguished between place attachment (bond between people and places) and place meaning (essence of a place), which combine to form a sense of place (symbolic and memorable aspects of a place). In their quasi-experimental research design project, Kudryavtsev, et al. (2012) surveyed a total of 87 teenage youth from the Bronx, NY, during the summer of 2010. The authors administered a 5-point Likert scale survey before and after a summer urban environmental education program, as well as to a 
control group involved in other non-environmental organizations. Using paired t-tests to compare pre/post program scores, the results showed that there was no significant change in either groups' sense of place attachment, but there was significant change in the ecological place meaning. The results of the youths' surveys supported previous research findings that place attachment was less affected by environmental education programs, due to extenuating societal factors. Whereas, place meaning could be influenced by other experiences, in this case, the involvement in environmental education projects. In the end, Kudryavtsev, Krasny, and Stedman concluded that" interventions such as urban environmental education may nurture sense of place, which might foster place-specific pro-environmental behaviors.”(Kudryavtsev et al., 2012 p. 9). At the writing of the report, they were pursuing further detailed research with youth and educators. These results may shed light on other ways to increase place meaning. This study will inform the evaluation of the OLWEDU to increase sense of place and foster pro- environmental behaviors.

In their 2011 report, the authors: Mary Santelmann, Hannah Gosnell, and S. Mark Meyers described an intergenerational and rural place-based study that included approximately thirty middle school students and local landowners near the Muddy Creek Watershed outside of Corvallis, Oregon. The intent of the project was to engage students in watershed education within the confines of a public-school curriculum and their own rural setting. Several site visitations to the local landowners' properties and a regional refuge were included in the project, including some restoration projects. The interactions of landowners and students were recorded, transcribed, coded, and analyzed to identify 
relevant themes. From the hands-on activities, site visits, and especially the student-led interviews, the students appeared to grasp the ways physical geography plays a role within the watershed in relation to use of space, patterns of development, and landownerrelated variations. In addition, they were exposed to the other factors that contributed to watershed management, such as economic, political, and regional issues. The authors commented that, almost as a sideline, the students' sense of place was enhanced by the intergenerational aspects of the project. Unfortunately, the pre-and posttest evaluations did not directly collect information regarding changes in understanding for the specific areas of focus for each of the groups of students, but some increased understanding of place-based watershed issues did arise through the use of journals. In conclusion, although the authors admit that this unique study was limited both in scope and breadth, they contend that it illustrated the power of place-based environmental education, and is worthy of being replicated in another watershed.

As has been described, the distinction between place attachment and place meaning is an important one when it comes to place-based education and environmental literacy. When referring to a person or group's sense of place, knowing more about a place does not necessarily translate into taking on a stewardship role in that area. While there seems to be ample evidence from the studies for improved sense of place and environmental awareness, the direct connection between the increase of knowledge and an outcome of behavioral change is more elusive. To approach that ultimate conclusion, several researchers have investigated the interim aspects of changes in attitude toward the environment (ATE) and intent to act (ITA). 


\section{Pro-environmental Attitudes}

To address the need for some formalized method of measuring environmental attitudes, Lynn Musser \& A. Malkus (1994), researched other attitudinal measures and then developed the CATES: The children's attitudes toward the environment scale. It went through a very elaborate test-retest process to narrow down the various scales to a more manageable size. It was also designed to be used with grade-school children instead of adults. They used simplified language to approach the underlying attitudes and behaviors like: I think (belief); I do (behavior); I like (affect). The researchers had found that previously, educators and researchers had often just made up their own attitude measures, which allowed them to tailor the instrument to the particular program. In their research, Musser \& Malkus (1994) pointed out three disadvantages to this practice: $1^{\text {st }}$ Risk of sensitizing the participants to the purpose of the study (Oskamp, 1991). The closer the match, the higher the sensitization. $2^{\text {nd }}-$ When each study has it own scalecomparisons across studies and the programs in question are difficult. $3^{\text {rd }}$ - Unless the reliability of the scale is assessed prior to the study, the results are open to possible alternative explanations, whereby observed changes could be due to unreliable measures rather than actual attitudinal changes. By creating a universal common measurement system, the researchers hoped to be able to evaluate the shift in attitudes across programs. The CATES has been used in several respected studies since its origin, and a modified version has been used in the OLWEDU study.

One of those studies putting the CATES into practice, took place in Beirut, Lebanon, by researchers Saouma Boujaoude and Reine Youssef. The results of their 
study with two classes of seventh graders, was published in 2004. The purpose of the study was to investigate the effects of teaching an environmentally oriented science unit related to water on student's achievement in science and on their attitude toward the environment. They used the quasi-experimental design of Pretest, Treatment, and Posttest. The dependent variables in the study were: a) general achievement in science; b) achievement at comprehension level; c) attitude toward the environment. In addition, since the study used intact groups, students' grades in math and science, as well as their score on the achievement test prior to treatment, were used as covariates. They modified the CATES slightly, by having the students checkmark boxes to indicate their stance instead of a numerical value. The results indicated that they students in the experimental group achieved significantly higher scores and developed significantly more positive attitudes toward the environment than students in the control group. Due to the similar age group and watershed focus, these findings will be compared to those of the OLWEDU.

\section{Formalized Watershed Education Evaluation Programs}

Dr. Michaela Zint (2012) of the University of Michigan and colleague, Andrew Kraemer, conducted a comprehensive literature review of watershed education-related research in 2011 for NOAA (National Oceanic and Atmospheric Administration). It was pursued in order to apprise NOAA's own Bay Watershed Education and Training Program's (B-WET) evaluation system. Since NOAA fully supports and funds Meaningful Watershed Education Experiences (MWEEs) they had a vested interest in determining which constructs of interest were currently the most reliable and valid. This 
invaluable review and synthesis of watershed education substantiated the need for "watershed literate" citizens. Zint and Kraemer examined various instructional and professional development practices and delineated the key conceptual objectives of students, teachers, and environmental education programs. Of special note were their findings that, while MWEEs do lead to increased scientific knowledge, there is little evidence so far that environmentally responsible behaviors increase. While Zint and Kraemer have certainly provided a wealth of analyses and suggestions for the evaluation of NOAA's B-WET programs, they have also highlighted where there is a dearth of data in several areas related to MWEEs. They concluded that most watershed education studies have focused on qualitative data, which were "appropriate for assessing students' in depth understanding of watersheds." (p.21) However, due to the required resources needed to code these types of qualitative studies, they were not feasible for the B-WET evaluation data needs, which were more quantitative. Another area with a noted lack of research was in the realm of professional development practices for teachers of watershed education, although they frequently referred to a 30 hour minimum exposure/instruction time that was reported in order to facilitate a paradigm shift in students of all ages. The authors welcomed the prospect of future research to add to this comprehensive review of watershed education-related research.

Joshua Gruver and A.E. Luloff's 2008 study examined the curricular behavior of several hundred Pennsylvania science teachers, with regards to the teaching of watershed curricula. The research was designed to uncover which watershed curricula teachers were utilizing, how they were implementing it in their regular curriculum, and how they rated 
their confidence level in regards to teaching about watershed issues. Gruver and Luloff's research was undertaken in 2004 primarily through the use of a mail survey, which was administered to 400 out of an initial group of 2000 Pennsylvania science teachers. In preparation for the study the lead author also attended the 2-day state-required teacher training on the administratively-developed Watershed Education (WE) curriculum. In their empirical research, the authors determined that there were several factors which determined the efficacy of the teachers, ranging from socio-demographics to changes in the way national standards affect curricula and pedagogy. In measuring overall teacher confidence, the authors operationalized these three variables: classroom confidence, selfefficacy in the classroom, and watershed knowledge. While socio-demographic factors were found to have some influence on curricular behavior, the levels of self-confidence and self-efficacy were found to be more statistically significant. From the results of the study, the authors surmised that those curricula that were easier to use, required less preparation time, and were both age and grade appropriate were typically more easily adopted by teachers. In addition, the time involved in professional development of a new curriculum was found to be prohibitive as well. The authors emphasized how important it is for State agencies, cooperative extensions, non-profit organizations, and other watershed curricula developers to be mindful of these factors. The researchers also stated the need for further research in this essential, but behind-the-scenes, aspect of watershed education.

Daniel P. Shepardson and others had also previously addressed the issue of professional development for teachers in watershed education (Shepardson, D., Harbor, 
I., Cooper, B., \& McDonald, J., 2002, Shepardson et al., 2003). Afterwards, he turned his attention on the students in his 2005 study (Shepardson \& Harbor, 2005) and again in this particular article, What is a watershed? Implications of student conceptions for environmental science education and the national science education standards. (Shepardson et al., 2007). In this more recent research he and several other colleagues (Bryan Wee, Michelle Priddy, Lauren Schellenberger, and Jon Harbor) examined the drawings and explanations of hundreds of K-12 students from twenty-five urban and rural classrooms all over the Midwest and East coast. With a constructivist focus on how the student conceptualized their understanding of watersheds, he and several others evaluated and codified the results. They used a chi-square test to determine statistical significance of the frequency of the identified conceptions, and then narrowed the forty four codes or concepts into four major categories. The four Conceptions were arranged from highest to lowest (1-4) with each of them, except \#4, depicting "a watershed as a natural environment involving a natural process based on the hydrologic cycle." (p560) in increasingly complex order. Although most students saw "a watershed as an area of land with high relief and elevation where water is cycled, and stored or transported", the students primarily focused on the cycling of water between the land surface and the atmosphere, rather than water movement across the land and in streams and rivers. Only $29 \%$ of the students had a more developed conception which incorporated runoff or groundwater, and most of them lived in rural areas. Shepardson had identified the need for a more in depth understanding of watersheds, including function and transport. Based on these findings, a number of concepts were listed (see Glossary, page viii) which were 
used to guide the watershed literacy portion of the OLWEDU. He also stated the need for future research to examine the relationship between students' experience and education and their outward conceptions of watersheds. The evaluation of such curriculums as the OLWEDU should help in this longitudinal endeavor.

\section{Local Watershed Education and Attitude Studies}

A similar case study was done locally, by a Graduate student at Portland State University, Rachel Stagner (2013). Stagner's study, was an evaluation of a local nonprofit watershed education program that served school-aged children in the Portland area. Its focus was on the environmental knowledge and attitude gain after the year-long program, with particular interest in differences between ethnic and gender groups. The instrument which measured the changes in attitude toward the environment (ATE) and intent to act (ITA) was modified only slightly from Galey Beatty (2007), another PSU Center for Science Education Graduate student's assessment report completed for the regional Bureau of Environmental Services (BES). These Knowledge and Attitude Questionnaires included a mixture of question types: multiple-choice, short-answer, and longer-answer to engage multiple levels of cognitive function. Stagner's mixed results did show positive findings for an increase in knowledge of local watershed and related science concepts, but that ATE scores were somewhat positive but not statistically so since there were variations within the ethnic groups which skewed the results. The fact that this case study was done locally, and used a relevant combined knowledge and attitude instrument, lent to its usefulness in finding an appropriate set of instruments to 
add to the triangulation of instruments compiled for the current evaluation of the OLWEDU.

\section{Summary}

The studies presented here illustrate the point that research literature regarding watershed literacy and environmental education is as broad as it is deep. The studies have shown that the term watershed is both a geographical and political term, which encompasses not only bodies of water above and below ground, but human designed municipal stormwater tributaries as well (Eflin \& Shaeffer, 2006; Hager, 2013). In addition, many of the authors, such as Tidball and Krasny (2011) remind us of the farreaching and nested aspects of socio-ecological systems which include human, social, environmental, and cosmic ecologies. Santelmann et al. (2011) emphasized the importance of applying the concepts of watershed literacy at "home" in a place-based collaboration. Whether urban or rural, these studies support the need for quality MWEEs at all levels of society, including schools (Shepardson, 2007; Zint \& Kraemer, 2012)

Many of the concepts or instruments from each of the readings above were helpful in carrying out this OLWEDU research. Zint and Kraemer's MWEEs (2012), Green's (2012) notion of physical, human, and social capital, or Kudryavisev, Krasny, and Stedman's (2012) place attachment vs. place meaning survey were all relevant to the study. It has become obvious to me, as it was to Shepardson (2007) that any research study focusing on watershed education will need to address the broader environmental, societal, and educational issues surrounding the topic. It appears that there is still a need for relevant quantitative and qualitative research that supports or refutes the connections 
between watershed literacy, place-based environmental education and overall sustainability awareness that these reports describe.

My research has attempted to add to this body of literature, illustrating another example of the ways in which standards-based public education is well suited to tackle community watershed issues and increase watershed literacy at the same time. The focus on awareness of local watersheds and stormwater concerns will help support and validate the need for increased connections between the mandates of local municipalities and citizens. As a place-based project, the OLWEDU revolves around students examining stormwater issues within their surrounding watershed and onsite at their perspective schools. By taking more ownership of their place in the water cycle, it is hoped that the students' increased understanding of watershed issues will "spill over" into more proenvironmental attitudes and behaviors. Finally, it is important that documenting the use of an engineering format to investigate and mitigate stormwater solutions has added to the body of research surrounding the use of STEM practices and the adoption of the Next Generation Science Standards. 


\section{Methods}

Overview. This quasi-experimental, mixed-methods research project investigated the potential of The Owl Lake Watershed Engineering Design Unit (OLWEDU) to increase the watershed literacy and pro-environmental attitudes of middle school students within the confines of public education. This was the second year of the curriculum's implementation in the sixth grade science curriculum at the only two middle schools in the district. Four teachers conducted the unit with more than five hundred students as part of their regular science and engineering instruction.

The key questions guiding this study were:

To what extent does the Owl Lake Watershed Engineering Design Unit increase:

a) The students' watershed literacy, including the ways human monitor and mitigate stormwater impacts on their watersheds?

b) The students' pro-environmental attitudes?

- How does using a place-based, STEM-formatted curriculum add relevancy to the unit?

The independent variable or treatment in this study is the OLWEDU unit itself. The duration of twenty four lessons over the course of six weeks, or approximately 30 hours, (Calendar: Table 2) is considered a long enough treatment to initiate a paradigm shift in teachers, but just scratches the surface when it comes to really instilling literacy in students (Zint \& Kraemer, 2012; Gruver \& Luloff, 2008).

The effectiveness of the program was determined by using a triangulation of qualitative and quantitative instruments under a single group pre-post-test quasi- 
experimental design, (Study design: Table 1) with multiple waves of measurement (Trochim, 2006). No control group was available since all of the available sixth graders in the district were involved in the treatment at the same time. In the quasi-experimental design format a Pretest is used as a viable control to measure the gains of the intervention. Trochim supports the use of a variety of instruments, "In fact, in almost every applied social research project I believe there is value in consciously combining both qualitative and quantitative methods in what is referred to as a "mixed-method" approach" (Trochim, 2006).

One of the key dependent variables, changes in watershed literacy (WSL), was measured using two quantitative instruments, the Pre/Posttest (PPT) (see Appendix A) and the Constructed Knowledge Questionnaire (CKQ) (see Appendix B). The Pre/Post Assessment (PPT) consisted entirely of multiple-choice items, and was administered to all sixth grade students as part of the standard curriculum, over five hundred. The constructed knowledge questionnaire (CKQ), was given to a smaller subset of the student sample, just over forty.

The second, watershed-related variable, which focused on human impacts on stormwater (HIS), was measured with both the PPT and the CKQ. The specific questions required knowledge of pervious and impervious surfaces, as well as other detrimental human practices.

A third dependent variable revolved around the engineering design process (EDP), incorporated under the technology, engineering, and math components of STEM. Ability in this domain was measured by the third section of the PPT and one on the CKQ. 
The following diagram (Table 1) illustrates the design of the study:

Table 1: Quasi-Experimental Design with multiple waves of measurement of the Owl Lake Watershed \& Engineering Design Unit (OLWEDU) research project.

\begin{tabular}{|c|c|c|c|c|c|}
\hline Teacher/Period & Pretest & $\begin{array}{c}\text { OLWED } \\
\text { Unit }\end{array}$ & Posttest & Survey & Interview \\
\hline C. 1 & $\mathrm{O}_{1}$ & X & $\mathrm{O}_{1}$ & $\mathrm{O}_{2}$ & $\mathrm{O}_{3}$ \\
\hline C. 2 & $\mathrm{O}_{1}$ & $X$ & $\mathrm{O}_{1}$ & & \\
\hline C. 3 & $\mathrm{O}_{1}$ & $X$ & $\mathrm{O}_{1}$ & & \\
\hline C. 4 & $\mathrm{O}_{1}$ & $X$ & $\mathrm{O}_{1}$ & & \\
\hline C. 5 & $\mathrm{O}_{1}$ & $X$ & $\mathrm{O}_{1}$ & & \\
\hline A. 1 & $\mathrm{O}_{1}$ & $X$ & $\mathrm{O}_{1}$ & & \\
\hline A. 2 & $\mathrm{O}_{1}$ & $X$ & $\mathrm{O}_{1}$ & & \\
\hline A. 3 & $\mathrm{O}_{1}$ & $X$ & $\mathrm{O}_{1}$ & & \\
\hline A. 4 & $\mathrm{O}_{1}$ & $\mathrm{X}$ & $\mathrm{O}_{1}$ & & \\
\hline A. 5 & $\mathrm{O}_{1}$ & $X$ & $\mathrm{O}_{1}$ & & \\
\hline A. 7 & $\mathrm{O}_{1}$ & $X$ & $\mathrm{O}_{1}$ & & \\
\hline B. 4 & $\mathrm{O}_{1}$ & X & $\mathrm{O}_{1}$ & $\mathrm{O}_{2}$ & $\mathrm{O}_{3}$ \\
\hline B.6 & $\mathrm{O}_{1}$ & $X$ & $\mathrm{O}_{1}$ & & \\
\hline B.7 & $\mathrm{O}_{1}$ & $X$ & $\mathrm{O}_{1}$ & & \\
\hline D.1 & $\mathrm{O}_{1}$ & $X$ & $\mathrm{O}_{1}$ & $\mathrm{O}_{2}$ & $\mathrm{O}_{3}$ \\
\hline D. 3 & $\mathrm{O}_{1}$ & $X$ & $\mathrm{O}_{1}$ & & \\
\hline D.4 & $\mathrm{O}_{1}$ & $X$ & $\mathrm{O}_{1}$ & & \\
\hline D.5 & $\mathrm{O}_{1}$ & $X$ & $\mathrm{O}_{1}$ & & \\
\hline D.6 & $\mathrm{O}_{1}$ & $X$ & $\mathrm{O}_{1}$ & & \\
\hline D.7 & $\mathrm{O}_{1}$ & $\mathrm{X}$ & $\mathrm{O}_{1}$ & & \\
\hline
\end{tabular}

Capital letter $*$ Number $=$ Last name of teacher $*$ Class period

$\mathrm{X}=$ Treatment (Owl Lake Watershed, Engineering Design Unit)

$\mathrm{O}_{1}=$ Pretest and Posttest $(\mathrm{n}=358)$

$\mathrm{O}_{2}=$ Survey Subset (given to one class out of each three of the four teachers) $(\mathrm{n}=44)$

$\mathrm{O}_{3}=$ Interview Subset (conducted with randomly-drawn students, having been identified as eligible for interview on their permission slips) $(n=10)$

The fourth and final dependent variable addressed the students' proenvironmental attitudes (PEA), which was measured by a recollection Proxy Pretest 
Design, (Trochim, 2006) using the Likert-scaled environmental attitude survey (EAS) portion (Appendix C) Both the CKQ and the EAS were administered after completion of the unit to a subset of forty-four students. The subset was derived from one class from each of three of the four teachers.

In order to determine how using a place-based (PBE) and STEM-framed curriculum impacted the students' engagement and sense of relevance in the project, ten students were interviewed. From those same three classes identified above an additional smaller, sub-set of ten students was chosen randomly by number to participate in one on one interviews. These were recorded and paraphrased during the interview process.

Participants. Along the Willamette River near Portland, Oregon, there lies a unique watershed and suburban community where this research project took place. The watershed area is known as Owl Lake Watershed. The specific OLWEDU curriculum and research was conducted at the two local middle schools in the Owl Lake School District. The sixth grade classes had been previously incorporated into the junior high school programs during the 2013-2014 year. The middle school science curriculum at the $6^{\text {th }}$ grade level, revolves around Earth Science and includes an Outdoor School experience. The OLWEDU was designed to not only incorporate STEM components into the curriculum, but to honor the Oregon Department of Education's (ODE, 2009) state engineering sample requirement.

Each school has two science teachers, who teach between three and six classes a day; two of the teachers also teach a half day of math. The overall district average of students meeting or exceeding the Oregon State Standards in math and science, as 
measured by the OAKS test, is in the $90 \%$ s, well above the state average of approximately $60 \%$. The student population is over three quarters Caucasian (ODE, 2013).

Most of the classes average between twenty-five and thirty students and are often divided into smaller working teams during instruction. For the purposes of this research, each class was considered a sub group of the main single group in the study design, for a total of twenty sample groups. Each subgroup was identified by the teacher's last name (coded) and the period in the schedule; the students' names were blanked out and numerically coded to preserve anonymity, while making it possible to match pre and post tests and also to retrieve the contact information on the permission slips.

Pre/Post (PPT) assessments, embedded into the unit, were given to all of the five hundred students as part of their regular curriculum. After processing the permission slips and accounting for both Pretest and Posttest, a total sample of three hundred and fifty eight were included in the final research. The constructed knowledge and environmental attitude questionnaires (CKQ and EAS) were given to just one class per teacher for a total sample size of forty four. The final number of actual interviews was restricted to ten students, due to time and scheduling constraints. Interviewees were selected on site and drawn randomly from the pool of students whose parents provide signed permission slips.

Treatment/Intervention. In its second year now, the treatment used for this research study, is known as the Owl Lake Watershed Engineering Design Unit (OLWEDU). The idea and purpose of the unit was originally conceived in 2012 in collaboration with The Center for Science Education (CSE) at Portland State University 
(PSU), the Owl Lake Watershed Council, the City of Owl Lake and the Owl Lake School District. One of the original graduate students, Riley Meinershagen, involved in the project, met with the $6^{\text {th }}$ grade team of teachers to discuss their academic needs and desires. The actual lessons were then created by Elizabeth Gardner and then piloted in 2013. It is important to note that other PSU graduate students in their CSE cohort were instrumental in designing specific aspects of the curriculum, such as the Stormwater Calculator and Stormwater Planting Guides. Assistance was also provided by the school district, the city planning department, two watershed councils, and a nearby state park, which added to its place-based breadth and impact. The curriculum was designed to not only address local watershed concepts, but to teach components of the Framework for K12 Science Education, NGSS standards and STEM practices, especially the engineering design process (EDP). This STEM and Place-based combination of content and process was especially pertinent in looking at stormwater mitigation practices in the context of the real world.

The main objectives of the OLWEDU unit were for students to be able to:

1. Explain what a watershed is and how it functions.

2. Describe impervious surfaces and connect their impact to the watershed.

3. Perform the Engineering Design Process to design mitigation for the impervious surface impact.

Each of these objectives was broken down into three to five components which were stated as learning progressions from novice ability to expert mastery. Each objective has been aligned and designed to coordinate with the Next Generation Science Standards 
(NGSS 2012). (Appendix E) Accomplishment of these objectives was measured by a PrePost Assessment that is embedded in the curriculum.

The OLWEDU unit is comprised of approximately 24 lessons lasting five-six weeks. (See Table 2 below) The unit begins and ends with the same multiple-choice Pre/Post Assessment of students' watershed concepts, understanding of human impacts on stormwater flow, and knowledge of the EDP. There is a correlated lab packet where the students' notes and calculations are recorded as they progress through the lessons. The final product of the unit is the engineering design work sample, which is scored using the 2011 edition of the Oregon Department of Education's Official Engineering Design Scoring Guide for Grades 6,7, and 8. References and activities related to knowing how to use this rubric are included in the unit.

The STEM-designed unit is divided into five weekly segments. After the Pretest is completed, the unit begins by covering the background science, including a review of the water cycle. Students are introduced, or reintroduced, to watersheds by making a simple paper model. In this way, the students can visually discern what makes up a watershed and are prompted to consider observable and unobservable mechanisms as outlined in the NGSS Performance Expectation MS-ESS2-4 (Appendix E) NGSS Lead States, 2013). Next, in order to learn what happens underground during the cycling of water on the planet, the students witness an infiltration demonstration onsite at their respective schools. This investigation on the school grounds is one of the many placebased features of the unit. The students also perform mathematical calculations during this activity. At this point the teacher introduces a number of concepts related to the 
watershed, addresses any misconceptions identified from the pre-test, and begins instruction in the Disciplinary Core Ideas (DCI) from the NGSS related to Earth and Human Activity (NGSS Lead States, 2013).

The fourth lesson directs the students' attention towards the issues of impervious surfaces and their unnatural interferences in the water cycle on the smaller scale of a residential home. This activity ties in awareness of human impacts on watersheds by asking the question: If the rain that falls on the roof, car, driveway, and paved street does not infiltrate, what happens to it? (Lesson 4). The first week's culmination project is directly place based, as the students are asked to calculate how much their campus contributes to the problem of untreated stormwater entering nearby assorted drainages. Using city developed grid overlays and aerial maps, the students calculate (NGSS Practice \#5) the total impervious surface area of the campus, including the volume of precipitation that fell onto it the previous year.

As the lessons progress into the second week, (Table 2) there is an introduction to the Engineering Design Process (EDP), which focuses and incorporates the onsite stormwater issues at the schools. In Lesson 6 the students establish and define the problems associated with stormwater, particularly on their school campuses. In the next lesson, they are introduced to the EDP. A modified version of the EDP is used for simplicity's sake, focusing on: Defining, Developing, and Optimizing solutions. Here the discussion of the relationships between Engineering (designing solutions) and Technology (the actual solutions) are addressed. As the students proceed with Lesson 8, they learn how to choose criteria (goals) and constraints (limitations) according to their 
own engineering challenges, as well as, understanding the stormwater management guidelines proposed by the local municipal authorities. In this case, they are provided with a modified Owl Lake Stormwater Manual developed in conjunction with the city. At this point, Lesson 9 involves completing the first section of their official Oregon Department of Education (ODE) Engineering Work Sample: Part 1, Identifying and Defining a Problem to be Solved.

Week three (Table 2) proceeds with Lesson 11 and some hands-on applications of collecting data for their specific plots. In this lesson the teacher divides the students into engineering design teams of four and gives each student a card that defines their role within the group in order to enhance their motivation and engagement in the task. The curriculum is not only designed to engage the students by mimicking real-life engineering situations, but it illustrates to the students that accountability is part of the process. In their teams, the students will continue to consult the aerial grid overlay of the school grounds and choose a portion where they will focus their calculations and potential stormwater solutions.

For the rest of the lessons into week four, the students measure, design and "test" their proposed mitigations to the stormwater runoff problem using site visitations, maps, and an online calculator. At this point they complete the ODE Work Sample: Part 2, Generating Possible Solutions. During the fifth week, each group presents their proposed stormwater solution, for the specific campus area they are studying, via a Design Charrette. The ODE Work Sample: Part 3, Testing Solutions and Collecting Data is completed. Using the PUGH chart format, the classes decide which stormwater solutions 
fit the criteria and constraints of the project. They are encouraged to modify their proposals as needed in response to their classmates' observations and recommendations. Week six, Work Sample: Part 4, Analyzing and Interpreting Results is done. The classes are given the Pre/Post Assessment. If time and logistics allow, the students present their ideas to parents, community members, school board, or the local watershed council.

Table 2: Weekly Assignments for the OLWEDU

\begin{tabular}{|c|c|c|c|c|}
\hline Pre-Assessment & $\begin{array}{l}\text { Watersheds and the } \\
\text { Water Cycle }\end{array}$ & $\begin{array}{l}\text { Infiltration } \\
\text { Investigation }\end{array}$ & $\begin{array}{l}\text { Runoff and } \\
\text { Impervious surfaces }\end{array}$ & Campus calculations \\
\hline \multicolumn{5}{|l|}{ WEEK 2: MAY 12, } \\
\hline \multirow[t]{2}{*}{ Campus Calculations } & $\begin{array}{l}\text { Establish and Define } \\
\text { the Problem }\end{array}$ & $\begin{array}{l}\text { Introduce the } \\
\text { Engineering Design } \\
\text { Process }\end{array}$ & $\begin{array}{l}\text { Choose Criteria and } \\
\text { Constraints }\end{array}$ & $\begin{array}{l}\text { Engineering design } \\
\text { teams are formed }\end{array}$ \\
\hline & & & & $\begin{array}{l}\text { Work Sample: Part } 1 \\
\text { Identifying and } \\
\text { Defining a Problem } \\
\text { to be Solved }\end{array}$ \\
\hline \multicolumn{5}{|l|}{ WEEK 3: MAY 19} \\
\hline $\begin{array}{l}\text { Tools for Collecting } \\
\text { Data on Site }\end{array}$ & $\begin{array}{l}\text { Select Sites on } \\
\text { Campus: LOJH or } \\
\text { LRJH }\end{array}$ & $\begin{array}{l}\text { Introduce the Pugh } \\
\text { Chart }\end{array}$ & $\begin{array}{l}\text { Introduce Stormwater } \\
\text { Manual }\end{array}$ & $\begin{array}{l}\text { Research Stormwater } \\
\text { Solutions }\end{array}$ \\
\hline \multicolumn{5}{|l|}{ WEEK 4: MAY 26} \\
\hline holiday & $\begin{array}{l}\text { Create a Detailed } \\
\text { Design }\end{array}$ & $\begin{array}{l}\text { Create Data from the } \\
\text { Design }\end{array}$ & $\begin{array}{l}\text { Evaluate the Detailed } \\
\text { Design }\end{array}$ & $\begin{array}{l}\text { Work Sample: Part } 2 \\
\text { Generating possible } \\
\text { solutions }\end{array}$ \\
\hline \multicolumn{5}{|l|}{ WEEK 5: JUNE 2, } \\
\hline $\begin{array}{l}\text { Hold a Design } \\
\text { Charrette }\end{array}$ & Design presentations & $\begin{array}{l}\text { Work Sample: Part } 3 \\
\text { Testing Solutions and } \\
\text { Collecting Data }\end{array}$ & $\begin{array}{l}\text { Post Assessment } \\
\text { Interviews and } \\
\text { Surveys conducted } \\
\text { by researcher }\end{array}$ & $\begin{array}{l}\text { Post Assessments } \\
\text { continue }\end{array}$ \\
\hline \multicolumn{5}{|l|}{$\begin{array}{l}\text { WEEK 6: JUNE 9, } \\
2014\end{array}$} \\
\hline $\begin{array}{l}\text { Design presentations } \\
\text { continue }\end{array}$ & Posttests are scored & $\begin{array}{l}\text { Work Sample: Part 4: } \\
\text { Analyzing \& } \\
\text { Interpreting Results }\end{array}$ & & School year ends \\
\hline
\end{tabular}




\section{Instruments}

Pre-Post Knowledge Assessment. (Appendix A) The OLWEDU curriculum already has a quantitative Pre-Post Assessment embedded in the first and last lessons. The multiple-choice questions were grouped according to the three main objectives of the unit: watershed literacy (WSL), impervious surfaces (HIS); and the Engineering Design Process (EDP). Included in the tests were questions which referred to a local watershed map, photo of a residence showing impervious surfaces, a completed PUGH chart, and other graphics depicting visual representations of a watershed. In addition a sheet of grid paper was included for use in determining area. It was decided to administer the original version in order to compare the students' current scores (2014) with the previous year's results (2013). Future modifications will be made based on these comparisons.

Constructed Knowledge Questionnaire. (See Appendix B) In order to further assess the students' knowledge of WSL, HIS, and EDP quantitatively, it was decided that an additional instrument was needed. According to Judith Gray "educators must use more than one assessment method" to take into account various learning styles and strategies. (Gray, 2005). These constructed responses were to be used as a double check on the Pre-Post Assessment to accurately measure watershed literacy and knowledge of human impacts on the environment with regards to stormwater. A Knowledge \& Attitude Questionnaire (Beatty, 2007; Stagner, 2013) was discovered during the search for an appropriate measure for environmental attitudes (see EAS below) which had a similar focus to the OLWEDU. The final version of the CKQ used a combination of structured and unstructured formats. (Trochim, 2006) Instead of a multiple-choice question asking 
what a watershed was like in the Beatty/Stagner version, in the CKQ the students were asked to describe a watershed to a friend and then draw a model of a watershed. As a place-based assessment, instead of answering a single question about what watershed their school was in as was done by Beatty (2007) and Stagner (2013), the students were asked to list their "watershed address" (also known as ecological address) by comparing their street address with their school's watershed address (OSU Extension, 1999). An another question was slightly altered to prompt the students to list two things that people can do to keep their watershed healthy and clean. A Beatty/Stagner question asking the student to list three native plants or animals was deleted and replaced by a couple of more pertinent questions regarding impervious surfaces and human impacts on their watersheds. A final question was added to prompt the students to explain a novel use of the engineering design process. The point was to use portions of the Beatty/Stagner but to also upgrade the questions to reflect $21^{\text {st }}$ century practices. "In the ideal, some of the assessment should consist of familiar tasks to judge student comprehension of what was taught; other assessment items should pose novel tasks to judge transfer of what has been learned?" (Stern \& Ahlgren, 2002, p 893).

In addition to the face validity given previously to the portions borrowed from Beatty and Stagner (Beatty, 2007; Stagner, 2013) the CKQ version of the instrument was given face validity with feedback from colleagues and instructors at PSU's CSE. A Markscheme (included in Appendix B) was then designed with suggested answers to score the questionnaire, which included examples of human impacts, impervious 
surfaces, and other ways to use the EDP. The CKQ was given at the same time as the following Environmental Attitude Survey (EAS).

Environmental Attitude Survey. (Appendix C) Finding an appropriate survey to measure place-based environmental attitudes pertaining to watershed awareness was challenging. In reviewing the selection of typically cited instruments, such as the CATES: Children's Attitudes Towards the Environment by Musser and Malkus (1994), and the CHEAKS: Children's Environmental Attitude and Knowledge Scale (Leeming, Dwyer, \& Bracken, 1995). I found these instruments to be too broad, too general, too simplistic, or too outdated. When considering the current sophistication and social standing of the students involved in the research study, it was imperative to find or develop an instrument which addressed current attitudes and behaviors. Such a survey, utilized by Rachel Stagner, was located within the archives of the CSE department at PSU (Stagner, 2013). This survey directly related to the watershed concepts and proenvironmental attitudes under examination, it was fittingly place-based by being a locally-cited instrument. The Stagner research had been done for a local, non-profit watershed education program that served school-aged children in the area. It had also been a part of the 2004-2006 Assessment Report for the Bureau of Environmental Services: Clean Rivers Education Program (Beatty, 2007). That instrument, in turn, had been modified from one of Michaela Zint's instruments used in the B-WET program (Zint, et al., 2002).

The complete Stagner Knowledge and Attitude Questionnaire (KAQ) instrument was examined by several experts, knowledgeable in watershed literacy concepts, to 
determine validity. The following passage, taken directly from the Rachel Stagner Thesis (2013) describes the reliability testing done on the instrument prior to my usage:

To determine how internally consistent or "reliable" our attitude survey was, a Cronbach's Alpha Reliability test was run on the pretest data in SPSS. Cronbach's Alpha for the overall ATE (questions 1-13) was 0.807, 0.771 for ITA (questions 1-6), and 0.676 for EA (questions 7-10). Sources suggest that a minimum alpha of 0.70 is acceptable for social science research, while an alpha of 0.80 is excellent (Garson, 2008; Simon, 2004). Accepting these benchmarks, our overall ATE survey would fall into the excellent category, the ITA portion would be below acceptable, and the EA portion would be good. However, it should be noted that the low number of items in both the ITA and EA sections of our survey may have more to do with the low individual section alphas than the consistency of the measure (Garson, 2008; Nunnally, 1978).

Therefore, a modified Stagner/Beatty Knowledge and Attitude Questionnaire, was utilized for the current research, which combined local watershed knowledge, and personal environmental attitudes, as well as intent to act in the future. As was mentioned above, the knowledge section of the Stagner KAQ was modified to form the CKQ of the current research. The attitude portion of the questionnaire became known as the environmental attitude survey (EAS) for the purposes of this research. The Likert-style questions allowed the students to choose a response based on a continuum from Strongly Disagree to Strongly Agree. Only some slight modifications were made between the two. The first element to change was the ordering of the sections; in the Stagner version the intent to act (ITA), (in the next 6 months, I intent to...) portion came before the attitude toward the environment (ATE) section. Since the EAS for this research was a retrospective survey, looking at what the students' attitudes were before and after participating in the OLWEDU, it was felt that it was better to have the questions in a more chronologic order: before, after, future. Additional slight modifications were made 
to the wording, substituting watersheds for streams and rivers in some cases. Other questions were deleted entirely: KAQ \#7, I think rivers and streams in our city are polluted; KAQ \# 11 My teacher thinks it is important to help protect our rivers and $\underline{\text { streams. }}$. These were replaced with questions more pertinent to the HIS focus: EAS\# 1, $\underline{\text { It }}$

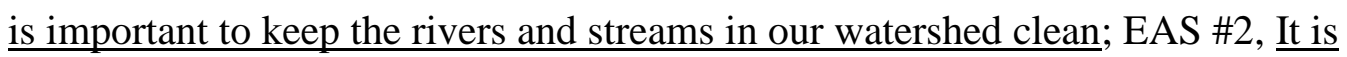
$\underline{\text { important to help protect our watersheds for drinking water.; EAS \#4 Our rivers and }}$ streams are impacted by impervious surfaces everywhere. With these few alterations in place, the Stagner KAQ had been reformatted into the CKQ and the EAS, and were given to a small subset of the students as an additional method to assess watershed knowledge and associated environmental attitudes.

Interview Questions. (Appendix D) As the one truly, qualitative, instrument the interviews, conducted with individual students in a semi-structured fashion, were vaguely similar to Stagner's (2013) in the way that they ask the students to reflect on the OLWEDU experiences and give feedback to the designers, researchers, and teachers. In order to assess some of the unique place-based elements of this unit, the questions for this particular research focused on the student's observations during the completion of the OLWEDU, especially the connections between the stormwater solutions they developed for the unit and those that might be found in the community. Several of the interview questions revolved around the STEM elements of the lessons, such as the degree of difficulty or which part was most meaningful. Questions regarding the potential for civic action were also included, including a prompt to find out whom else they had discussed the concepts of the OLWEDU with. Overall the intent was to ascertain the students' 
affective reactions to the place-based curriculum and also probe into their connections with the broader STEM concepts presented. The interview questions received face validity during specific assessment-related exercises at PSU, spring of 2014, and from the original author of the curriculum, Elizabeth Gardner.

Procedures. The curriculum had already been presented to the teachers during the 2012-2013 school year, so they were familiar with it for the 2013-2014 time period of this research. Only one teacher was unfamiliar with it previously. The OLWEDU unit took place in the spring of each year 2013 and 2014, following the sixth graders' studies of Land Forms and Weather unit. Table 3 below illustrates the overall timeline in which the curriculum and research took place. As a change from 2013, the Pretest was given earlier in the year in order to perhaps inform the teachers' instruction.

Phase 1: At the beginning of the Winter quarter, 2014, the students were given the OLWEDU Pre-Assessment. These were scored using the Scantron machine at the schools. Each student's name, period, and teacher were coded, along with the classification from the permission slips of whether they were able to participate in the research or not. At that point all $(n=515)$ of the students' results were added, regardless of permission, so that the teachers could use the information to inform instruction. After they were scored, individually accounted for, and coded, the results were transferred and tallied onto individual Excel spreadsheets for each teacher and class. A compiled spreadsheet was also created to compare data across teachers and schools. The data entered from the Pretests consisted of the total score and the exact letter answer 
Table 3: Timeline of the study for school-year 2013-2014

\begin{tabular}{|c|c|c|c|c|c|c|c|c|c|}
\hline & Jan & Feb & Mar & Apr & May & Jun & Jul & Aug & Sep \\
\hline $\begin{array}{l}\text { Phase 1: } \\
\text { Give Pretests } \\
\text { (teachers) }\end{array}$ & $X$ & & & & & & & & \\
\hline $\begin{array}{l}\text { Score Pre-tests } \\
\text { (researcher) }\end{array}$ & & $\mathrm{X}$ & $X$ & $X$ & & & & & \\
\hline $\begin{array}{l}\text { Develop } \\
\text { Supplementary } \\
\text { Lessons (researcher) }\end{array}$ & & & $X$ & $X$ & & & & & \\
\hline $\begin{array}{l}\text { Phase 2: } \\
\text { Teach the Unit } \\
\text { (teachers) }\end{array}$ & & & & & $X$ & $X$ & & & \\
\hline $\begin{array}{l}\text { Give Post-tests } \\
\text { (teachers) }\end{array}$ & & & & & & $X$ & & & \\
\hline $\begin{array}{l}\text { Phase 3: } \\
\text { Administer Surveys } \\
\text { (researcher) }\end{array}$ & & & & & & $X$ & & & \\
\hline $\begin{array}{l}\text { Administer Interviews } \\
\text { (researcher) }\end{array}$ & & & & & & $X$ & & & \\
\hline $\begin{array}{l}\text { Phase 4: } \\
\text { Analyze Pre-Post Tests } \\
\text { (researcher) }\end{array}$ & & & & & & & $X$ & $X$ & $X$ \\
\hline $\begin{array}{l}\text { Analyze Surveys } \\
\text { (researcher) }\end{array}$ & & & & & & & $X$ & $X$ & $X$ \\
\hline $\begin{array}{l}\text { Analyze Interviews } \\
\text { (researcher) }\end{array}$ & & & & & & & $X$ & $X$ & $X$ \\
\hline $\begin{array}{l}\text { Submit results to } \\
\text { teachers (researcher) }\end{array}$ & & & & & & & & & $X$ \\
\hline
\end{tabular}

off of the Scantron sheet. This information was deciphered using the Quick Analysis

function of Excel to show averages and trends in which questions were most frequently missed and which answers were most often incorrectly chosen. Areas of explicit lack of 
knowledge were highlighted. The results of the analysis was forwarded to the teachers to be used as formative assessment. In order to front load the lessons and incorporate some of the background information contained in the first few lessons, the teachers were encouraged to integrate concepts from the OLWEDU with their studies of Weather and Landforms. Due to the time delay in processing over five hundred sets of data, the teachers did not receive the results until several weeks later.

Phase 2: During the Spring of 2014, (Table 3) the researcher and PSU faculty provided resources to the teachers and support for using the maps, grids, and online simulations with the students. The actual OLWEDU was conducted during the months of May and June. (Tables 2 and 3) Due to end of the year time constraints, most of the teachers had to cut the unit short and abbreviate the Design Charrette. At the end of the unit, the students completed the final Post Assessment (PPT). The PPTs were given the final week of the school year and collected by the researcher shortly after. These results were also scored, coded, and transferred to Excel spreadsheets in the same manner as the pre-assessment.

Phase 3: During the last week of the unit, the teachers had already coordinated with the researcher when to come to one of their classes. Arrangements were made with the teachers for the researcher to give the constructed knowledge questionnaire (CKQ) (Appendix B) and environmental attitude survey (EAS) (Appendix C) and to conduct the interviews (INT). A few of the students were chosen to participate in the interviews by a live drawing of their coded number. Individual semi-structured interviews were conducted in a nearby private area. These were recorded and notes were taken by the 
researcher. Due to time constraints only ten total interviews took place. In some cases the students completed the Posttest, CKQ, EAS and Interview back to back.

Phase 4: After gathering all the data from the various instruments, the data were analyzed according to research protocols for the genre of each instrument. The Pre-Post assessments were examined using the Quick Analysis feature of Excel as well as Minitab for statistical significance. The CKQ and EAS were handled separately, with a Markscheme being used to score the CKQ and the results of the EAS being added directly to the Excel spreadsheets. The recordings from the interviews (INT) were listened to and additional notes were made onto the original interview sheets. The specific procedures will be outlined next.

Following the completion of the Posttests, the Scantron sheets scored by a combination of the teachers and researcher by the end of June. At that point, any additional permission slips were also accounted for. There were some scoring issues identified on two of the teachers' key cards for numbers \#11 and 16. Student scores were corrected and adjusted accordingly. An additional column was added for the Posttest scores, where the total Posttest score was entered. Each of the letters of the incorrect answers were inserted under the columns for each question. Later these were changed to reflect either correct or incorrect answers.

With regards to the scoring of the constructed knowledge (CKQ) (Appendix B), which was a combination of structure and unstructured questions, it was decided to code the qualitative responses, quantitatively. (Trochim, 2006) Consequently a Markscheme (included in Appendix B) was devised which listed potential responses and equivalent 
points. The points for each question were tallied onto an Excel spreadsheet. For interrater reliability purposes, I had two of my colleagues who were familiar with the OLWEDU curriculum, also score the students' papers. Each of them were given the Markscheme and copies of the students' CKQ and EAS assessments. There were two questions, \#1 and \#7 that were more open ended and difficult to come to consensus on with my colleagues. This difficulty of the scorers constructing meaning from the students' constructions, based on their own personal constructions, during the evaluation process was reported by Daniel Shepardson (2007) during his exploration of students' constructed drawings and explanations of watersheds. In order to address the reliability of scores, then, I used a mode score for entering the points into the spreadsheet.

The scoring the environmental attitude survey (EAS) (Appendix C), was much more straightforward and reliable. Since it was based on a Likert scale, the order and hierarchy of answers was inferred, although Bowen and Bartley (2014) caution about using parametric data in this way. They do agree that there are instances where scale construction can be done successfully, especially when the questions are closely related. Bowen and Bartley go on to state that this "face validity" is normally backed up with a Cronbach's alpha calculation, which was completed by Rachel Stagner, as mentioned above. Consequently, after originally entering the lettered responses in the Excel database, they were later changed to numerals in order to facilitate the statistical analysis in Minitab and enable using the means for descriptive analysis purposes. There was one exception to the ordinal nature of the statements, and that was with question \#6 which was worded in a reverse fashion: $\underline{I \text { would work on a project to help our rivers and streams }}$ 
ONLY if I had to for school. In order to attend to this scoring issue, the points were adjusted when entering them onto the final Excel spreadsheet.

The final instrument used contained the Interview questions (Appendix D). A semi-structured interview process with a set script of questions was followed, with only a few variances occurring during the interview process. Each interview lasted around fifteen minutes and was both recorded manually and on tape recorder. The notes were reviewed within a few days, and clarity of answers was examined, and additional notes added. The audio files of the interviews were consulted to clarify the answers and add body to the data. Months later the interviews were coded and classified according to the variables of concern. A key comment was chosen from each of the ten students to exemplify the concept or shed light on each variable and the OLWEDU as a whole. Following this examination, the responses were sorted and tabulated once again to show positive, negative, or neutral support for the additional place-based education and STEM variables.

Phase 5: In preparing the data for formal analysis using Minitab by a professional statistician, other changes were made in the organization and presentation of the data. The individual letter answers on the PPT were changed to reflect either a correct (1) or an incorrect (0) response. The letter answers on the EAS were modified to numbers as well. Subtotal columns for each variable were constructed and color coded in Excel for each instrument. A data table (Appendix F) was designed to show relationships between the instruments, co-variables and the various hypotheses. 


\section{Data Handling and Analysis}

\section{Evaluation protocols}

In order to avoid bias which might have arisen from using real names, each group was identified by the teacher's last name and the period in the schedule. For privacy and research protocol purposes, the teachers' and students' names were coded by the Group ID and a personal number within the group. Individual student's names were blanked out after matching the permission slips to the pre-post Scantron slips. After the answers were recorded on the Scantrons, they were transferred to an Excel spreadsheet using the student's personal code. Those students who are specifically identified as being eligible for interviews were identified and listed on the Excel sheet. (Appendix G) Later the coded numbers of the potential students for interviews were placed on individual cards for the randomized drawing and designation. After the initial whole group report to the teachers, the materials and results from the students who are not eligible to participate in the study were removed.

In order to evaluate the effectiveness of this NGSS standards-based watershed curriculum, I referred to several researchers' analysis tools. (Stern et. al, 2013; Shepardson, et al., 2007; Zint \& Kramer, 2012). Daniel Shepardson's extensive analysis of students' conceptions of watersheds was brought to my attention somewhat too late for me to use when scoring the watershed literacy portion of the constructed knowledge questionnaire (CKQ), but was still referred to when analyzing the results. Marc Stern and colleagues developed a list of program characteristics associated with the Best Practices (BP) in Environmental Education which was also used to appraise the place-based nature 
and environmentally focused curriculum as a whole (Stern, et al., 2013, p. 3).The research team of Michaela Zint and Andrew Kraemer developed a list of desirable qualities used to evaluate many state and national constructs of interest, or MWEEs, designed to address watershed literacy, which I will use to help evaluate the watershed literacy portions of the OLWEDU (Zint et al., 2012). 


\section{Results}

\section{Quantitative Analysis}

The following quantitative analysis was derived from three out of the series of four instruments: Instrument 1a Pre/Posttest (PPT), (Appendix A). Instrument 2, the constructed knowledge questionnaire (CKQ) (Appendix B) and Instrument 3, the environmental attitude survey (EAS) (Appendix C), designed to evaluate and support the stated hypotheses: which focus on the extent that the OLWEDU increases watershed literacy (WSL), knowledge of human impacts on stormwater (HIS), understanding of the engineering design process (EDP), and promotion of pro-environmental attitudes (PEA). The results from each of the instruments will be presented in total and then broken down into these pertinent sub-variables. The findings from the various subsections, combined subsections, or paired questions, will also be presented. The qualitative results from the final Instrument 4, the Interviews (INT) (Appendix D) will be presented as Qualitative results and used to substantiate the findings regarding cumulative STEM outcomes, Place-based aspects, and overall sentiments about the OLWEDU.

Statistical methods included, General Linear Models and paired t-tests, ANOVA when available, and some regression analysis was performed using Excel's Quick Analysis. In some cases, where statistical analysis was not available, only the raw mean score and average (academic) percentage scale are given. The academic-mean percentage scale is used as a balancing factor in instances where the total points score is not equivalent, such as between the Posttest (n/18) and the CKQ (n/30). Other analyses are referred to which were completed within the Excel spread sheets Quick Analysis that 
cannot be translated into moveable graphs, such as the above, or below average color coding and comparisons. An example screenshot can be seen in Appendix G. The following table (Table 4) summarizes the statistical results for each of the key instruments measuring knowledge and pro-environmental behaviors.

TABLE 4: Descriptive statistics for Pre/Posttest and Environmental Attitude Survey (EAS).

\begin{tabular}{|c|c|c|c|c|c|c|c|c|}
\hline \multicolumn{9}{|c|}{ Statistical Analysis Results } \\
\hline $\begin{array}{l}\text { Independent } \\
\text { Variable }\end{array}$ & $\begin{array}{l}\text { Mean } \\
\text { score }\end{array}$ & $\begin{array}{l}\text { Std. } \\
\text { Dev. }\end{array}$ & $\begin{array}{l}\text { Std. } \\
\text { Error } \\
\text { Mean }\end{array}$ & Lower & Upper & $\mathbf{t}$ & df & Sig. P \\
\hline $\begin{array}{l}\text { Total Knowledge } \\
\text { Score: Pre vs Post } \\
\text { S= } 358 \text { (n/18 pts) }\end{array}$ & $\begin{array}{l}7.51 \\
12.74\end{array}$ & 2.73 & 0.14 & $\begin{array}{l}- \\
5.627\end{array}$ & -4.829 & $\begin{array}{l}- \\
25.72\end{array}$ & 712 & $.000 *$ \\
\hline $\begin{array}{l}\text { Total PEA: } \\
\text { EAS (Q's 1-7 n/35) } \\
\text { Before } S=44\end{array}$ & 22.16 & 4.19 & 0.68 & -3.88 & -8.09 & -5.66 & 76 & 0.000 \\
\hline After $S=42$ & 28.14 & 5.25 & 0.81 & & & & & \\
\hline
\end{tabular}

\section{Knowledge: Pre/Posttest (PPT)}

With regards to the overall watershed/stormwater/engineering literacy, there is a positive correlational relationship of knowledge gained between before the students engaged in the OLWEDU and after they finished. The results of the Pre/Posttest (n/358) analysis are 
very strong and encouraging, with a 70\% increase in performance. Along with the overall positive increase in scores, the interval-ratio analysis illustrated by the scatterplot below, (Figure 1) confirms a positive trend, despite the wide range of scores that were involved in the analysis. A two-sample t-test of the Pre and Posttest scores confirmed this increase to be statistically significant, $t(-25.72)=-5.627, p=0$. (Table $4 \&$ Figure 2$)$.

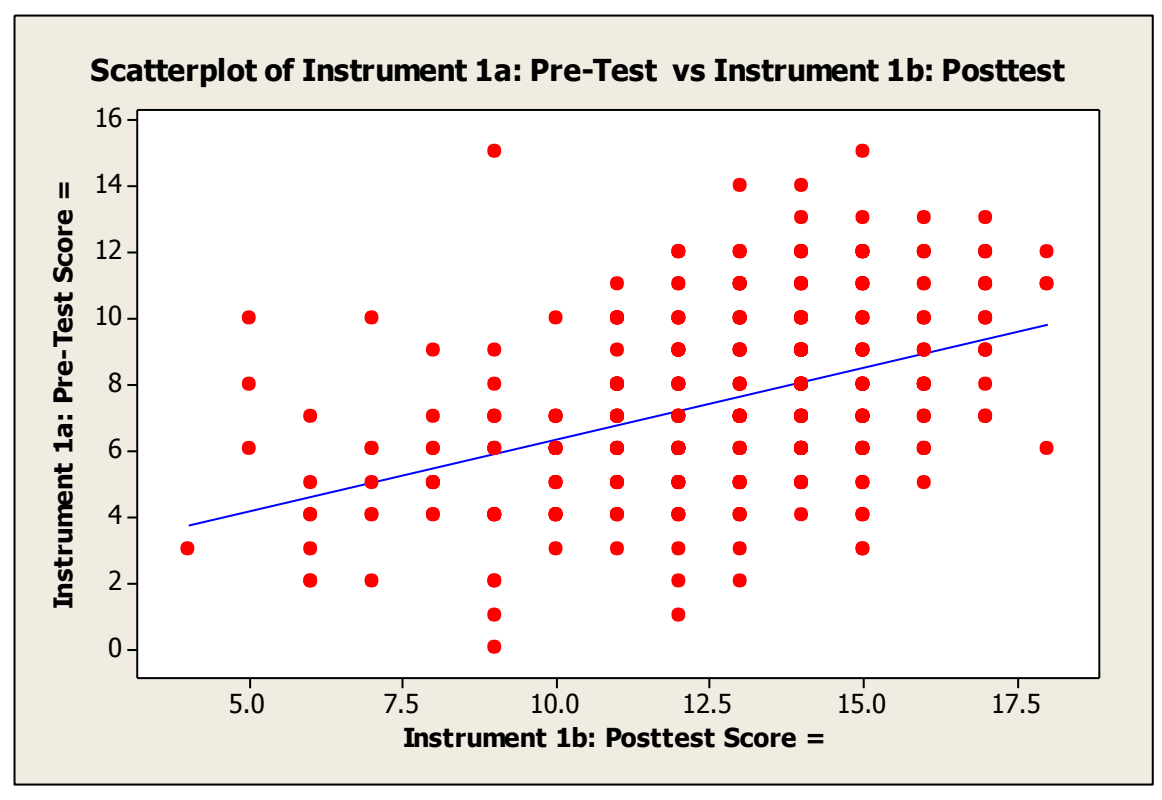

Figure 1: Cluster analysis of student scores on Pre and Posttests showing positive regression line.

There was an observable increase in the students' cumulative scores of 5.19 mean points between the Pre-test $(7.51 \mathrm{~m})$ and the Posttest $(12.73 \mathrm{~m})$ as illustrated by the Box plot in Figure 2. Even with the removal of the outliers, the increase in scores would be evident. Given that the sample size was an ample 358, these results confirm the first hypothesis, which is that the OLWEDU was markedly effective in carrying out the objectives of increasing watershed literacy (WSL), knowledge of human impacts on stormwater (HIS), and an understanding of the engineering design process (EDP). 


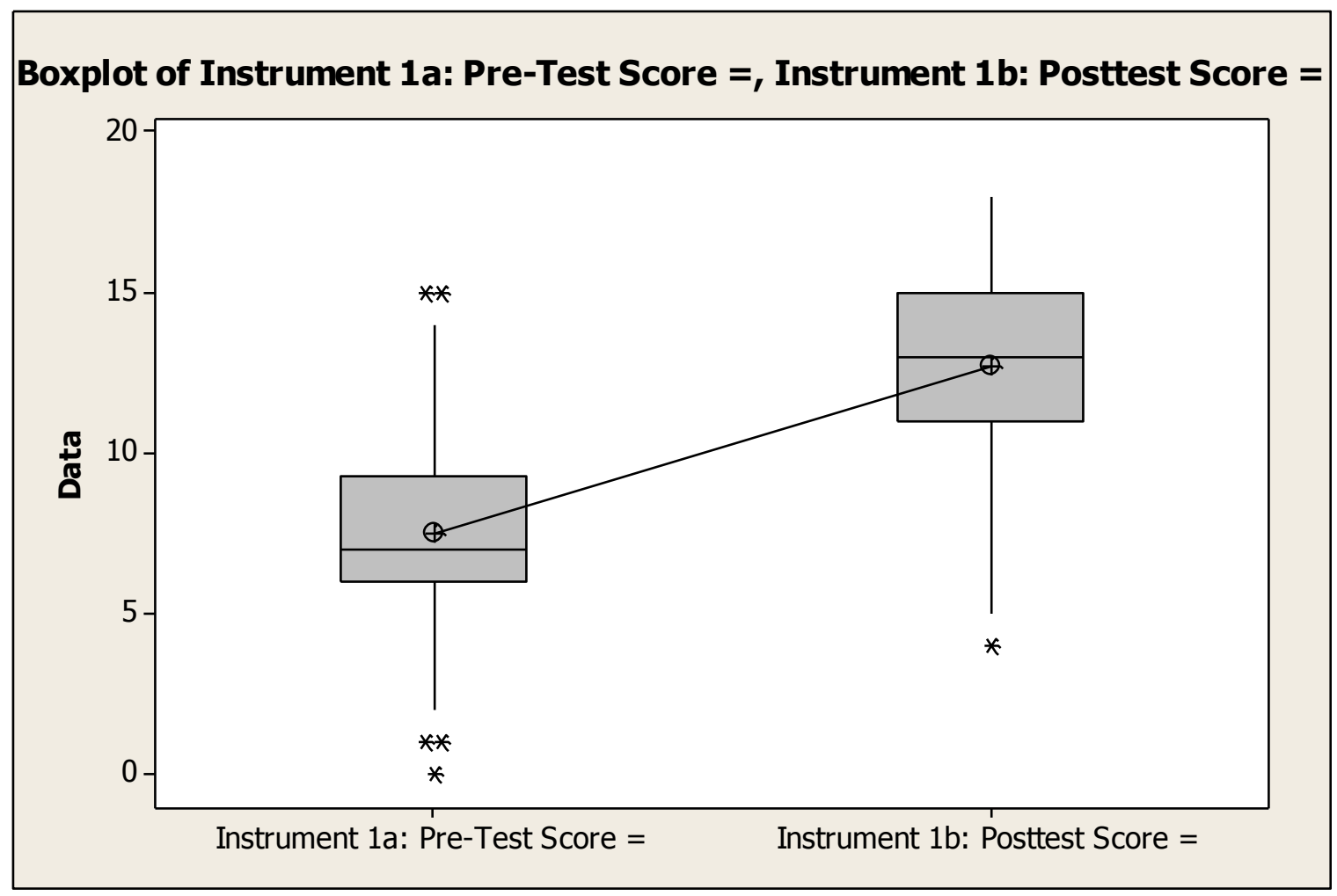

Figure 2: Boxplot of Instrument 1a: Pre-Test Score =, Instrument 1b: Posttest Score = showing range of scores and outliers.

The cumulative percentage of scores at $72 \%$ shows a typical normal distribution.

It must be noted that this percentage was derived from a total of all of the scores and some of the scores were potentially lower due to either leaving an answer blank, or submitting two conflicting answers, rather than answering incorrectly. When each variable or objective (WSL, HIS, EDP) of the Posttest is examined separately, the scores also hover around overall average of $72 \%$, with the exception of a remarkable performance of $86 \%$ in the HIS questions. Details can be viewed in the Descriptive Data for Knowledge Instruments Table 5 below, showing the mean score as well as the percentage score results for each of the sub-variables. 
Table 5: Descriptive data for Knowledge instruments: Pre/Posttest (PPT) and Constructed Knowledge Questionnaire (CKQ) with variables broken out.

\begin{tabular}{|c|c|c|c|c|c|c|c|c|c|}
\hline $\begin{array}{l}\text { Knowledge } \\
\text { Instrument } \\
\text { and/or } \\
\text { Variable } \\
\text { >>>>>> }\end{array}$ & $\begin{array}{l}\text { Pretest } \\
\text { (1a) } \\
\text { S=358 } \\
\text { total } \\
\mathrm{n} / 18\end{array}$ & $\begin{array}{l}\text { Posttest } \\
\text { (1b) } \\
\text { total } \\
\text { n/18 }\end{array}$ & $\begin{array}{l}\text { PPT: } \\
\text { WSL } \\
\text { (1b) } \\
\text { n/9 }\end{array}$ & $\begin{array}{l}\text { PPT: } \\
\text { HIS } \\
\text { S=358 } \\
\text { n/3 }\end{array}$ & $\begin{array}{l}\text { PPT: } \\
\text { EDP } \\
\text { S=358 } \\
\text { n/6 }\end{array}$ & $\begin{array}{c}\text { CKQ } \\
(2) \\
S=44 \\
\text { total } \\
n / 30\end{array}$ & $\begin{array}{l}\text { CKQ: } \\
\text { WSL } \\
\text { S=44 } \\
\text { n/20 }\end{array}$ & $\begin{array}{l}\text { CKQ } \\
: \text { HIS } \\
\text { S=44 } \\
\text { n/8 }\end{array}$ & $\begin{array}{l}\text { CKQ: } \\
\text { EDP } \\
\text { S=44 } \\
\mathrm{n} / 2\end{array}$ \\
\hline $\begin{array}{l}\text { Mean Score } \\
S=358\end{array}$ & 7.51 & 12.7 & 6.65 & 2.47 & 4.1 & $*$ & $*$ & $*$ & $*$ \\
\hline $\begin{array}{l}\text { Mean Score } \\
S=44\end{array}$ & 7.4 & 13 & 6.39 & 2.59 & 4.3 & 16.36 & 8.7 & 6.86 & .8 \\
\hline $\begin{array}{l}\text { Percentage } \\
\text { Score } \\
S=44\end{array}$ & $41 \%$ & $72 \%$ & $71 \%$ & $86 \%$ & $72 \%$ & $55 \%$ & $44 \%$ & $86 \%$ & $40 \%$ \\
\hline
\end{tabular}

\section{Posttest Knowledge: Sub-Variable Watershed Literacy (WSL)}

When watershed literacy (WSL) performance is examined separately, it is comparable to the overall PPT average increase of $72 \%(\mathrm{n} / 358)$ (Table 5). The mean score of 6.65 translates to $71 \%$ for the watershed literacy (WSL) variable. Referring to the bar graph for WSL (Figure 3), which compares the Pretest scores with the Posttest scores, the students show an inclusive $66 \%$ better understanding of watersheds. In some cases $(\mathrm{Q} \# 2,3,9)$ the increase in correct scores was well over a hundred percent, $170 \%$, $269 \%$, and $143 \%$ respectively. Other notable increases were noted on Q\#1(87\%) and Q\#7(57\%), two key questions addressing where watersheds are found and how they are interconnected. 


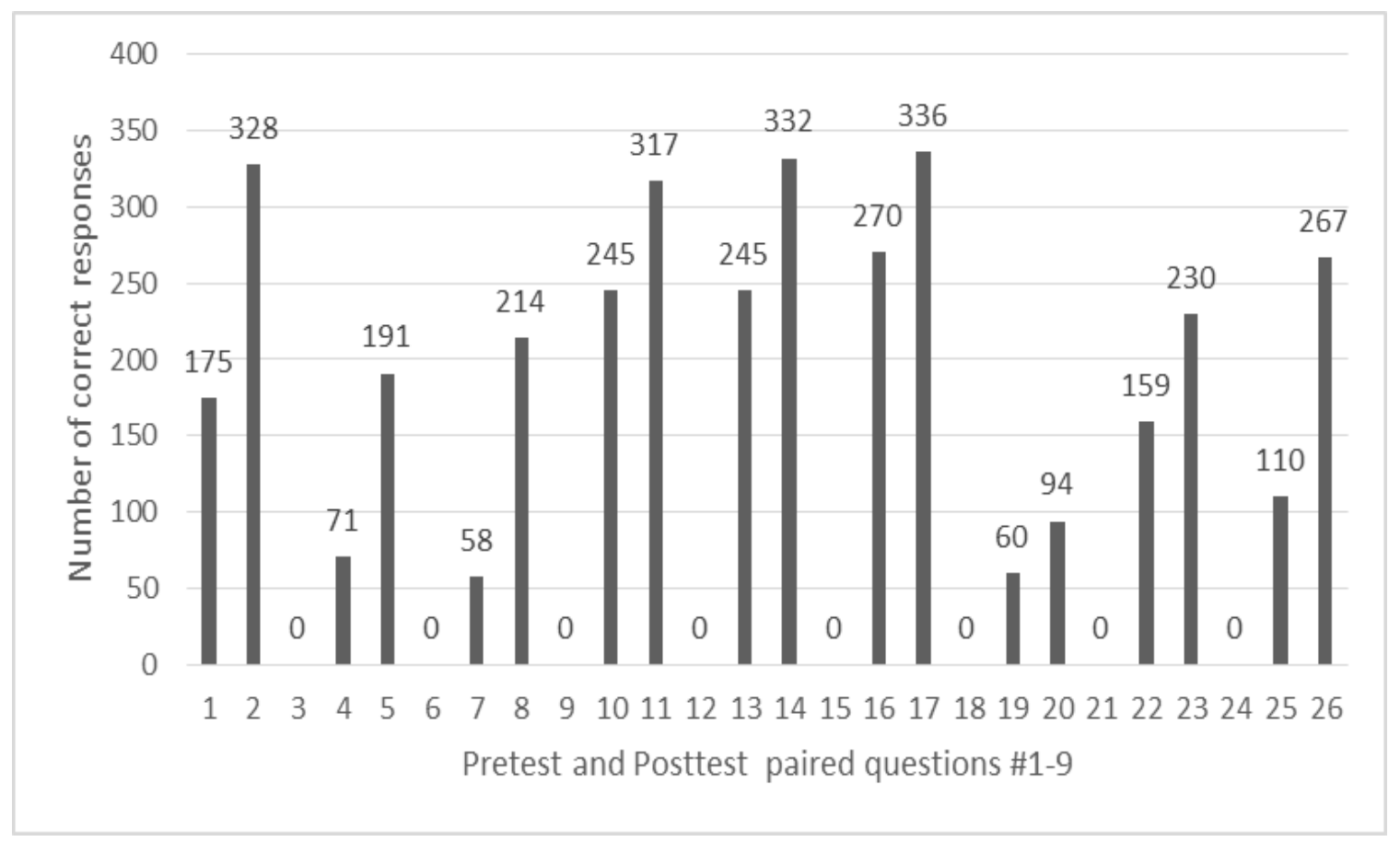

Figure 3: Comparison of number of correct responses for Pretest and Posttest (n/358) questions with watershed literacy WSL objective: Key to $X$ axis: question $\# 1=$ columns $1 / 2, \# 2=4 / 5$, $\# 3=7 / 8$, \#4=10/11, $\# 5=13 / 14, \# 6=16 / 17, \# 7=19 / 20$, \#8=22/23, \#9=25/26

Despite the remarkable increases in a couple of the questions, the following trends were identified: The questions that had the highest number of incorrect answers were $(\mathrm{Q} \# 2,3$, $7=$ columns $4 / 5,7 / 8,19 / 20$ ) which dealt with the more abstract aspects of watersheds. (See Appendix A for exact wording of questions), including potential metaphors or symbols for watersheds $(\mathrm{Q} \# 2$ = columns 4/5). There some evidence of continued difficulty identifying the underlying forces involved in the energy transfer throughout watersheds $(\mathrm{Q} \# 3=$ columns 7/8). The students still seem to lack a comprehensive view of the nested aspects of watersheds, $(\mathrm{Q} \# 7=$ columns 19/20). These questions will be described more in the discussion section. The questions $(\mathrm{Q} \# 4,5,6=$ columns 10/11, $13 / 14,16 / 17)$ that had the least increase in scores were pretty straightforward ones to begin with. 


\section{Posttest Knowledge: Sub-Variables Human Impacts on Stormwater (HIS)}

Examining the stormwater (HIS) section separately, (the students reached a mean score of 2.59 , translating to $83 \%$ proficiency, well above the overall PPT average of $72 \%$ (Figure 4)). There was a moderate gain of $31 \%$ more correct responses on question \#10, and almost doubling (86\%) of correct answers on \#11. The positive trend extended to question \#12 where there was almost a quadrupling (242\%) of correct answers. It might be noted that question \#12 (columns 7/8), was worded in the negative, "Which of the following is not an impact of impervious surface?" so therefore the students did much better at understanding the underlying meaning and identifying the correct answer after the instructional unit. With only three questions in this section, not many conclusions can be drawn from this data alone. However, these outcomes are reinforced when combined with the results of the CKQ in the next section.

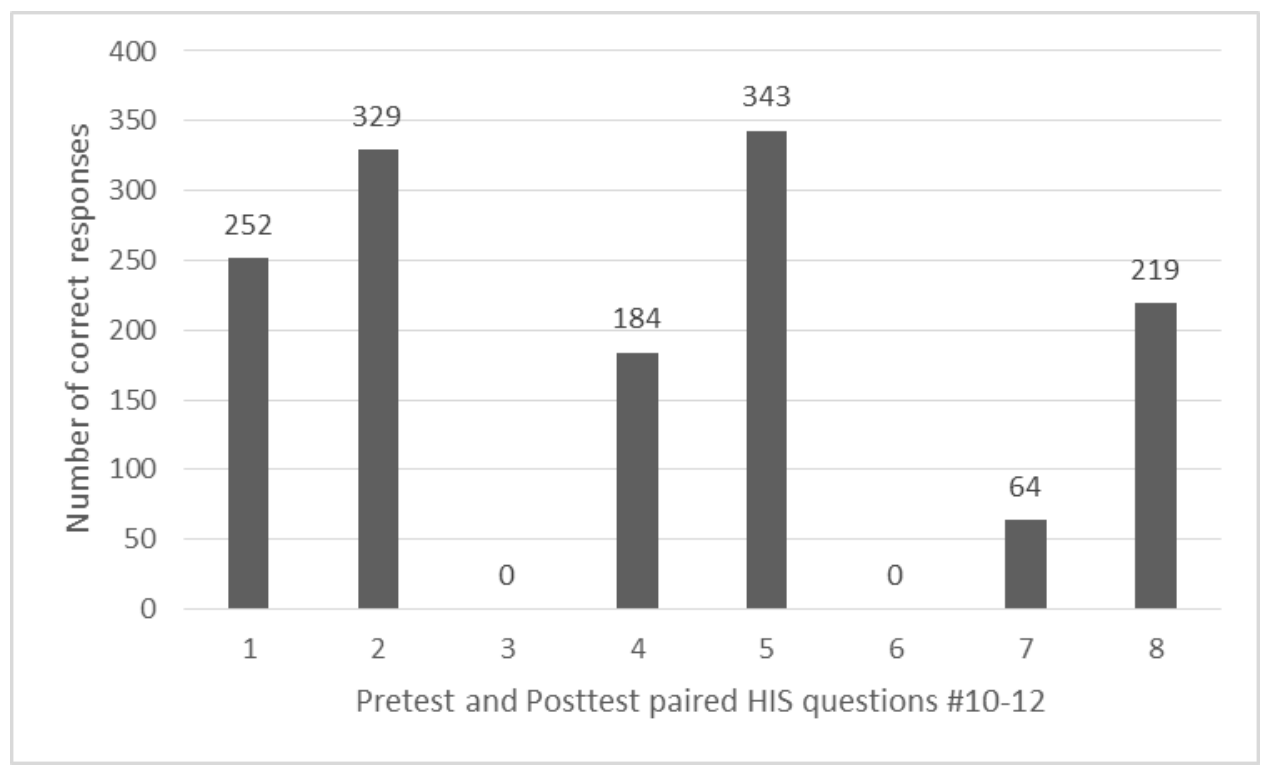

Figure 4: Comparison of number of correct responses for Pretest and Posttest (n/358) questions with HIS stormwater objective: question $\# 10=$ columns $1 / 2, \# 11=4 / 5, \# 12=7 / 8$ 


\section{Posttest Knowledge: Sub-Variables Engineering Design Process (EDP)}

This part of the test required the students to know how to use a PUGH chart to weigh criteria and constraints to identify solutions, a tool and skill that was novel to them. In examining the EDP scores (Q\# 13-18) of the Pre and Posttest (Figure 5, Table 5) the mean score was 4.3 , for an average total percentage score of $70 \%$ and just under the cumulative average score of $72 \%$. The gains were tremendous, with near doubling on three questions, Q\# 13 (90\%), Q\#15 (98\%), and Q\#17 (100\%). Questions \#14 (53\%), \#16 (51\%), and \#18 (70\%) all had remarkable improvements as well. This equates to a $76 \%$ increase of correct answers. It must be remarked that Question \#16's (columns 10/11) low scores have been problematic since the beginning for a variety of reasons ranging from wording errors to errors on some of the scoring keys.

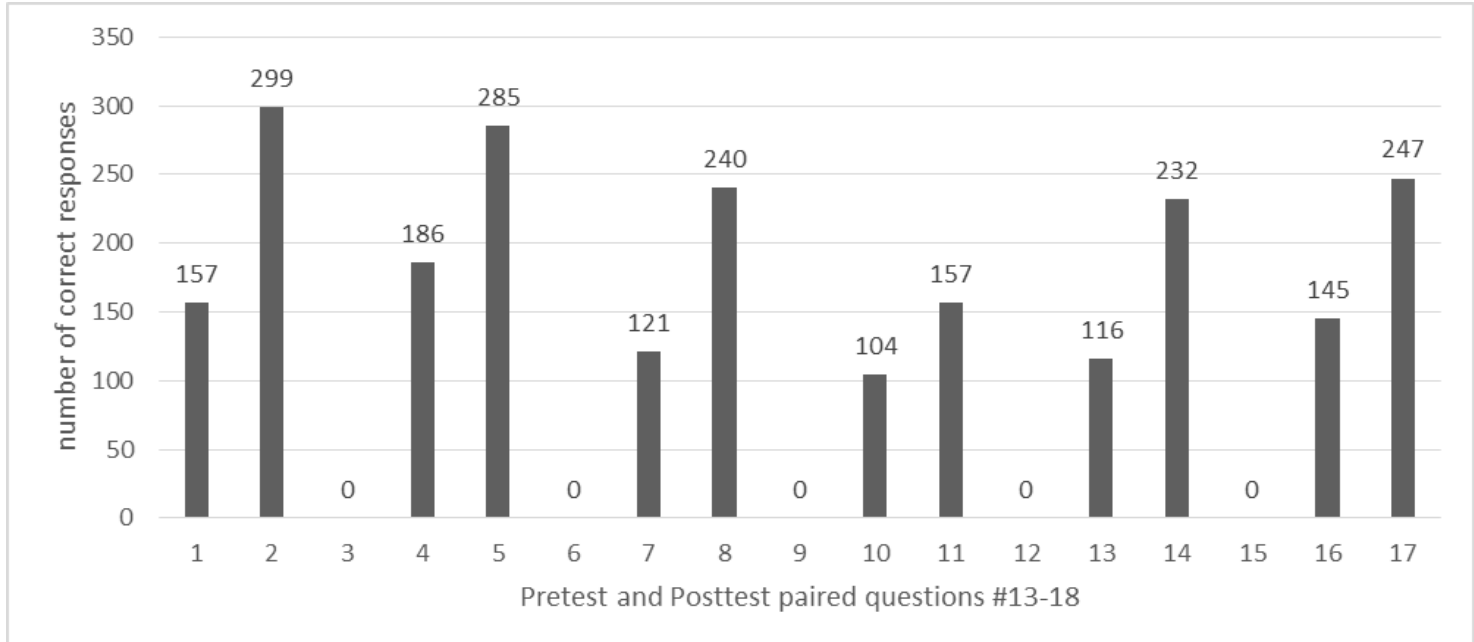

Figure 5: Pre/Post (n/358) comparison for the Engineering Design Process (EDP) for questions \#13-18. Key: question \#13= columns (1/2), \#14 (4/5), \#15 (7/8), \#16 (10/11), \#17 (13/14), 18 (16/17).

Please note, in comparing the cumulative mean Pretest and Posttest scores for the whole sample size $n / 358$ to that of the subgroup sample $n / 44$ (those who received the other 
assessments), (See Table 5) there is enough reliability between the two sets to support the rest of the analysis as being representative of the general sample population. The mean score for the entire sample for Pretest is $7.5(\mathrm{n} / 358)$ as compared to $7.4(\mathrm{n} / 44)$ in the subgroup. For the Posttest, the full sample mean score was 12.7 and the sub-sample mean was 13. Interestingly enough the results from the 2013 Pilot year were also quite similar. Out of a total sample group of 351, the Pretest mean score was found to be 7.9 and the Posttest mean score was 12.0 (Gardner 2013). Therefore for the remainder of this analysis, when comparing Posttest scores and the results from the other instruments, I will be using the sub-sample size of 44 .

\section{Constructed Knowledge Questionnaire (CKQ)}

As a new summative instrument for 2014 and lacking a proper pre-assessment for comparison, the results of the Constructed Knowledge Questionnaire (Figure 6) was not staged to show the comparative gains nature of a Pre and Post assessment. The sample size of 44 was also much smaller. It was designed to augment and support the findings of the multiple-choice posttest (PPT). With a cumulative mean score of $16.3 / 30$ or $55 \%$ achievement, (See Table 5) the results of the CKQ do not illustrate the same level of achievement that the Posttest does. There are several factors which could have contributed to the students' low ability to transmit their knowledge into a written form, which were alluded to in the methods section and will be covered in the following discussion section.

When examining the raw data results of the Constructed Knowledge Questionnaire (CKQ), (Table 5) for each variable, the results vary. With regards to the 
variable of watershed literacy (WSL), it is immediately apparent from their average overall percentage of $44 \%$ that the students had difficulty putting their newfound knowledge into words, drawings, and comparisons. Although the mean points of 8.7/20 received were low, about half of the students did perform above that average as the Excel spreadsheet shows in Appendix G. When prompted by the CKQ question \#1: $\underline{\text { How would }}$ you describe a watershed to a friend? Draw a model of a watershed... (Appendix B), they typically responded with correct, but limited definitions, like " $A$ watershed is an area where gravity pulls the water into larger body of water". Their representations were also limited and predictable, showing rain coming down from a mountain via rivers, and ending up in a lake. The biggest drop in scores was on the task requiring them to compare their school's postal address to its "watershed address" (CKQ\#2), even when they were prompted by labels and hints. On CKQ\#3, where the students were asked to describe ways the lake gets its water, over half of the students received full points, giving a variety of answers, most of them stating rain and creeks, and a few listing ground water and storm drains, illustrating a broader understanding of the sources.

The impressive $86 \%$ average score on the human impacts on stormwater (HIS) portion of the CKQ, (Table 5) shows evidence of high comprehension of the factors involved with human influences on stormwater and the environment and in knowing the distinction between pervious and impervious surfaces. On CKQ \#4, which asks the students to list two examples of ways in which humans impact their watersheds, a couple of students adeptly answered: "They create too many impervious surfaces which limits the recharging of groundwater." (B7.08) and (B7.06). Several other students answered 
the same question by stating: "We might put harmful chemicals on our plants to keep away bugs, but when it rains the rains take the chemicals too. " (C1.09) The same student answered CKQ \#5: Describe the difference between pervious and impervious surfaces. Give examples. by stating: "pervious surfaces water can go through and can soak into it. Example - plants and soil, rain gardens." In answering the same question \#5, another student answered: “impervious surfaces are surfaces the water can't infiltrate in to like school roof or pavement." (C1.14). From the many similar responses there is sufficient evidence to document the fact that the students learned how humans impact watersheds. They were able to not only state the difference, but give examples of pervious and impervious surfaces. The students were also adept at showing a deeper understanding of the problem, giving suggestions for how humans can improve watershed health, (CKQ \# 6) such as: "You could wash your car on the lawn so the water can get naturally cleaned by the ground" (C1.14). These are only a few of the examples which show evidence of an expanded comprehension of anthropogenic effects on the local environment and watersheds in general, and support the effectiveness of the OLWEDU in conveying and improving students understanding of HIS.

On the final question (CKQ \#7), which asked the students to give an example of where they could use the EDP .... in some other way than a stormwater solution: the scores were again quite low, an average of $40 \%$, but this was based on only one question. The lower points was because most of the students were unable to give a novel example of where to use the EDP and either gave another stormwater example or a typical answer such as" if I was an engineer" or "when building a new office". Some were right on 
target, such as this student's statement: "You use the Engineering Design Process every day of your life, even if you don't know it. You are constantly improving and redoing things." (D3.02) Even a few creative answers were given, like this one: "I would improve hamster balls. I would make them bigger so they're big for people like me to roll around in them like hampsters do." (D3.12) These results support a key goal of the unit, which was getting the students to realize the broad reach and move beyond common applications of the EDP.

\section{Attitude}

We turn our attention now to the student's Pro-environmental Attitude (PEA) (Table 6) as shown by their performance on the environmental attitude survey (EAS), which compared their retrospective, self-assessed attitudes towards the environment from Before to After having completed the OLWEDU unit. The mean score of 28.1 for After the OLWEDU showed an increase of $27 \%$ over the original mean score of 22.1 from Before having completed the unit. This positive relationship was confirmed by a twosample T-Test, which showed a T-value of -5.66 , and a P-value $=0.0$. This results of this correlation was illustrated quite dramatically in the following Boxplot diagram in Figure 6 below. 
Table 6: Descriptive statistical analysis results for the Environmental Attitudes Survey (EAS)

\begin{tabular}{|c|c|c|c|c|c|c|c|c|}
\hline \multicolumn{9}{|c|}{ Statistical Analysis Results } \\
\hline $\begin{array}{l}\text { Independent } \\
\text { Variable }\end{array}$ & $\begin{array}{l}\text { Mean } \\
\text { score }\end{array}$ & $\begin{array}{l}\text { Std. } \\
\text { Dev. }\end{array}$ & $\begin{array}{l}\text { Std. } \\
\text { Error } \\
\text { Mean }\end{array}$ & Lower & Upper & $\mathbf{t}$ & df & Sig. P \\
\hline $\begin{array}{l}\text { Total: EAS (Q's 1- } \\
7 \text { n/35) Before } \\
\text { S=44 }\end{array}$ & 22.16 & 4.19 & 0.68 & -3.88 & -8.09 & -5.66 & 76 & 0.000 \\
\hline After $S=42$ & 28.14 & 5.25 & 0.81 & & & & & \\
\hline
\end{tabular}

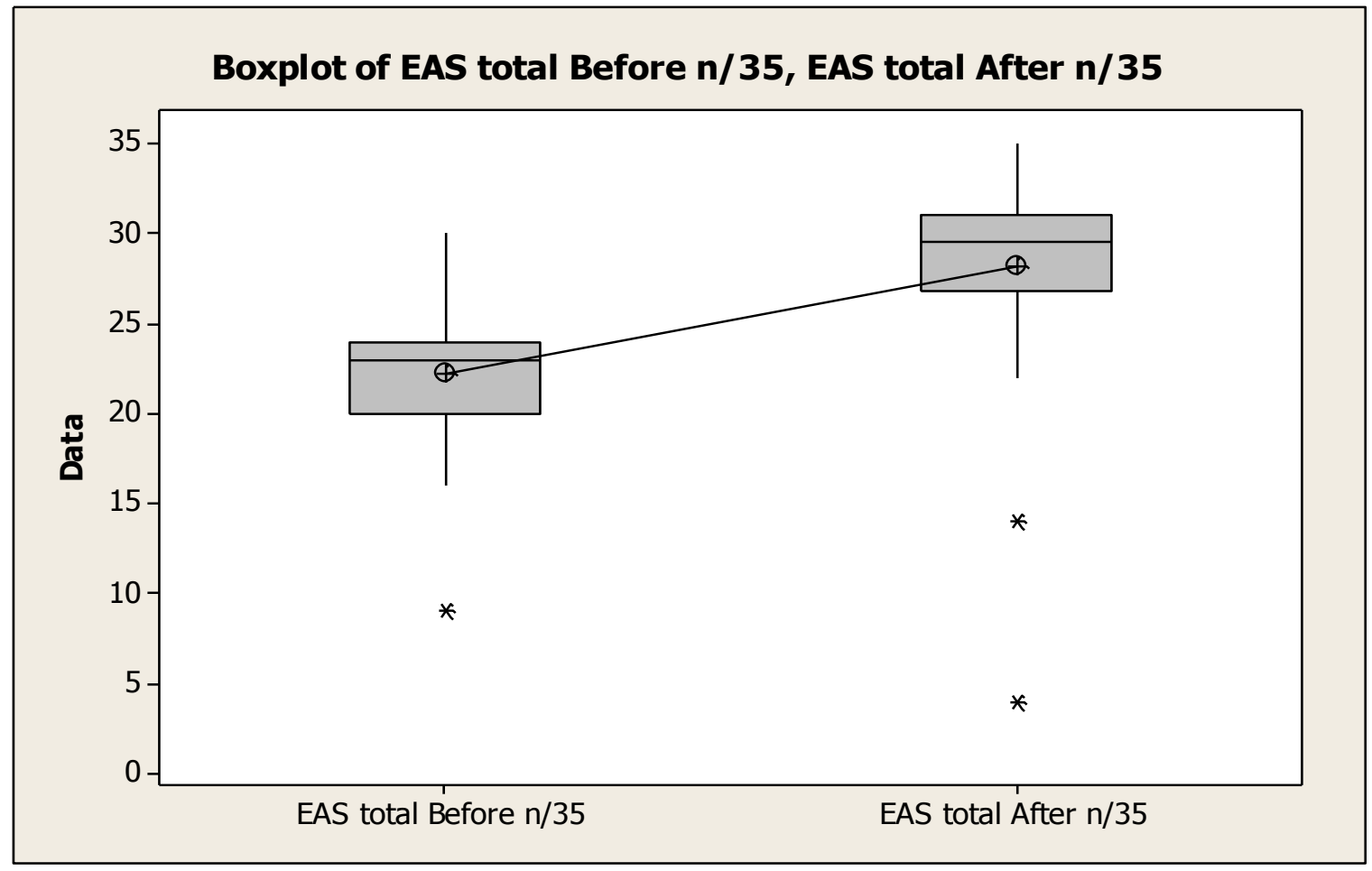

Figure 6: Box Plot of Environmental Attitude Survey (EAS) total Before n/35, EAS total After n/35 
A positive correlation for the EAS results of increased pro-environmental attitude (PEA) after having participated in the OLWEDU is also exhibited in the accompanying scatter plot graph in Figure 7 below. The same outliers are noted in both graphs, but looking at the groupings in the scatter plot graph there is a visible top-heaviness to the student data for After the OLWEDU on the right which could suggest even a higher increase in pro-environmental attitude if the outliers were removed. Coming in the next section, are the results of an ANOVA analysis on this level of Change between the environmental attitudes (PEA) Before to After the OLWEDU. (Figure 8)

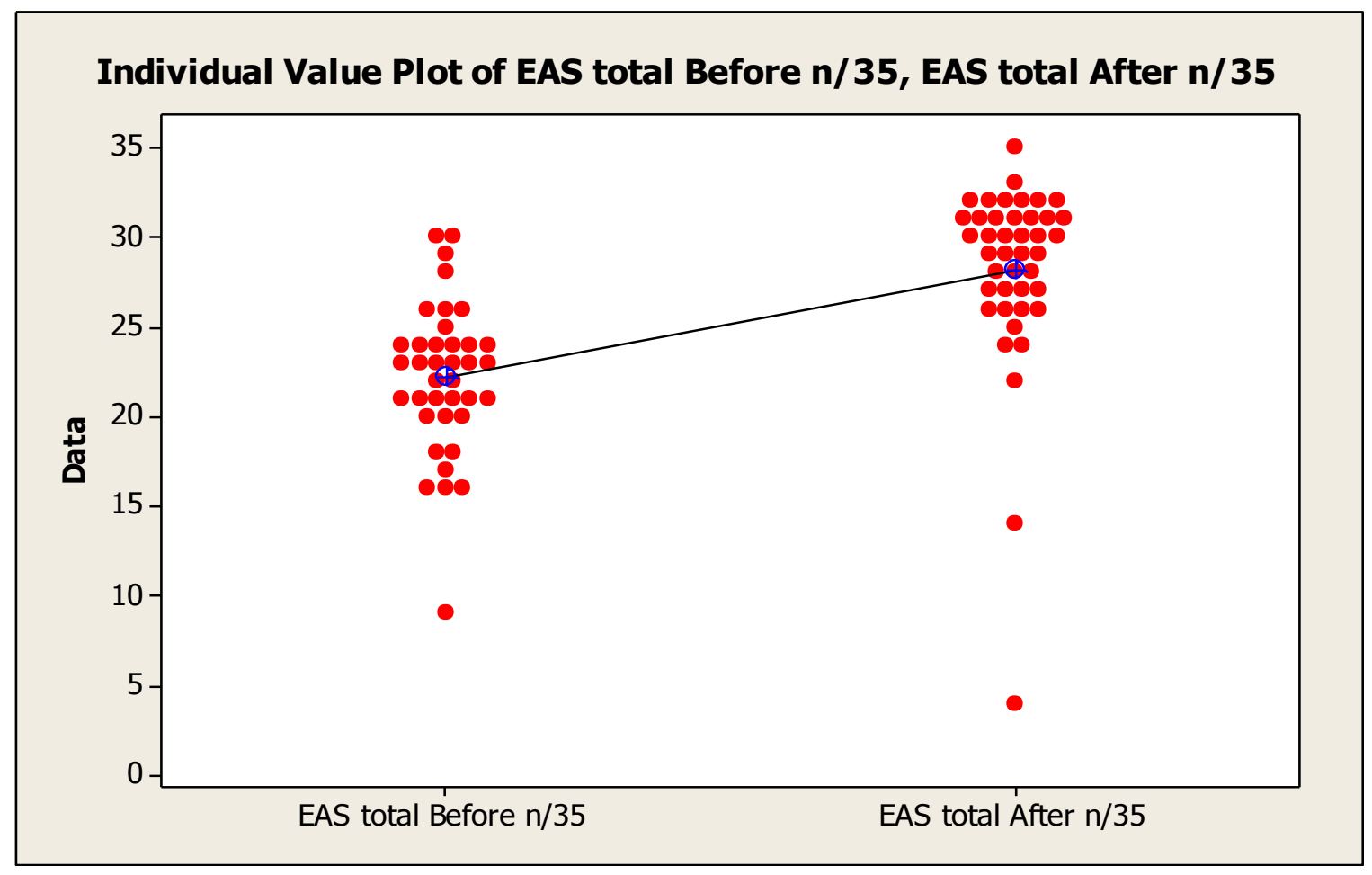

Figure 7: Cluster graph results from EAS total Before n/35, EAS total After n/35

One confounding numerical issue to note is that while the actual difference between these two means equals 6 points, the results from the Change scores reflect a mean of 7.5 (Table 7), which would lower the impact of the overall increase. 
Table 7: Descriptive data for Environmental Attitude EAS instrument.

\begin{tabular}{|l|l|l|l|l|}
\hline $\begin{array}{l}\text { Environmental } \\
\text { Attitude }\end{array}$ & EAS (3) & EAS (3) & EAS (3) & EAS (3) \\
Instrument & $\begin{array}{l}\text { Before } \\
\text { OLWEDU }\end{array}$ & After OLWEDU & Change \\
n/35 & OLWEDU & $\begin{array}{l}\text { Future } \\
\text { Intentions n/30 }\end{array}$ & \\
\hline $\begin{array}{l}\text { Adapted score } \\
\text { S=44 }\end{array}$ & 22.16 & 28.14 & 7.53 & 21.1 \\
\hline Percentage score & $63 \%$ & $80 \%$ & $17 \%$ & $70 \%$ \\
\hline
\end{tabular}

The Whisker plot (Figure 7) below illustrates the degree of Change from Before to After the OWLEDU for specific questions on the environmental attitude survey (EAS), Q\#s 1-7. (Table 7) Each of the following EAS attitudinal questions has a corresponding sub-variable: (\#1-2) WSL, (\#3) PEA, (\#4) HIS, (\#5) PBE, (\#6) PEA/PBE, (\#7)

HIS/PEA. (Appendix C) It is important to note that there is an overall statistical increase, including a range of 2 levels in gains in the questions $(\# 3,5,6$, and 7) which have a specific pro-environmental and place-based content. 


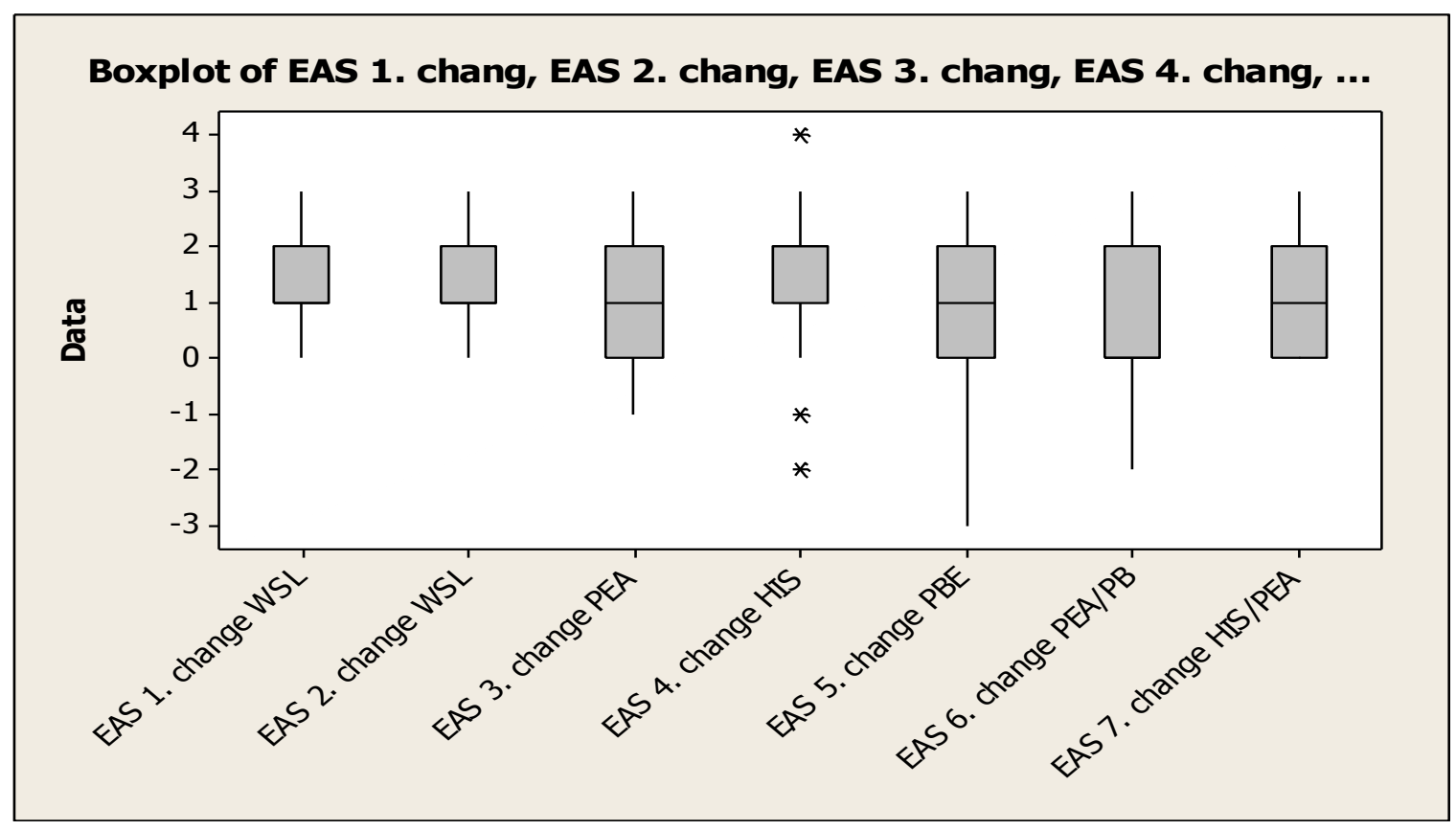

Figure 8: Whisker plot showing degree of change for Environmental Attitude Survey

The next series of results incorporates the query about the Future intentions of students into this analysis, as seen in Table 7, by comparing the students' responses from the Before, After, Future sections of the EAS. The mean Before score was 22/35=63\% points, the mean After score was 28/35 =80\%, and the mean Future score was 21/30= $70 \%$. It must be noted that the total possible points was 30 for the Future as compared to 35 points on the Before and After section. Therefore, when adjusted for this difference, the percentage score for each becomes: 30\% Before, 39\% After, and 31\% Future. So although there was a statistically significant gain between the students' initial (Before) impressions of their environmental attitudes and their standings at the time of the survey (After), there is room for speculation as to their future ability to put their beliefs into action. 


\section{Summary of Quantitative Data}

Putting all of the data from the PPT, CKQ tests and PEAS surveys together in Figure 9 below, there appears to be some relationship among students' level of academic success and level of self-identified change in attitude. Those who have a higher level of combined (PPT and CKQ) literacy scores also seem to exhibit an increased proenvironmental (PEA) tendency, as determined by the amount of Change (the difference between the Before and After scores) on the EAS. Note that the lighter-colored tops of the bars signify the amount of Change. The reverse also appears to be evident in the graph below (Figure 9) where many of the lower scores do not even register a change at all.

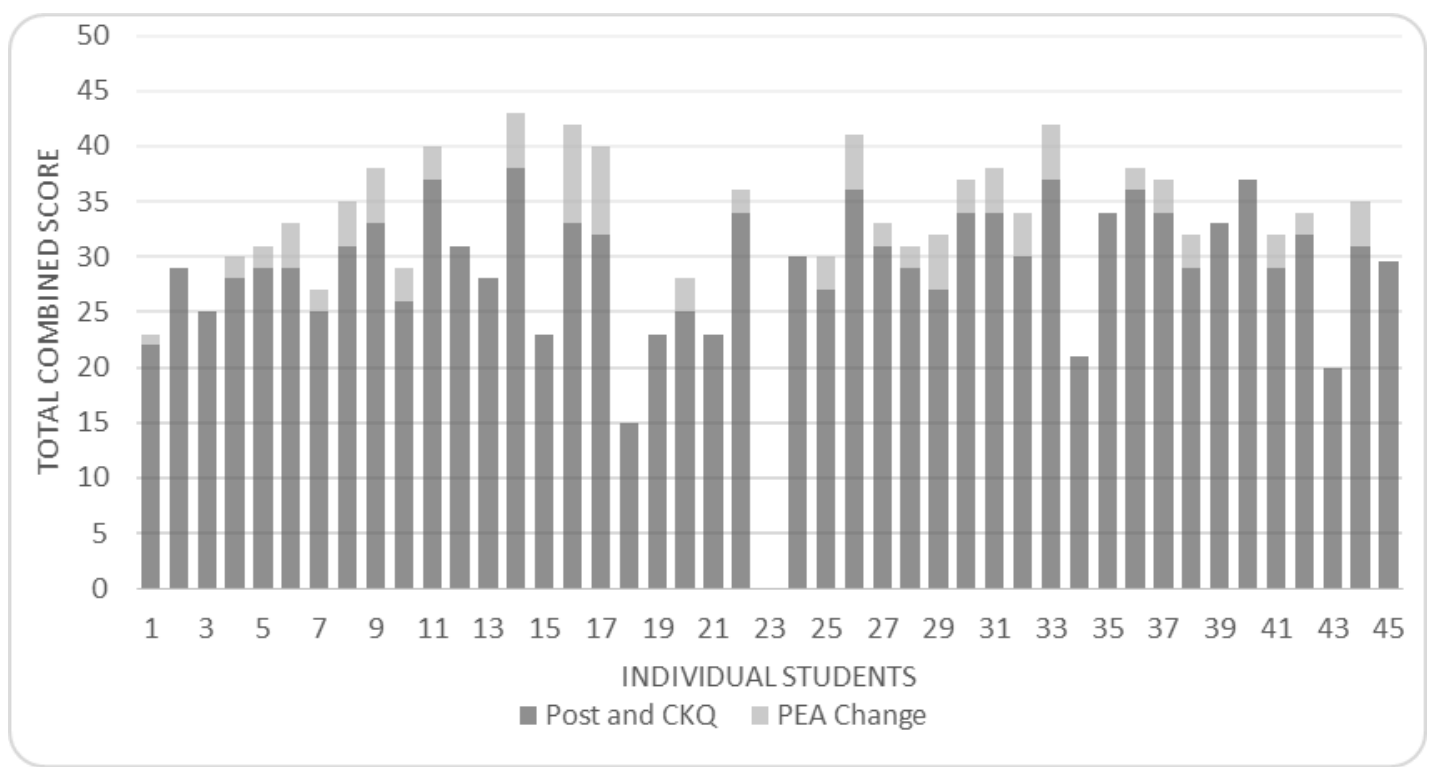

Figure 9 : Bar graph showing combined PPT and CKQ mean scores and level of Change (lighter colored bar) in environmental awareness.

In general the aggregate results, from all of the quantitative data presented, are positively supportive of the continued use of the OLWEDU to improve watershed literacy, knowledge of human's ability to monitor and mitigate their impacts on their 
watersheds, and solidify students' attitudes toward the environment. The specific results from the individual instruments do show variations in their ability to document knowledge gain. The limitations of each will be reported on later in this thesis.

\section{Qualitative Data from Interviews}

The following Table 8 of tabulated non-parametric data shows whether the students' interview responses were supportive of the Place based and STEM elements of the OLWEDU. The majority of responses (97) were positive, which means that their statements were in alignment with the intent of the question. A neutral response was one that was neither positive nor negative, because they made statements like: "nothing too challenging", or "no one part sticks out"; there were only twenty three in all. None of the answers were considered negative. In general, all of the answers were very supportive of the OLWEDU and the Place based and STEM aspects of the curriculum. Most of the comments during the interviews signified growth in awareness, knowledge, purpose, and community connections.

Table 8: Frequency data for Interview (INT) responses

\begin{tabular}{|c|c|c|c|c|}
\hline $\begin{array}{l}\text { OLWEDU Interview questions: } \\
\text { STEM and PBE overview }\end{array}$ & Total & Positive & Neutral & Negative \\
\hline $\begin{array}{l}\text { 1) When did you first become aware of the term } \\
\text { watershed? (in this unit, at school, outdoor school, } \\
\text { Tryon Creek Park, or other) }\end{array}$ & 10 & 9 & 1 & 0 \\
\hline $\begin{array}{l}\text { 2) How did using the local maps of the watershed and } \\
\text { school make the unit more meaningful? Did they } \\
\text { help you understand your own sub-watershed } \\
\text { better? }\end{array}$ & 10 & 8 & 1 & 0 \\
\hline $\begin{array}{l}\text { 3) Looking back, what do you remember most about } \\
\text { the Watershed Unit? Explain. }\end{array}$ & 10 & 10 & 0 & 0 \\
\hline $\begin{array}{l}\text { 4) What was the most interesting part about the Unit? } \\
\text { Why? }\end{array}$ & 10 & 10 & 0 & 0 \\
\hline
\end{tabular}




\begin{tabular}{|c|c|c|c|c|c|}
\hline 5) & $\begin{array}{l}\text { What part of the project did you find to be the most } \\
\text { challenging? Was that good or bad? }\end{array}$ & 10 & 5 & 5 & 0 \\
\hline 6) & $\begin{array}{l}\text { Which stormwater solution did your group focus } \\
\text { on? How well do you think the solution would work } \\
\text { at your school? }\end{array}$ & 10 & 10 & 0 & 0 \\
\hline 7) & $\begin{array}{l}\text { Where have you noticed rain garden-type structures } \\
\text { in your community or neighborhood? Do you have } \\
\text { any at your house? }\end{array}$ & 10 & 9 & 1 & 0 \\
\hline 8) & $\begin{array}{l}\text { Who did you talk with outside of school about } \\
\text { stormwater, engineering or anything else about } \\
\text { what you were doing in the Unit? (a friend, a } \\
\text { relative, or someone else?) }\end{array}$ & 10 & 7 & 3 & 0 \\
\hline 9) & $\begin{array}{l}\text { How did learning about the EDP make you think } \\
\text { about how humans solve problems? }\end{array}$ & 10 & 7 & 3 & 0 \\
\hline 10) & $\begin{array}{l}\text { In what ways, if any, did studying about stormwater } \\
\text { issues make you think any differently about where } \\
\text { you live? }\end{array}$ & 10 & 10 & 0 & 0 \\
\hline 11) & $\begin{array}{l}\text { Would you be willing to be part of a club that } \\
\text { promotes watershed health and stormwater } \\
\text { solutions? Otherwise, when might you use } \\
\text { something that you learned in the curriculum? }\end{array}$ & 10 & 6 & 4 & 0 \\
\hline 12) & $\begin{array}{l}\text { Any final thoughts about how we could make the } \\
\text { OLWEDU a better learning experience? }\end{array}$ & 10 & 6 & 3 & 0 \\
\hline & Totals & 120 & 97 & 23 & 0 \\
\hline
\end{tabular}

The positive results from this mixed-method combination of measures have shown individually, and in combination, that the OLWEDU does in fact increase watershed literacy and environmental attitudes. Most of the students' scores improved at least $50 \%$ and many times over $100 \%$ in each objective. The highest level of knowledge gain was in the human impacts on stormwater variable, one of the key objectives of the OLWEDU curriculum. As has been documented, there is statistical support for each of the main hypotheses of this study; watershed literacy, knowledge of human impacts on stormwater, and pro-environmental attitudes did increase after participation in the OWLEDU curriculum. The verbal portions of the CKQ and Interviews supported this knowledge gain and also illustrated the depth of their newfound understanding. 


\section{Discussion}

It is encouraging to report that the statistical outcomes from most of the measures used in this research study show a positive increase in both watershed literacy and environmental attitudes. In several areas, the actual increases in the knowledge base were $100 \%$ or more. While the overall trends are statistically positive, individual variable results did vary by instrument and by student. Each variable and hypothesis will be discussed in this section with regards to the summary of data collected and potential areas of confusion and error. These quantitative and qualitative results have met many of the requirements for MWEEs (Zint \& Kraemer, 2012) and Sterns EE program evaluations (MJ Stern, et al., 2013). Therefore, this discussion will also touch on how this research supports the work of others interested in improving environmental literacy, watershed and stormwater literacy in particular, such as those proposed by M.J. Stern et al. (2013) in their EE program evaluations: knowledge, awareness, skills, attitudes, intentions, behavior, and enjoyment. In presenting the specific results for this study, therefore, I will employ the hierarchy set forth by the Campaign for Environmental Literacy in describing how these increases in knowledge and environmental attitudes fit into the "Climbing the Environmental Literacy Ladder": awareness $>$ knowledge>attitudes $>$ skills $>$ collective action (see details in definitions section) (Campaign for Environmental Literacy, 2007).

\section{AWARENESS}

To begin with, then, I would like to claim that participation in the OLWEDU did indeed succeed in fostering a "General awareness of the relationship between the environment and human life." (Campaign for Environmental Literacy, 2007) The 
elevated results "voicing" agreement (Agree $=4$ and Strongly Agree $=5$ ) on the environmental attitude survey (EAS) (Table 7, Figure 7) Illustrate that the students are keenly aware of environmental issues. Many of the studies used for this research show a similar increase in awareness after participating in their programs (Austin, 2010; Kudryavtsev, et al., 2012; Musser \& Malkus, 1994; Santlemann, et al., 2011; Stern et al., 2013). This awareness or "change in recognition or cognizance of issues or concepts." (Stern et al. 2013) was exemplified by this student's comment, "I learned ways to relate it to where I live. When I look out the window and see impervious and pervious surfaces every day." Many of the students said that they (and even their parents) had not realized that stormwater was such a problem for the city. Another student said that they had been "oblivious" to "how big of effect" impervious surfaces had on watershed function; the unit made them "more aware of how watersheds work." These statements show that the students were starting to understand the relevancy and impact of learning about watersheds and humans impact on the environment. The STEM and place-based components of the OLWEDU were no doubt helpful in guiding the students along the first step of increasing awareness on the "Environmental Literacy Ladder" (Campaign for Environmental Literacy, 2007)

\section{KNOWLEDGE}

To measure the extent of increase in science-based "knowledge and understanding of human and natural systems and processes" (Campaign for Environmental Literacy, 2007), after completing the OLWEDU, two instruments were used, the Pre/Posttest (PPT) and the Constructed Knowledge Questionnaire (CKQ). The 
study reports a solid $70 \%$ statistically significant increase in mean scores for the PPT, (Table 5) supporting one of the key hypotheses for this study. The fact that the 2014 sample size was 358 makes these findings worthy of consideration, and beg for comparison with other similar curriculums or future studies. Gains such as these are encouraging and have been reported on a smaller scale by others studying watershed literacy. (Beatty, 2007; Boujaoude \& Yousef, 2004; Hager, 2013; Shepardson, 2007; Stagner, 2013; Zint, et al. 2010). It appears that as a whole the students gained a broader understanding of human's impacts on watersheds, supporting the overarching hypothesis that the OLWEDU increases not only watershed literacy (WSL), understanding of human impacts on stormwater (HIS), but also skill with the engineering design process (EDP).

Some historical patterns in the data deserve to be highlighted. It is interesting to note that the 2014 increase in scores on the PPT (Table 4) from a mean of 7.51 to 12.74 mirror the results of 7.9 and 12.0 from the previous year's analysis of the piloted OLWEDU (Gardner 2013). Both of these increases would be considered positive outcomes by researchers, Stern, et al. (2013). Another important point to report, is that when the PPT means from the full sample group $(n=358)$ were compared to those of the sub-sample group $(n=44)$ which participated in the CKQ and EAS, both of the means were exactly 5.8. Breaking down the scores into each objective, a similar pattern is found. The WSL scores are 6.7 (358) and 6.4 (44). For the variable of human impacts on stormwater (HIS), the difference between the full group mean of 1.53 and the sub group mean of 1.66 is only 0.13 . Finally, the difference between the engineering design portions is only 0.2 , with the full group's mean score at 4.1 and the sub group's score at 4.3 . 
Further analysis of the exact answers provided similar results, so for most of the remainder of this discussion I will be referring to the average from the subgroup and full group interchangeably. This practice was used by William Kuechler and Mark Simkin (2010) in their comparison of classes' scores in their research on multiple choice and constructed response testing.

With regards to the constructed knowledge questionnaire (CKQ), the other instrument used to measure inclusive watershed literacy, the limited and mixed (Stern, et. al., 2013) outcomes from it alone are less encouraging (Table 5). As a summative assessment, there were no actual figures for comparison of growth, but having the written constructed responses were very enlightening and informative. The overall raw percentage rating of $55 \%$ on the CKQ would not be considered successful under most assessment scales. However, there is evidence by some educational researchers that constructed response assessments do often show a lower overall achievement rate in comparison to multiple-choice measurements, since the probability of answering correctly on a multiple choice test is higher. (Frary, 1985; Kuechler \& Simkin, 2010). The difficulty of putting one's knowledge into verbal form was illustrated with this constructed response instrument. In order to use the CKQ to back up the gains on the PPT the cognitive levels of the individual questions and sections would have to have been more closely calibrated (Simkin \& Kuechler, 2005).

As a final analysis of relationships between the students' performance on the PPT and the CKQ, the Quick Analysis in Excel, (Appendix G), the following patterns were discovered: Fourteen students' scores stayed above average; eleven students' scores 
stayed level with the average; one student stayed below average; fifteen students did better on the CKQ; and four did worse. So although direct comparisons are difficult to make between the multiple-choice Posttest and the constructed answer Knowledge Questionnaire, there is evidence that most (26) students' abilities basically stay the same, and a few (17) actually did better on the written tests.

The complexities of figuring out why students generally performed at a lower than optimal rate will be taken into consideration as we discuss the specific results from each of the three variables (WSL, HIS, EDP), or curriculum objectives, of the OLWEDU.

\section{Watershed literacy (WSL)}

Depending on the specific questions with a watershed focus (WSL), the scores from PPT (Appendix A) questions \#1-9 all improved dramatically. (Figure 3) The average improvement was $64.4 \%$ overall, supporting the effectiveness of the OLWEDU to increase watershed literacy. Questions PPT \#1-3, 9 improved the most, over a hundred percent increase. The increase in correct responses was four fold on question PPT \#3, which asked the students to "describe the two elements most responsible for the movement of water within a watershed". It should be noted, however, this increase still resulted in only half of the students getting the correct answer. The underlying phenomenon associated with this question has just been added to the new science standards (NGSS Lead States, 2013). The student modeling activities included in the OLWEDU curriculum of building paper watersheds and calculating infiltration, both onsite and mathematically, certainly promoted a clearer understanding of gravity, but less so the role of energy from the sun. 
On the Pre/Posttest there were a few other questions that were problematic from the beginning which impacted the final results, leading to lower than scores that didn't reflect what was actually known. For example, the students' ability to choose a symbolic representation on PPT \#2 was limited, with just over half of the students answering correctly, despite an increase of over $100 \%$ in correct responses from the Pretest to Posttest. This very well could be due to the choices they were given to choose from since it is very difficult to find an iconic metaphor for such a phenomenon as a watershed. Perhaps this dilemma will be addressed in the future iterations. It would also be informative to have the students draw their own metaphoric representations of a watershed.

Nonetheless, when the students were asked to describe a watershed to a friend, on the first part of the CKQ \#1, most of them were able to state that smaller bodies of water ran into larger bodies of water, and some included gravity in this process, but the underground connection and linked nature of watersheds was weak. This disconnect was also apparent when they were also asked draw their idea of a watershed on the second part of CKQ\#1. The majority of drawings showed surface water coming from high elevations down to only one, or possibly two, large bodies of water, such as a river or lake, but with little illustration of the integrated groundwater processes. Shepardson would categorize most of these as a Conception 1: Watershed as a natural and dynamic process involving a developed hydrologic cycle. He does caution those that "We should note that this conception does not reflect a developed conceptual model of a watershed, but simply a developed view of the hydrologic cycle.” (Shepardson, et al., 2007, p.561). 
Shepardson (2007) results from his study concur with these findings, and would support considering the students' drawings as representative of developing conceptualizations of watersheds, mostly Conception 3s and 2s, with few Conception 1s, with 1 being the highest comprehension level. Shepardson (2007) stated the need for a curriculum that is "sequenced in a way that moves student toward scientific understanding." (p.573). Conceivably he would agree with the use of such drawings as formative as well as summative measures of comprehension. He also recommended the need for "Longitudinal studies of students' developing conceptions (that) would also be useful in determining the impact of experience and schooling on students' conceptualization of watersheds." (Shepardson, et al., 2007, p.577).

This ability to understand the interlocking aspects of watersheds, above and below ground, is crucial in comprehending watershed function and the impact humans have on stormwater and the environment. (Hager, 2013; Shepardson, et al., 2007; Zint \& Kraemer, 2012). It is important that students come away with a basic understanding of groundwater and these interconnections. The increase of over one hundred percent on PPT Q\#s 4, 5, 9, 10 is positive evidence that the students achieved a better understanding of groundwater from having completed the Unit and various infiltration exercises. This is an example of where having onsite and concrete applications of knowledge was beneficial to their comprehension of the phenomenon. In the end, the combined results from the PPT and CKQ would have to be considered mixed, since the written and drawn responses did not necessarily back up the gains shown in the multiple choice assessment. 


\section{Human Impacts on Stormwater (HIS)}

This benefits of connecting the OLWEDU to real-life scenarios, can be seen in the Human Impacts on Stormwater (HIS) section of the both the PPT and the CKQ, where the results from both assessments were positive (Table 5). The extent to which the students gained a better understanding of how humans impact stormwater systems was demonstrated by the number of students answering correctly on PPT questions \#10-11 regarding impervious surfaces (Figure 4), which increased to at least 90\%. Especially noteworthy is the four-fold increase in mean from 64 to 219 on question \#12, which asks the students to identify "Which of the following is not an impact of impervious surface?" This performance shows a distinctive increase in the understanding of the environmental science behind the use of impervious surfaces, which aligns with Policy \#4: "Effective response to complex problems requires understanding of the natural and built environment." (101 ${ }^{\text {st }}$ US Congress, 1990).

The students' $86 \%$ performance on the CKQ questions \#4-6 (Table 5) also illustrates their developing understanding of pervious and impervious surfaces and their relationship to watershed function. The majority of the statements made on the CKQ were on target, albeit somewhat repetitive, showing a sample wide comprehension of many of the issues surrounding humans, stormwater, and the environment. One student's understanding is put this way: "Humans build paved driveways and sidewalks which create impervious surfaces that water cannot infiltrate through and it empties into storm drains." (D3.09) Another student picks up from there to state: "When we wash our car the soap can get in and pollute the water." (B1.14) The ability to first understand that 
"Human activities have significantly altered the biosphere, sometimes damaging or destroying natural habitats and causing the extinction of other species. But changes to Earth's environments can have different impacts (negative and positive) for different living things. (MS-ESS3-3)" (NGSS Lead States, 2013). This wide reaching impact is simply put by Environmental Literacy Council (2008), “A pollutant that enters at the headwaters not only can disturb the area at the point of entry, and it can also affect each source of water into which the tributaries drain." (www.environliteracy.org). One student who was interviewed said that "more people should learn about stormwater, how it is not filtered, see how it's hurting things." (D3=15) This cause and effect relationship between humans and their environment is crucial as a foundation to understanding the power that humans have in changing current practices (Stern, 2007).

The most exciting news to report was that the students seem to have excelled in the HIS department, with percentages in the eighties on both the PPT and the CKQ. (Table 5) This was perhaps due in part to these questions being more aligned in knowledge base (Simkin \& Kuechler, 2005). These findings suggest that the students did become more aware of such human impacts on the environment as pervious and impervious surfaces, by actively studying stormwater issues and solutions at their schools. As will be seen in the next section, the students' performance in the EDP sections illustrate the benefits of using applicable "adult" practices to study scientific concepts and community issues. 


\section{SKILLS}

\section{Engineering Design Process (EDP)}

"Problem solving and critical thinking skills" (CEL, 2007) were one of the key components to the OLWEDU. Not only did the curriculum satisfy the ODE's engineering requirements, the engineering design features of combining the science, technology, engineering, and math portions of this STEM- framed unit brought together skills that the students can use in many areas of their lives. The OLWEDU was decidedly challenging, and had mixed results in the EDP department as shown by the final PPT and CKQ scores. With an overall academic success rate of 68\%, the EDP section of the PPT showed some significant gains on the students' application of the engineering design process (EDP), of approximately $100 \%$ increase in three of the questions and over 50\% (Stern's (2013) minimum positive limit) on the other three (Figure 5). The CKQ results were limited (Table 5) and of mixed significance, mostly due to the fact that the students did not exactly answer correctly the only question presented.

On the PPT, question \#13 focused on the distinction between electronics and technology in general, i.e. electronics are technology, but not all technology is electric. In questions \#14-17, the students were presented with a problem scenario involving the use of a PUGH chart. These particular questions were limited in addressing knowledge of the complete EDP series of iterative steps, since they focused mostly on knowing how to use a PUGH chart to decipher criteria and constraints. Both the teachers and the students had initially reacted with apprehension to learning how to use the chart, but in the end they accepted the strengths of this decision making tool. Paraphrasing one student's comment 
during the interviews, the "EDP made sense, how people develop things. The PUGH chart made it easier, especially since I am not good at (making) decisions." As a whole, the EDP was a key feature of the Unit and the students had to produce a Work Sample showing their understanding of all of the steps, which were self and teacher scored using the Engineering Design rubric from the Oregon Department Education (ODE, 2012). By learning several of the practices involved in identifying problems and designing solutions the students are more prepared to take on the role of engineers and be able to "monitor and mitigate" stormwater challenges on site at their schools (NGSS Lead States, 2013).

In an attempts to have the students apply their newfound understanding to a novel task the CKQ Q\#7asked them to describe a unique way of using the EDP, other than building stormwater solutions. In asking the question I was hoping to flesh out each aspect of the EDP, but the limited wording of the question did not convey a complete prompt for that. Ultimately, I was looking for an original example of a student identifying a problem and the process by which solutions could be arrived at. In the end, most of the responses either described a stormwater example from the unit, or were quite typical, like using the EDP to build a building, or other structure. Certainly there will be opportunities for future research into the abilities of students to use "adult" decisionmaking tools to solve societal and environmental problems. Apparently, sixth grade is not too young to start this process; a similar fifth-grade engineering design curriculum, entitled Design in the Watershed, (Trauth-Nare \& Austen, 2015) has already been released and is featured in the January 2015, National Science Teachers Association (NSTA) Science \& Children magazine. 


\section{ATTITUDE}

\section{Environmental Attitude}

It was encouraging to note statistically significant results on the Environmental Attitude Survey (EAS) (Table 6) since this was one of the keystone questions guiding this research. These findings, summarized in Table 7, support the hypothesis that increased awareness and knowledge of environmental issues through the participation in a placebased unit can affect the intent to act. A few researcher have been successful in finding a similar correlation between knowledge gain and increased attitudes (Boujaoude \& Youssef, 2004). This is not always the results reported by other researchers (Beatty 2007; Carrier 2013; Kudryavtsev et al., 2012; Stagner 2013; Zint \& Kraemer, 2012). Formulating an attitude shift is more difficult to plan for and detect. "Developing attitudes of appreciation and concern for the environment is a subtle process that is difficult to deliberately program.” (Campaign for Environmental Literacy, 2011).

Even though it was designed as a retrospective survey the students seemed to have had no problem comprehending the point of considering their attitudes about the environment before the OLWEDU and after, and easily identified the direction of change. As Flaxen Conway and colleagues from the OSU Watershed Stewardship Education program point out in using a 'post-then-pre' design when measuring "behaviors (opinions or confidence levels)", "The retrospective pretest at the end of the training program is more accurate that a standard pretest because it's answered in the same mindset as the posttest. The problem of 'response-shift bias' in self-report, pre-post designs is therefore minimized." (Conway, et al. 2003, p.5). The fact that there was a 
range of between a $10 \%$ to $25 \%$ self-reported change in attitude, reflects well on how the students saw themselves as having changed their opinions, towards the stewardship of environment, in response to having been part of this learning experience.

The second section of the EAS asked them to project and think about how participating in the OLWEDU would affect their intent into the future. (Table 7) Whereas Stagner and Beatty both reported negative results on their Environmental Attitude (EA) surveys they did report more positive intent to act (ITA) results (Beatty, 2007; Stagner, 2013). It should be noted, however, that although there was an increase in self-reported pro-environmental understanding of current issues after having participated in the OLWEDU, from a $63 \%$ agreement Before the unit to a strongly in agreement of $80 \%$ After, that enthusiasm was tempered and returned to $70 \%$ when Future intensions were considered, nearly the same level as before the OLWEDU (Table 7). This pattern might suggest that although the students feel themselves to be more aware of problems in the watershed, they are hesitant to project their behavior into the future. These findings support the hypothesis that increased awareness and knowledge of environmental issues through the participation in a place-based unit can affect the intent to act. From reading the interview notes, most of this backtracking tendency had more to do with feeling overwhelmed at school, home, and other obligations, rather than lack of motivation or interest. Several of the students who were interviewed stated in response to interview question \# 11 that they would be willing to be a part of a watershed-based club if they had time, it was convenient, and someone they knew was also participating in a proenvironmental project in the community. Student B7.11 stated, "I would if I had enough 
time." "I definitely want to help others learn about the solutions." There were several similar statements that could be used as evidence of a growing "capacity for personal and collective action and civic participation" (CEL, 2007) presented in the CKQ, the EAS, and the Interviews.

One of the most interesting trends that surfaced in examining and comparing the change in attitudes noted on the EAS with the combined PPT and CKQ knowledge scores, (Figure 9) was that there seemed to be a relationship of more Change declared by the students showing higher scores, and little to no Change on those with the lower scores. Whether this can be attributed to self-efficacy or motivational resilience is only speculative and deserves further research. For now, it can be said that one of the general by-products of participating in the OLWEDU is an increased awareness of watershedrelated issues with an accompanying self-reported "agreement" of the need for humans to protect their watersheds. As cautioned by the Campaign for Environmental Literacy (2007), "Education is not deterministic: literacy alone does not guarantee that the learner will exhibit a specified set of behaviors. Rather, it guarantees only that the learner has the capacity for such behaviors." This statement is supported by the findings of many other researchers involved in connecting attitude change to knowledge gain. (Boujaoude \& Youssef, 2004; Stagner, 2013; Stern, 2007; Zint, \& Kraemer, 2012). Regardless of the ultimate outcomes, the hypothesis that there would be a significant increase in the students' PEA after the OLWEDU was upheld. The support for this correlation and hypothesis by other researchers is encouraging and leads to the need for further dedicated inquiries of how to foster pro-environmental attitudes even more. 


\section{Place Based connections}

The ability to use local maps and track some of the movements of water through local drainages that is one of the features that makes the OLWEDU place based and adds to its value in promoting a sense of place, place meaning, and pro-environmental attitudes. (Santelmann, et al., 2011; Kudryavtsev et al., 2012). One student's comments show the synthesis of what they had learned about their local watersheds: "I think that seeing the Lake $O$-going into the $W$-River and stuff, um, it really helped give more of a visual of where our watersheds were and where the creeks and canals were, and more of a visual for like everyone. That way they can understand watersheds and where they are in our city." (P7.11)

On questions CKQ \#2 (Appendix B) and PPT \#4-6 (Appendix A), which addressed the local and nested aspects of the Owl Lake watershed, the increase in the number of students recording the correct answer was only approximately $20 \%$ more on the PPT from Pre to Posttest (Figure 3). This seems to be mostly due to the students already having answered these questions correctly on the Pretest. On further examination of the difficulty of individual questions, it was found that the answers were simplistic like other "tasks that can be answered successfully by general intelligence alone, or some "test wiseness" (Stern \& Ahlgren, 2002, p.902). Question PPT\#6 did require the students to use place-based techniques to consult a map of the watershed and track the drainages of several local streams, and the results show this ability. Unfortunately, this knowledge did not transfer over to CKQ \#2, the chart where the students were asked to match their school's street address with the corresponding local drainages and streams, otherwise 
known as their "watershed address" (Friends of Tryon Creek, 2015; Oregon State Extension, 1999). If one truly comprehends the nested aspect of place, this should not be a difficult concept to transfer to watersheds.

Despite the ability to read the map correctly and identify the flow of water into the lake, the students had difficulty when answering questions on both the PPT and the CKQ. Especially problematic was the lack of correct answers for both the Pre and Posttest on question \#7 which states: "Much of the rainwater that falls on our community makes its way to O Lake, and from there, to..." The majority of the students picked the first and somewhat correct answer: a. the Willamette River. Although this is true, it shows that the students do not perhaps understand the broader concept of nested watersheds by following the flow of the water to the Pacific Ocean (Shepardson et al., 2007). In their defense, it could be said that the students' answers could reflect a test taking flaw by failing to read through the remaining choices of answers which might have ultimately allowed them to document their understanding of the linking of watersheds.

From the specific place-based questions on the PPT and the comments on the CKQ and during the Interviews it seems that the students' sense of ecological place meaning was enhanced by the study of their local watershed and particular schools and neighborhoods. In addition, the results from the second portion of the EAS regarding future intent, along with some of the Interview responses, the students of Owl Lake are eager to use their newly acquired knowledge to improve their communities and watersheds. These results are encouraging and supported by others, like Kudryavtsev \& Krasny (2012), who reported "Our research shows that, to a certain extent, interventions 
such as urban environmental education may nurture sense of place, which others have found might foster place- specific pro-environmental behaviors.” (Kudryavtsev, et al., 2012). Our results differed from Kudryavtsev and colleagues in that, they found no significant change in sense of place attachment, only significant change in ecological place meaning. A sense of place attachment, being an explicit "bond between people and places", in comparison to place meaning, where "symbolic meaning are ascribed to places." (Kudryavtsev et al., 2012). These researchers concluded that a variety of factors influence sense of place, including time spent engaging in activities in the area as well as learning more about their surroundings. They purported that there is a need for more studies on this matter.

\section{STEM relevancy}

One of the STEM practices that the students found challenging and relevant in the OLWEDU curriculum, was the integrated use of science, technology, engineering, and math. Several of them stated that "calculating the impervious surfaces" (D3.15) with the online calculator and "making a big map of the area" (B7.22) with scaling, were the most challenging aspects of the unit. The students could see how this application of math and technology was more realistic than just doing simulated math problems. The use of various technologies within the curriculum, while challenging, also illustrated firsthand the potential of new tools to solve old problems. The students' engagement in the unit had the potential to accelerate the motivational resilience of the students, "characterized by students' enthusiastic hard work and persistence in the face of challenging STEM 
coursework." (Saxton et. al. 2013) as this quote from student T3-15 implies: "if you don't get it at first, don't be upset, you have lots of tries, it gets easier."

Learning and then applying the science within this stormwater unit was shown to be relevant by many students as they integrated all the parts of the lessons together. When prompted by the question, What was the most interesting part about the Unit? one student replied:

"Probably, um, learning about how we can help with the problems of impervious surfaces. Because whenever the rain goes into impervious surfaces, it doesn't infiltrate into the ground refilling aquifers. It just goes into storm drains, picking up all the pollution and draining to the rivers. " (D3.04)

These statements illustrate the integration of the students' conceptions of the water cycle, stormwater, impervious surfaces, groundwater, and, watersheds and correlate with current science standards, "The crosscutting concepts of patterns; cause and effect; and interdependence of science, engineering, and technology are called out as organizing concepts for these disciplinary core ideas.” (NGSS Lead States p.233, 2013). In addition, the student's comments "more accurately reflects the way concepts are applied in the real world by scientists, engineers, and other STEM professionals." (Saxton et al., 2013).

As an additional STEM bonus, by actively participating in the activities of the OLWEDU unit, individually and as part of a group, the students experienced "belonging/relatedness, competence/efficacy, autonomy/ownership, and purpose." (Saxton et al., 2013). They were placed in a position to feel that what they were doing was relevant beyond the classroom. When asked: "How did learning about the EDP make you think about how human solve problems?" many of them responded like this student, 
(D3.09), that it "made more sense how people develop things" to solve problems; learning about the PUGH chart "made it easier". Another student stated the relevance this way: "the EDP gave us more of an overview of all the solutions in our community, and our limits, what we can't do." (P7.11). It appears that learning about the engineering procedures used to identify problems, then create solutions, and effectively evaluate those solutions, were seen as valuable and relevant $21^{\text {st }}$ Century STEM skills.

In summary, the combination of quantitative and qualitative results from this mixed-method evaluation have shown my hypotheses to be true. The Owl Lake Watershed \& Engineering Design Unit (OLWEDU) does significantly increase students' level of watershed literacy, knowledge of human impacts on stormwater, and promote pro-environmental attitudes. These results add additional support to the body of research by others who are concerned with increasing watershed literacy (Beatty, 2007; Boujaoude \& Yousef, 2013; Haury, 2000; Shepardson, 2007; Stagner, 2013; Zint \& Kraemer, 2012) and those who are more concerned with making the connections between humans and their impacts on the environment (Green, 2012; Hager, 2013; Littledyke, 2008; Stern et al., 2013; Tidball \& Krasny). The fact that the results showing a positive change in environmental attitude were encouraging, since that has not always been shown to be the case in previous studies (Kudryavtsev \& Krasny, 2012; Stagner, 2013; Stern et al. 2013; Zint \& Kraemer, 2012). Finally, the place-based features of the unit were shown through the students' comments to be important and applicable (Green et al., 2012; Littledyke, 2008). In addition, student evidence was given in verbal and written form, that having a $21^{\text {st }}$ Century, STEM format added to the ultimate relevancy of the unit. 


\section{Conclusions}

The overwhelming results from this case study support the benefits of using OLWEDU to increase watershed literacy, improve understanding of human impacts on stormwater and the environment, and encourage pro-environmental attitudes. The OLWEDU has been statistically shown to promote watershed literacy by incorporating the science of hydrology into the study of the working system of the local watershed. The curriculum successfully taught the children to identify anthropogenic barriers which hinder or even block the natural flow of water through the environment, above and below ground. After having completed this watershed and engineering unit, the students are now better equipped to explain the dynamic "structure, function, interaction and change and of Earth's interconnected physical systems.” (Oregon Environmental Literacy Plan, 2010; NGSS Lead States, 2013). By increasing their level of knowledge about the scientific connections between the water cycle, watersheds, soils, and impervious surfaces, the students have proven that they better understand the complexities of human impacts on watershed functions and "the threats to human health and environmental quality" $\left(101^{\text {st }}\right.$ US Congress, 1990). In this way, the use of the OLWEDU has upheld many of the educational mandates it was designed to address.

In summary, the research outcomes from this OLWEDU-focused case study have indeed shown the hypotheses to be correct. Participation in the OLWEDU does lead to:

\footnotetext{
$\checkmark$ increased watershed literacy,

$\checkmark$ increased knowledge of human impacts on the water cycle, stormwater in particular,

$\checkmark$ an increase in pro-environmental attitudes
} 
$\checkmark$ increased understanding of the relevancy of STEM practices, including familiarity with the Engineering Design Process

$\checkmark$ amplified sense of place

After participating in the OLWEDU, students have become more familiar with their own watersheds, they have learned how humans impact the water cycle, both above and below ground. By learning about the impacts that humans have imposed on watershed systems, the students are better prepared to "analyze how changes in the environment affect human systems..., how human activities and systems change the environment, and the interrelationship between environmental quality and human health and wellbeing." (Oregon Environmental Literacy Plan: strand 3, 2010).

\section{Limitations}

As a whole, there were few limitations which reduced the validity of this study, and these were mostly tied to the limits of each type of measurement instrument. The use of the Pre and Posttests (PPT) built into the curriculum definitely provided more reliable statistical results. Multiple-choice pretests have been found to be an effective formative assessment, especially when nontraditional material is being introduced. However, having just multiple-choice assessments like the PPT is limiting in that it does not directly address what the students actually know, but only their ability to choose a correct answer out of a given list of choices. A student can answer a multitude of multiple choice questions, focusing on one phenomenon and still not be able to describe or represent it adequately. (Simkin \& Kuechler, 2005).

For example, compared to the limited responses to the PPT question asking where watersheds are found, the more explicit descriptions and drawings provided in response 
to a related CKQ question asking to describe a watershed gave a better snapshot of the students' comprehension of how watersheds work. This falls under one of the common task categories that has been identified where multiple-choice is insufficient, "Rephrase general propositions in one's own words, or representing the benchmark's idea" (Saxton et al, 2013; Simkin \& Kuechler, 2010; Stern \& Ahlgren, 2002). Other PPT questions mentioned earlier, like \#7 and \#12 had their own wording issues, and show the difficulty in formulating higher order questions. Question \#16 on the PPT was problematic from the onset since the wording was confusing, prompting a correction, which didn't transfer to all of the key cards. One other note to chart, was the fact that due to the multiplechoice format on the PPT, there was no leeway for creative solutions to show application of the engineering design process (EDP), only the preset ones from the PUGH chart. The addition of a constructed-answer assessment (CKQ) was helpful to broaden the quantitative data and to bridge some of the gaps between the limitations of multiple choice assessments and more authentic assessments. (Saxton, et al, 2013). However, there are several restrictions which make constructed response assessments less desirable in a study of this magnitude. Not only were the two types of assessments, the PPT and the CKQ scored differently, the results could not be adequately compared. This difficulty was described by Simkin and Kuechler in 2005. Further research of theirs has shown that unless the depth of knowledge levels for each of the questions and instruments has been aligned, then it is unrealistic to expect to be able to directly compare the results (Kuechler \& Simkin, 2010). 
An additional limitation was that the inter-rater reliability in scoring did become cumbersome and made the statistical analysis of the constructed knowledge questionnaire (CKQ) less valid. Not only were the students' definitions and representations difficult to decipher, they were extremely hard to score using a Markscheme, even with the backup of two other colleagues. This difficulty was also experienced by Daniel Shepardson (2007) in his research on students' conceptualizations of watersheds. As Shepardson puts it, this difficulty lies in categorizing student constructions and authors' constructions of student constructions. "Therefore, the codes and categories constructed by the authors [within a sociocultural context] are shaped and colored by the authors, their experiences and conceptions of a watershed." (Shepardson et al., 2007, p. 557). Therefore, in the future I would suggest using a standardized coding scheme such as Shepardson's, to score the students CKQ assessments. This practice of using an existing instrument and coding scheme is proposed by several other researchers as well in order to address both the reliability and validity issues found in the use of an original instrument. (Musser \& Malkus, 2004; Stern, 2013; Zint \& Kraemer, 2012).

In discussing the limitations of the environmental attitude survey (EAS), what is typically considered a qualitative survey was used in a quantitative way. Some might caution against doing a parametric analysis on Likert-style, ordinal data, by summing across the columns and creating a scale construction (Bowen \& Bartley, 2014). But others agree that there are perfectly valid uses and reasons for doing so, "However, once you have a number of related survey questions all addressing some central concept... then there's a way to construct parametric data from nonparametric data (i.e. frequencies) 
so that higher-order analysis can be done--- such as averaging, standard deviations, ttests, and ANOVA tests." (Bowen \& Bartley, 2014, p.86). Therefore, since all of the questions were focused around the central concept of watersheds and associated environmental attitudes, it was decided to proceed with a numerical analysis. In addition, the source instrument had been previously documented with a Cronbach's Alpha score.

As has been demonstrated, the OLWEDU has succeeded in achieving many of the academic objectives. In some ways the curriculum itself was the results of an engineering design problem; the challenge being "How do we design a standards-based, watershed, stormwater and engineering place-based curriculum?" Below are lists of actual and assumed criteria and constraints involved with the OLWEDU curriculum itself.

\section{Criteria (satisfied):}

$\checkmark$ Meet City, State, and National water education mandates.

$\checkmark$ Utilize STEM principles and outcomes (Conceptual knowledge, Higher-order thinking skills, Affective and motivational resilience).

$\checkmark$ Framework and Next Generation Science Standards (Essential Questions, Practices, Disciplinary Core Ideas, Cross-cutting Concepts).

$\checkmark$ Hydrology (water cycle, watersheds, groundwater, infiltration, stormwater)

$\checkmark$ Humans (natural resource use, cause and effect, pervious and impervious)

$\checkmark$ Technology (online videos, research, calculators, maps)

$\checkmark$ Engineering Design Process (Problems, Solutions, Testing, Retesting, Sharing)

$\checkmark$ Math (area, volume, ratios, formulas, automated calculations, algebra)

$\checkmark$ Organized (24 well written lessons, with supplementary lab books and work samples) 
Constraints:

- Sixth grade recently added to middle schools

- New science curriculum to teach

- Limited science background for teachers

- Multiple classes per day

- Time limitations (daily and for whole unit)

- Few field studies

- Theoretical proposals (stormwater solutions not able to be carried through)

- Out of range of many community resources (SW Soil and Water, Metro, Clackamas Water Providers)

Many of the foundational criteria have been successfully satisfied within the curriculum. Some of the constraints are inherent in the setting and cannot be adequately addressed.

To carry on a research study even of a moderate size such as this one has its regrets and limitations. For instance it was difficult to take on the role of a researcher and to just report and not diagnose as a teacher would. With that said, I can now respect the diligence that goes into academic research. From my in depth examination of the curriculum both as a teacher and as a researcher, I make the following recommendations.

\section{Recommendations}

While it is apparent from the various instruments used in this study, that there was indeed a significant increase in watershed literacy and pro-environmental attitudes after exposure and participation in the OLWEDU, there is always room for improvement and opportunities for future research. This is especially the case if attitude and ultimately behavioral changes are viewed as part of the favorable outcomes of the unit. According to 
Michaela Zint (2012) and her colleagues, "to achieve behavioral outcomes, in addition to learning outcomes, programs should also have the characteristics outlined...:"

- place-based authentic hands-on science inquiry with sufficient opportunities to examine and discuss data,

- outdoor learning experiences that include preparation and reflection phases as well as the nature of the experience itself (e.g., appropriate amount of structure, opportunities to directly interact with environment, facilitating and role modeling by educators),

- demonstrations/models that make invisible parts of watershed systems visible,

- use of instructional technologies, and

- $\quad$ service learning.

Several of these elements are already in place within the current framework of the OLWEDU and just need to be expanded. My recommendation would be to work from the successes and motivations already achieved by the teachers and students, and prepare to broaden the scope of this unit to include more onsite outdoor learning experiences and service learning opportunities. It would be satisfying if the students would actually get to participate in the planning and construction of a few stormwater solutions on their school campuses. From these statements, it appears that the students feel the same way. Although C1.13 stated "I learned a lot", this person felt that they were "indoors too much" and "could do most of the unit outside." In the words of C1.15, there should be "more hand's on projects" using "plots of the school". This student also said that the Unit should "start earlier in the trimester". Clearly there is much that has been successful about the OLWEDU and proves that this curriculum is a viable method to 
teach watershed literacy, human impacts on stormwater, and engineering practices, while also encouraging pro-environmental attitudes in a place-based setting.

An additional area of educational research, not directly addressed by this research, has to do with student variations in performance. There were definitely some observable differences in results identified between class groups, perhaps due to the links to grouping by math ability mentioned earlier, or other class demographic influences. For example Boujaoude \& Yousef's (2004) study could be used as comparative resource, “Since the study used intact groups, students' grades in math and science as well as scores on the achievement test prior to treatment were used as covariates." (p.65). A focus of this kind, would add to the body of research that has already begun and would also serve to improve the current curriculum. (Carrier, 2013; Stagner, 2013).

There is also the possibility of influence from more front loading by particular teachers, or from increased prior teacher pedagogical content knowledge (PCK) (Austin, 2012; Carrier, 2013; Gruver \& Luloff, 2008). These covariates were not addressed in this particular study, but perhaps this could be one of the focuses of future research on the OLWEDU. This would help inform some of Marc Stern's (2013) research as to which instruction strategies target and increase knowledge, awareness, skills, attitudes, intentions, behavior, and enjoyment in students.

Along with a study of the pedagogic practices, it would be helpful to have some longitudinal studies conducted on the middle schoolers, at least $6^{\text {th }}$ through $8^{\text {th }}$ grade. Zint \& Kramer's (2012) recommendation is that it takes 1-2 years for many of these watershed and environmental concepts to become ingrained. As they become more 
mature and participate in community service-learning projects, it would be informative to see what impact their experiences in the OLWEDU have on their choices and involvement. Even a shorter term assessment of what impact the students' newfound watershed and stormwater literacy will have on their own households and neighborhoods would be informative to the local watershed council and city bureaus.

As far as other potential research possibilities, it would seem that more attention could be focused on assessing other STEM curriculums that are combining watershed literacy with human impacts on the environment (Saxton, et al., 2013; Stern, et al., 2013). This is especially true for programs that are integrating engineering into their units (NSTA Science and Children, 2015). Of particular interest is the practice of assimilating the Next Generation Science Standards into existing environmental place-based curriculums, whether formal or informal ones (Achieve, 2014, NOAA, 2014). Another area of potential interest would be the integration of STEM units like the OLWEDU into Geography programs. (Eflin \& Sheaffer, 2006; Smith et al. 2006).

One of my final recommendations to the OLWEDU curriculum itself, would be to increase the pre-assessment activities, such as pre-conceptions of what and how watersheds work. These might also focus on the underlying forces within and interrelationships among the various factors involved in watershed structure and stormwater function. These concepts and formative assessments could easily be integrated into other units in the $5^{\text {th }}$ and $6^{\text {th }}$ grade curriculum. There is also a need for students to have a better understanding of the connections of watersheds and stormwater to their drinking water. The list could go on. 
The OLWEDU is already a rich standards based, STEM principled, inclusive, placebased unit with limitless possibilities for future research. One of the biggest research potentials is in evaluating its effectiveness in other schools and districts. It is this comparison across demographics which will validate it and strengthen it for future generations of young citizens.

In retrospect, the need for environmental and watershed literacy has been nationally mandated and well documented by a variety of stakeholders. In light of climate change predictions and increases in urban populations, there will be attention focused on stormwater accumulation and infrastructure. As a public institution, it would seem that schools would be a logical venue to promote environmental education science literacy, and civic responsibility. Assisting students along the continuum of the literacy ladder from awareness to knowledge, attitudes, skills, and collective action is certainly a worthy endeavor. Being able to carry out investigations on the school campus or nearby in the community fits well with the premises of place-based education. The strength of using STEM practices aligned with both national and state standards, should be noted.

"By asking questions and solving meaningful problems through engineering in local contexts (e.g., watershed planning...), diverse students deepen their science knowledge, come to view science as relevant to their lives and future, and engage in science in socially relevant and transformative ways." (Appendix I: Engineering Design in the NGSS April 2013)

This researcher hopes that the results from this research-based focus on the Owl Lake Watershed Engineering Design Unit are used to make future progress in fostering increased watershed literacy, understanding of humans' impacts on the environment, and practical use of engineering design procedures well into the $21^{\text {st }}$ Century. 


\section{References}

Achieve. (2014). Where did the water go? Watershed study - middle school sample classroom assessment. Version 1-published November 2014. Creative commons.

Austin, T. B. (2010). An environment-based education approach to professional development: A mixed methods analysis of the creeks and kids watershed workshop and its impact on K-12 teachers. (Thesis). Portland, Oregon. Portland State University.

Beatty, G. (2007). Assessment report: Clean rivers education program. Bureau of Environmental Services. In partnership with the Center for Science Education at Portland State University. Portland, Oregon.

Boujaoude, S., Youssef, R. (2004). The effect of teaching an environmentally-oriented science unit on students' attitude and achievement. Science Education International, 15 (1). Beirut, Lebanon.

Bowen, M., Bartley, A. (2014). The basics of data literacy: Helping your students (and you!) make sense of data. National Science Teachers Association. NSTA Press. Arlington, Virginia.

Campaign for Environmental Literacy. (2007). What is environmental literacy? Retrieved from www.fundee.org/facts/envlit/whatisenvlit.htm.

Carrier, SJ (2013). Elementary science indoors and out: teachers, time, and testing. Research in Science Education (Australasian Science Education Research Association) ISSN (0157-244X), 43(5), p. 2059-2083.

Conway, F.D.L., Godwin, D., Cloughesy, M., Nierenberg, T. (2003). Watershed stewardship education program: A multidisciplinary extension education program for Oregon's watershed councils. Journal of Extension, 41 (4). Retrieved from http://www.joe.org/joe/2003.

Eflin, J., \& Sheaffer, A. L. (2006). Service-learning in watershed-based initiatives: Keys to education for sustainability in geography? Journal of Geography (Houston) ISSN (0022-1341), 105 (1), p. 33-44.

Environmental Literacy Council. Updated (2008). Copyrighted 2013. Watersheds. Retrieved from www.environliteracy.org.

Frary, R. (1985). Multiple-choice versus free-response: a simulation study. Journal of Educational Measurement 22 (1), pp. 21-31. National Council on Measurement in Education. 
Gardner, E. (2013). Engineering a healthier watershed: Middle school students use engineering design to lessen the impact of their campus' impervious surfaces on their local watershed. (Proposed thesis). Portland, Oregon. Portland State University.

Gray, J. (2005). "Four 'A's Text Protocol." National School Reform Faculty. Harmony Education Center. http://www.nsrfharmony.org/protocol/doc/4_a_text.pdf>.

Green, O., Shuster, W. D., Rhea, L. K., Garmestani, A. S., \& Thurston, H. W. (2012). Identification and induction of human, social, and cultural capitals through an experimental approach to stormwater management. Sustainability ISSN (20711050), 4(8), 1669-1682. Doi: 10.3390/su4081669

Gruver, J., and A.E. Luloff. (2008). Engaging Pennsylvania teachers in watershed education. Journal of Environmental Education 40.1 (2008): 43+. Educators Reference Complete. Web. 8 Jan. 2014.

Hager, GW (2013). Socioecological revitalization of an urban watershed. Frontiers in Ecology and the Environment ISSN (1540-9295), 11 (1), p. 28.

Haury, D. L. (2000). Studying watersheds: A confluence of important ideas. ERIC Digest. ERIC Clearinghouse for Science Mathematics and Environmental Education. Columbus, OH. ED463950. Retrieved from www.eric.ed.gov.

Kraemer, A., Zint, M., \& Kirwin, J. (2007). An Evaluation of National Oceanic and Atmospheric Administration Chesapeake Bay Watershed Education and Training Program Meaningful Watershed Educational Experiences. Washington, DC: National Oceanic and Atmospheric Administration.

Kudryavtsev, A., M. E. Krasny, R. C. Stedman. (2012). The impact of environmental education on sense of place among urban youth. Ecosphere 3 (4). Retrieved from http://dx.doi.org/101890/ES11-00318.1

Kuechler, W. L., Simkin, M. G. (2010). Why is performance on multiple-choice tests and constructed-response tests not more closely related? Theory and an empirical test. Decision Sciences Journal of Innovative Education. 8 (1), pp.5574.

Leeming, F. C., Dwyer, W. O., \& Bracken, B. A. (1995). Children's environmental attitude and knowledge scale: Construction and validation. Journal of Environmental Education, 26 (3), 22. 
Littledyke, M. (2008). Science education for environmental awareness: approaches to integrating cognitive and affective domains. Environmental Education Research, 14(1), 1-17, DOI: 10.1080/13504620701843301.

Louv, R. (2005). Last child in the woods: saving our children from nature-deficit disorder. Chapel Hill, NC. Algonquin Books.

Mange, K., \& LaBarge, G. (1996). Educating youth in water quality land use principles through outdoor education. Ohio Journal of Science. 96 (1):23-26, 1996. Department of Agricultural Engineering, The Ohio State University, Columbus.

Meinershagen, R. (2014). Solving Local Watershed Problems: A measurement of student success with the engineering design. Proposed thesis. Portland, Oregon. Portland State University.

Michigan (State of) Environmental Education Curriculum. (2004). What is a watershed? The watershed concept. Retrieved from http://techalive.mtu.edu/meec/module01/whatiswatershed.htm.

Musser, L., \& Malkus, A. (1994). The children's attitudes toward the environment scale. The Journal of Environmental Education, 23(3), pp. 22-26.

National Resource Council (NRC). (1996). National science education standards. Washington, DC. National Academies Press. CrossRef.

National Resource Council (NRC). (2011). Successful K-12 STEM education: Identifying effective approaches in science, technology, engineering, and mathematics. Division of Behavioral and Social Sciences and Education. Washington, DC. National Academies Press.

National Environmental Education Training Foundation. (1998) The national report card on environmental knowledge, attitudes and behaviors. Washington, DE.

National Science Teachers Association (NSTA). (2015b). The power of water: Fourthand fifth=grade students model change in human-environment interactions. Science and Children, 52 (8). Pp50-56. www.nsta.org/sc1504.

NGSS Lead States. (2013). Next Generation Science Standards: For states by states. Washington, DC: National Academies Press. www.nextgenscience.org.

Oregon Department of Education (ODE). 2014. Retrieved from www.ode.state.or.us/teachlearn/realstandardsbd.aspx 
Oregon State Extension Service. 1999. Give Water a Hand Leader Guidebook and Youth Action Guide. Board of Regents of the University of Wisconsin System, USA.

Peckumn, G (2003). "Water education: protecting our future". Journal - American Water Works Association (0003-150X), 95 (2), p. 84.

Portland Metro STEM Partnership (PMSP). (2013). http://pdxstem.org/about-us/stem-inoregon/

Promise of Place. What is place-based education (PBE)? Promise of Place. Retrieved from www.promiseofplace.org.

Rector, P., Lyons, R., Yost, T. (2013). The art and science of rain barrels: a service learning approach to youth watershed action. Journal of Extension. (51) 2, Article \# 2IAW9.

Santelmann, M., Gosnell, H., \& Meyers, S. (2011). Connecting Children to the Land: Place-Based Education in the Muddy Creek Watershed, Oregon. Journal of Geography, 11(3), 91-106. Doi:10.1080/00221341.2011.534172

Saxton, E., Burns, R., Holveck, S., Kelly, S., Prince, D., Rigelman, N. \& Skinner, E. A. (2013). A common measurement system for K-12 STEM education: Adopting an educational evaluation methodology that elevates theoretical foundations and systems thinking. Studies in Educational Evaluation. 40 pp 18-35.

Schuler, T. R. \& Holland. (1999). Article 127: On watershed education. Watershed Protection Techniques. 3(3): 680-686.

Shepardson, D. P., Wee, B., Priddy, M., Schellenberger, L., \& Harbor, J. (2007). What is a watershed? Implications of student conceptions for environmental science education and the national science education standards. Science Education, 91(4), 554-578.

Simkin, M. G., Kuechler, W. (2005). Multiple-choice tests and student understanding: What is the connection? Decision Sciences Journal of Innovative Education. 3 (1), pp.73-93.

Smith, G.A., and Sobel, D. (2010) Place and community-based education in schools. Routledge, Taylor \& Francis Group, NY and London. ISBN 978-0-415-87519-6.

Smith, J., Edwards, P., Raschke, J. (2006). Using technology and inquiry to improve student understanding of watershed concepts. Journal of Geography. 105, pp 249258. 
Stagner, R. M. (2013). Effects of ethnicity and gender on sixth-grade students' environmental knowledge and attitudes after participation in a year-long environmental education program. (Thesis). Portland, OR. Portland State University.

Stern, L., and Alhren, A. (2002). Analysis of students' assessments in middle school curriculum materials: Aiming precisely at benchmarks and standards. Journal of Research in Science Teaching. Vol. 39. No.9, pp.889-910.

Stern, M. J., Powell, R. B., Hill, D. (2013). Environmental education program evaluation in the new millennium: what do we measure and what have we learned? Environmental Education Research, DOI:10.1080/13504622.2013.838749.

Tidball, K.G., and M.E. Krasny. (2011). Toward an ecology of environmental education and learning. Ecosphere, Vol 2 (2), Article 21. Doi:10.1890/ES10-00153.1

Trauth-Nare, A. and D. Austen. (2015). Design in the watershed: Fifthgrade students use STEM principles to improve local water quality. Science and Children, 52 (5). Pp 36-42. National Science Teachers Association (NSTA).www.nsta.org/SC1501.

Trochim, W, M. K. 2006. Research Methods Knowledge Base online version. Retrieved from www.socialresearchmethods.net/kb.

United States of America (USA) $101^{\text {st }}$ Congress. (1990). National Environmental Education Act. Public Law 101-619-Nov. 16, 1990.

United States Environmental Protection Agency (EPA). 2009. National water quality inventory: Report to congress. (EPA 841-R-08-001). Retrieved from http://water.epa.gov/lawsregs/guidance/cwa/305b/2004report_index.cfm.

USDA Forest Service. (1993). Investigating Your Environment: An Interdisciplinary Curriculum for grades 7-12. Public Affairs Natural Resource Education.

Zint, M., Kraemer, A., Northway, H. \& Lim, M. (2002). Evaluation of the Chesapeake Bay Foundation's Conservation education programs. Conservation Biology 16 (3). Pp.641-649.

Zint, M., Kraemer, A. (20120. NOAA B-WET Evaluation System Plan: Watershed Education Literature Review. Bay Watershed Education and Training Program, National Oceanic and Atmospheric Administration, Washington, D. C. 


\section{Appendix A}

\section{Owl Lake Watershed \& Engineering Design Pre-Post Assessment:}

This pre-assessment will not affect your grade. When you come across something unfamiliar, please read all of the options and make your best guess. Do not write on this test packet.

Select the option that best completes the sentence or answers the question.

1. Watersheds are found
a. in cities.
b. anywhere there are people.
c. in wilderness areas.
d. in dry locations.
e. in all of the above options.

2. Which item best illustrates a watershed?

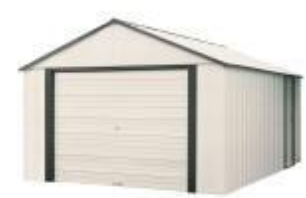

b.

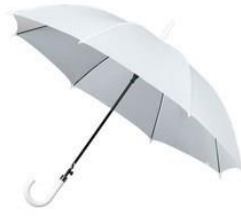

c.

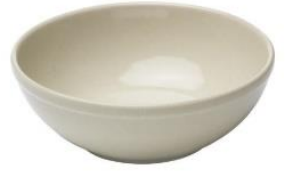

d.

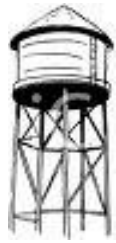

e.

3. Which option best describes the two elements most responsible for the movement of water within a watershed?
a. Sun and moon
b. Moon and wind
c. Wind and gravity
d. Gravity and sun
e. none of the above options.

4. Groundwater is
a. water that sits on the ground.
b. water that is stored on the ground.
c. water that is stored underground.
d. water in streams and rivers.
e. all of the above options. 
5. Altogether, human development such as houses, roads, stores, and factories, has

a. not affected watersheds.

b. made watersheds healthier.

c. made watersheds less healthy.

d. created watersheds.

e. happened only outside of watershed areas.
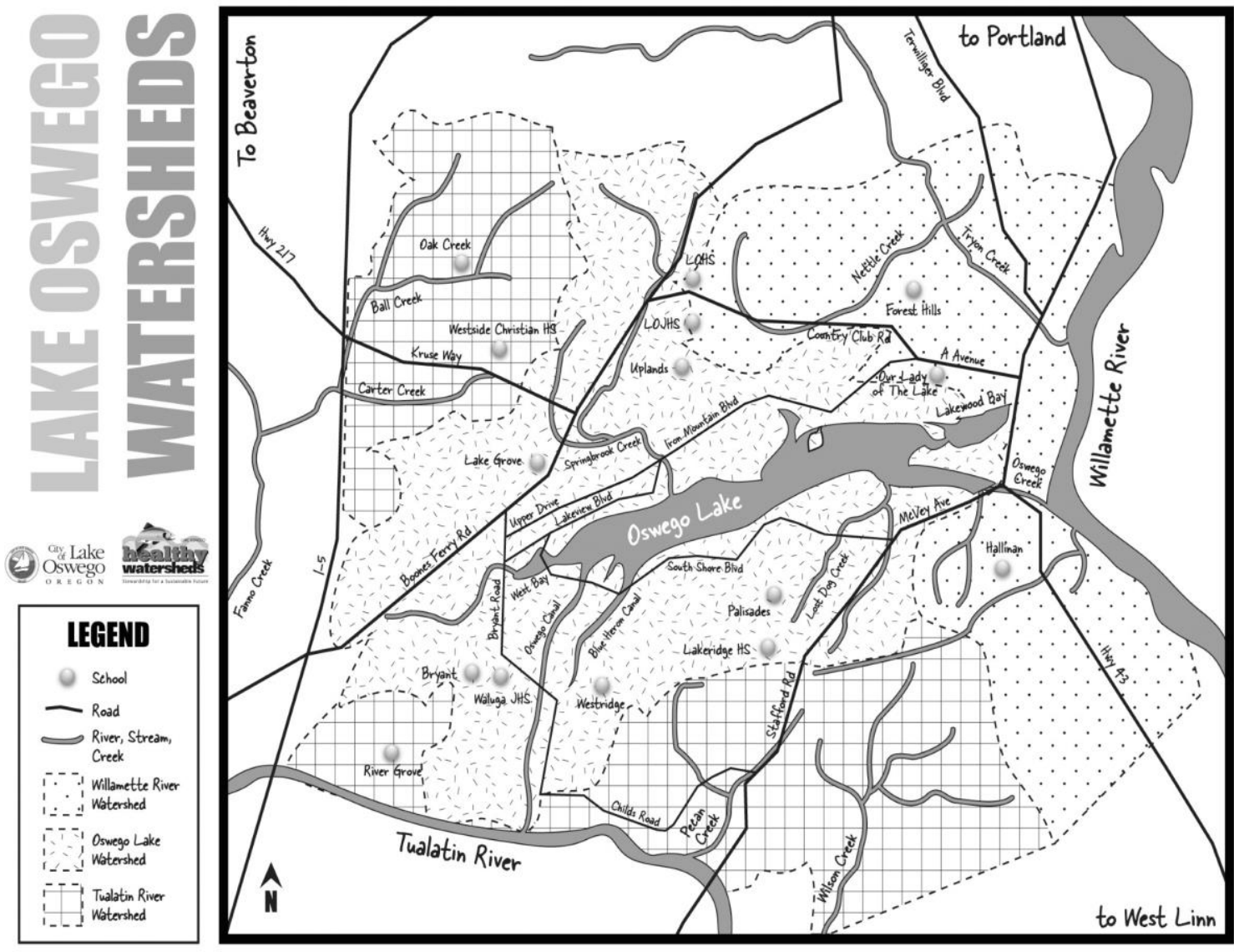

For more information visit www.ci.oswego.or.us/engineer/environ/surface.htm

6. According to the map above, which creeks drain into Oswego Lake?
a. Springbrook Creek and Carter Creek
b. Lost Dog Creek and Springbrook Creek
c. Tryon Creek and Lost Dog Creek
d. Wilson Creek and Tryon Creek
e. $\quad$ Carter Creek and Wilson Creek 
7. Much of the rainwater that falls on our community makes its way to Owl Lake, and from there, to
a. the Willamette River.
b. the Columbia River.
c. the Pacific Ocean.
d. all of the above options.
e. none of the above options.

8. When rain falls in Lake Owl, which of the following is not a path it might take?
a. $\quad$ Street $\square$ Lost Dog Creek $\square$ Oswego Lake
b. $\quad$ Tree $\square$ evapotranspiration $\square$ cloud
c. $\quad$ Lawn $\square$ Oswego Lake $\square$ Springbrook Creek
d. $\quad$ Soil $\square$ groundwater $\square$ Tryon Creek
e. $\quad$ Roof $\square$ drainage ditch $\square$ Ball Creek

9. After weeks of dry weather, the water flowing in creeks
a. seeps in from groundwater.
b. pours in from underground rivers.
c. flows in from rivers on the surface.
d. is piped in from water storage tanks.
e. condenses from the atmosphere.

10. When heavy rain falls on a paved street,
a. most of it stays there until it evaporates.
b. most of it is absorbed by the pavement.
c. most of it sinks into the ground through the pavement.
d. most of it gets carried away by vehicles.
e. most of it flows off the road into ditches or storm drains. 
11. Look to the labeled picture below: which option lists all of the impervious surfaces?

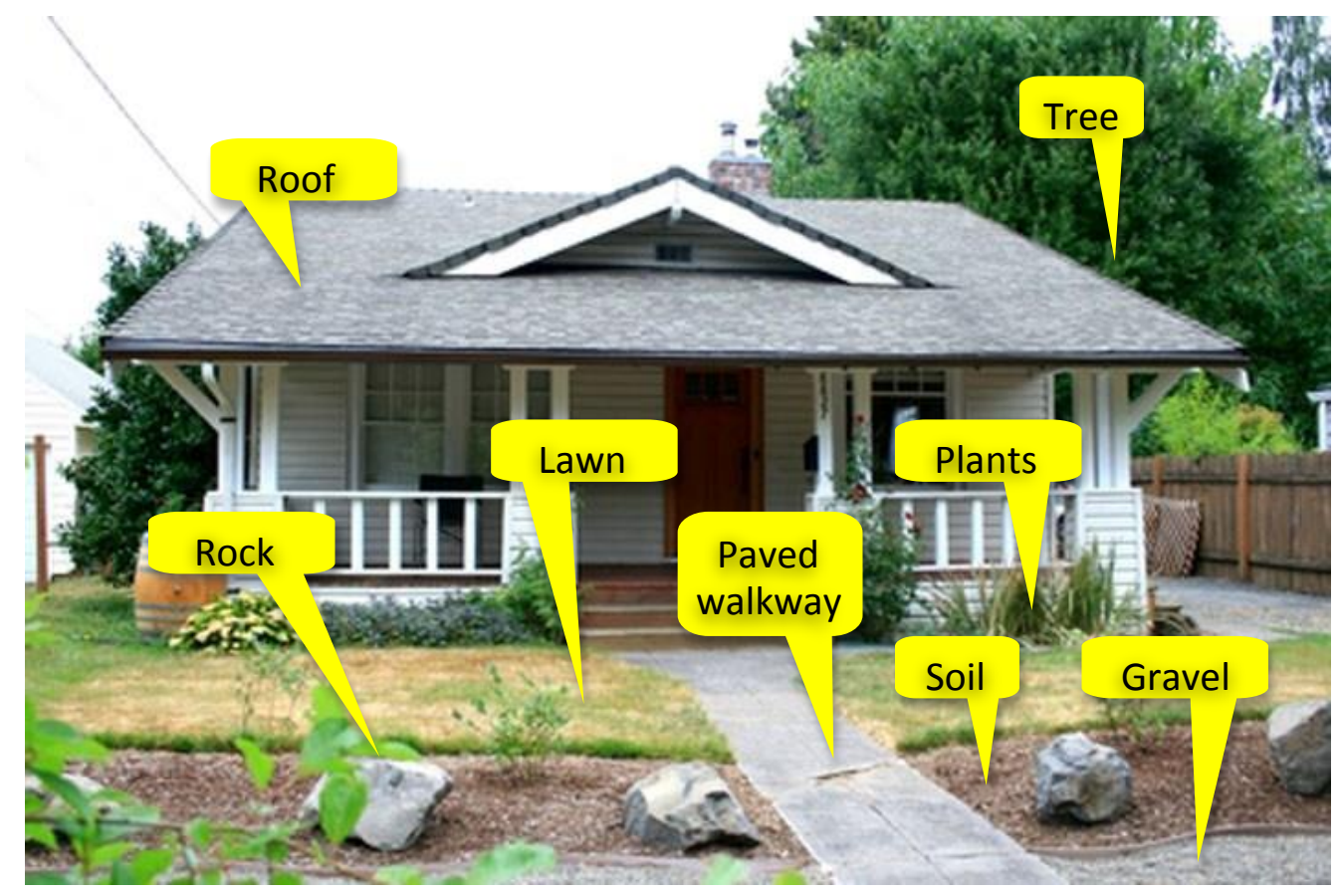
a. Paved walkway, soil, lawn, gravel
b. Roof, paved walkway, rock
c. Lawn, plants, tree
d. Soil, gravel, rock, roof
e. Plants, soil, tree, rock, gravel, lawn

12. Which of the following is not an impact of impervious surface?
a. The lake has less nutrients for algae
b. Creeks that dry up in summer
c. Loss of habitat for plants and animals
d. Erosion in streams
e. Water entering streams is polluted 
13. Sitting on a desk are the items below. Which of these are examples of technology?

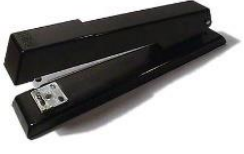

stapler

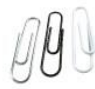

paperclips

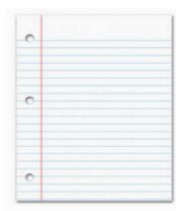

lined paper
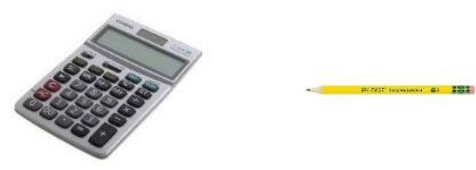

calculator

pencil

cell phone
a. The cell phone and calculator
b. The cell phone, calculator, and stapler
c. The cell phone, calculator, stapler, and paper clips
d. The cell phone, calculator, stapler, paper clips, and pencil
e. All are examples of technology

For questions $14-17$ refer to Gloria's Pugh chart below.

\begin{tabular}{|c|c|c|c|c|c|}
\hline PROBLEM TO & \multicolumn{5}{|c|}{ Rabbits keep eating the vegetables that I am growing for my family } \\
\hline $\begin{array}{l}\text { Evaluate each } \\
\text { solution against each } \\
\text { criterion and } \\
\text { constraint } \\
\text { 0: Does not meet } \\
\text { 1: Meets a little bit } \\
\text { 2: Meets halfway } \\
\text { 3: Completely meets }\end{array}$ & 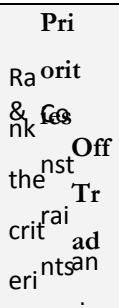 & $\begin{array}{l}\text { SOLUTION A } \\
\text { Build a } 1 \text { meter } \\
\text { wooden fence } \\
\text { mmmmmm }\end{array}$ & $\begin{array}{l}\text { SoLUTION } \\
\text { B Only grow } \\
\text { plants that } \\
\text { rabbits don't } \\
\text { like to eat }\end{array}$ & 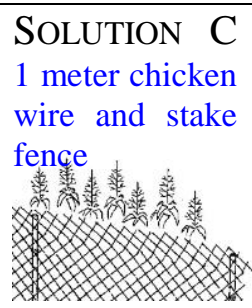 & $\begin{array}{l}\text { SOLUTION D } \\
\text { Set rabbit traps } \\
\text { and let them out } \\
\text { somewhere } \\
\text { else }\end{array}$ \\
\hline $\begin{array}{l}\text { CRITERION } 1 \\
\text { Have homegrown } \\
\text { vegetables to eat }\end{array}$ & 1 & 3 & 1 & 3 & 2 \\
\hline $\begin{array}{l}\text { CRITERION } 2 \\
\text { Easy to maintain }\end{array}$ & 4 & 3 & 3 & 2 & 1 \\
\hline $\begin{array}{l}\text { CRITERION } 3 \\
\text { Nice enough to look at }\end{array}$ & 5 & 3 & 3 & 2 & 2 \\
\hline $\begin{array}{l}\text { CONSTRAINT } 1 \\
\text { Won't hurt the } \\
\text { rabbits }\end{array}$ & 3 & 3 & 3 & 3 & 2 \\
\hline $\begin{array}{l}\text { CONSTRAINT } 2 \\
\text { Is not very expensive }\end{array}$ & 2 & 1 & 2 & 3 & 2 \\
\hline $\begin{array}{l}\text { After scoring each } \\
\text { against each criter } \\
\text { constraint, total th } \\
\text { at the bottom } \square\end{array}$ & $\begin{array}{l}\text { solution } \\
\text { on and } \\
\text { scores }\end{array}$ & 13 & 12 & 13 & 9 \\
\hline
\end{tabular}


14. In the above Pugh chart, solution A earned a score of 1 for constraint 2 . This means building a 1-meter wooden fence

a. "Does not meet" the constraint of "Is not very expensive"

b. "Meets a little bit" the constraint of "Is not very expensive"

c. "Meets halfway" the constraint of "Is not very expensive"

d. "Completely meets" the constraint of "Is not very expensive"

e. is the best solution

15. According to the Pugh chart, Gloria should choose the chicken wire fence. Why?

a. It had the highest total score

b. It had the lowest total score

c. It scored higher than solution A in constraint 2, which had high priority

d. It scored higher than solution $\mathrm{D}$ in criterion 2, which had low priority

e. It came in second place in criterion 3

16. Gloria built the chicken-wire fence. Unfortunately, some rabbits can still jump over it and eat her vegetables. What should she do?

a. Improve the current fence and see if it solves the problem

b. Keep the current fence and add solution B or solution D

c. Remove the chicken-wire fence and build the wooden fence

d. Remove the chicken-wire fence and decide between solution B or solution

e. Brainstorm new solutions and try one of them

17. According to the chart, Gloria believes that

a. Solution $\mathrm{C}$ would be harder to maintain that Solution $\mathrm{A}$

b. Solution B is more expensive than Solution A

c. Solution D is less attractive than solution $\mathrm{C}$

d. Solution B is more dangerous for the rabbits than Solution D

e. All of the solutions would allow Gloria to grow enough

vegetables for her family

18. Look to the half sheet of paper with a gray shape and grid. Follow the instructions and record your answer by selecting one of the options below.

a. $\quad 30$ square meters

b. $\quad 40$ square meters

c. $\quad 50$ square meters

d. $\quad 60$ square meters

e. It is impossible to estimate without more information 
Appendix B

Constructed Knowledge Questionnaire for OLWEDU

ID: Name

Date Period

1. How would you describe a watershed to a friend? Draw a watershed on the back of this paper.

2. Compare the two tables below and fill them in for your school's watershed address?

\begin{tabular}{|l|l|}
\hline \multicolumn{1}{|c|}{ Your school's address: } & \multicolumn{1}{c|}{ Your school's watershed address: } \\
\hline Street: & Local drainage: (you may not know this) \\
\hline Neighborhood: & Sub watershed:(..Creek) \\
\hline City: & Watershed (council): \\
\hline State: & Main watershed: (hint W) \\
\hline Region: & Regional watershed: \\
\hline National: & Continental watershed: \\
\hline
\end{tabular}

3. Explain and give two examples of how Lake Owl gets its water.
a)

b)

4. List two examples of ways in which humans impact their watersheds:

a)

b)

5. Describe the difference between pervious and impervious surfaces. Give examples.

a)

b)

6. What are two things that people can do to keep their watersheds healthy and clean?

a)

b)

7. Give an example of where you might use the Engineering Design Process in your life, somewhere other than a stormwater solution: 
Knowledge Questionnaire and Interview Markscheme for OLWEDU

Total Points

ID:

Name

Date

Period

\section{How would you describe a watershed to a friend? Draw a watershed on the back of this paper.}

Total of 6 points possible

2-3 pts. Must include both the land and the water relationship. Possibilities...

1. A watershed includes the land where one body of water contributes water to a larger body of water.

2. A watershed includes both the land and water that drain a given site, i.e. larger body of water.

3. Watersheds are everywhere, where water $\underline{\text { lands }}$ and is pulled down by gravity. 2-3 pts Drawing must show relationship between land and water, 3 pts if nested aspects of multiple watersheds are shown.

2. Compare the two tables below and fill them in for your school's watershed address?

12 points, 1 each for each section

\begin{tabular}{|l|l|}
\hline \hline \multicolumn{1}{|c|}{ Your school's address: } & \multicolumn{1}{|c|}{ Your school's watershed address: } \\
\hline $\begin{array}{l}\text { Street: } \text { Country Club Road or Jean } \\
\text { Road }\end{array}$ & Local drainage: (you may not know this) \\
\hline $\begin{array}{l}\text { Neighborhood: various accepted, } \text { ie. } \\
\text { Bryant Woods }\end{array}$ & $\begin{array}{l}\text { Sub watershed:(...Creek) } \\
\text { Lost Dog Creek or Springbrook Creek, } \\
\text { others? }\end{array}$ \\
\hline City: Lake Owl, or Lake Grove, etc. & $\begin{array}{l}\text { Watershed (council): } \\
\text { Owl Lake, or Tryon Creek }\end{array}$ \\
\hline State: Oregon & Main watershed: (hint W)Willamette \\
\hline Region: Pacific Northwest & Regional watershed: Columbia \\
\hline $\begin{array}{l}\text { National: } \text { United States, } \text { or North } \\
\text { America }\end{array}$ & Continental watershed: Pacific Ocean \\
\hline
\end{tabular}

3. Explain and give two examples of how Lake Owl gets its water.

2pts (since this should have been worded Owl Lake, there might be references to drinking water source) possible correct answers include:

- $\quad$ Rain and snow, i.e. precipitation

- The canal

- Tualatin river (via the canal)

- Groundwater

- Stormwater drains

- $\quad$ People watering their lawns 


\section{List two examples of ways in which humans impact their watersheds:}

2 pts. There are many ways in which this question may be answered, check for understanding of impact on watersheds

- Amount of pervious surfaces in and around homes, businesses, schools, etc.

- Using pesticides and herbicides on their lawns

- Choice of soaps that they use

- $\quad$ Not picking up their animal wastes, dog poop

- Oil residue from vehicles

- Erosion control

- Planting plants to soak up extra water

- Use of metals for ornamentation

5. Describe the difference between pervious and impervious surfaces. Give examples.

4pts. 2 for definition and 2 for examples. Possible answers, others available

- Pervious surfaces allow the water to soak in or infiltrate into the ground

- Examples of pervious surfaces are: lawns, bricks, gravel, dirt, gardens, rocks

- Impervious surfaces do not allow rain to soak in, instead it has to run off the sides or is directed to the lowest spot

- Example of impervious surfaces are: driveways, roads, parking lots, roofs, playgrounds,

- Check for basic understanding on other reasonable answers

\section{What are two things that people can do to keep their watersheds healthy and clean?}

2 pts. Several possible answers, check for direct impact

- Pick up their garbage

- Pick up pet waste

- Watch what they use on their gardens, lawns, sidewalks, and driveways

- Watch water consumption

- Minimize impervious surfaces

- Install stormwater measures: rain barrels, rain gardens, green roofs, bio swales

7. Give an example of where you might use the Engineering Design Process in your life, somewhere other than a stormwater solution:

1-4 pts Answers may vary; looking for identification of Problem, Possible solutions, Design trial, and Revising based on results or modeling calculations. 1 point possible for giving examples of each; Problem, Possible solutions, Evaluation of solution, and Revisions. 


\section{Appendix C: Environmental Attitude Survey.}

Do you agree with the following statements? They are in order L to R from Disagree to Agree.

a) Draw a circle around the letter of what you think now, after completing the WEDU.

b) Draw a triangle around the letter that shows how you felt before you began the unit.

c) Draw an arrow in either direction from what you thought before to what you think now.

\begin{tabular}{|lcccccc|}
\hline Attitude Questionnaire for WEDU & $\begin{array}{c}\text { Strongly } \\
\text { Disagree }\end{array}$ & Disagree & $\begin{array}{c}\text { Neither } \\
\text { Agree Nor }\end{array}$ & Agree & $\begin{array}{c}\text { Strongly } \\
\text { Agree }\end{array}$ \\
\hline $\begin{array}{l}\text { 1. It is important to keep the rivers } \\
\text { and streams in our watershed clean. }\end{array}$ & A & B & C & D & E \\
\hline $\begin{array}{l}\text { 2. It is important to help protect our } \\
\text { watersheds for drinking water. }\end{array}$ & A & B & C & D & E \\
\hline $\begin{array}{l}\text { 3. It is my personal responsibility } \\
\text { to help protect natural areas such as } \\
\text { streams rivers and wetlands }\end{array}$ & A & B & C & D & E \\
$\begin{array}{l}\text { 4. Our rivers and streams are } \\
\text { impacted by impervious surfaces } \\
\text { evervwhere }\end{array}$ & A & B & C & D & E \\
\hline $\begin{array}{l}\text { 5. The local government cares } \\
\text { about our rivers streams, and } \\
\text { watersheds }\end{array}$ & A & B & C & D & E \\
\hline $\begin{array}{l}\text { 6. I would work on a project to } \\
\text { help our rivers and streams ONLY } \\
\text { if Ihad to for schol. }\end{array}$ & A & B & C & D & E \\
\hline $\begin{array}{l}\text { 7. We can make our watersheds } \\
\text { cleaner for people and wildlife. }\end{array}$ & A & B & C & D & E \\
\hline
\end{tabular}

Draw a square the number that best matches your feelings for the following statements in the future. Mark ONLY ONE per statement.

\begin{tabular}{|lccccc|}
\hline In the next 6 months, I intend to... & $\begin{array}{c}\text { Very } \\
\text { Unlikely }\end{array}$ & Unlikely & Likely & $\begin{array}{c}\text { Very } \\
\text { likely }\end{array}$ & Definitely \\
\hline $\begin{array}{l}\text { 8. Change one thing that I do around my } \\
\text { house and neighborhood to prevent water } \\
\text { pollution. }\end{array}$ & A & B & C & D & E \\
\hline $\begin{array}{l}\text { 9. Tell others about ways they can protect } \\
\text { our rivers and streams. }\end{array}$ & A & B & C & D & E \\
\hline $\begin{array}{l}\text { 10. Volunteer in activities to help } \\
\text { watersheds. }\end{array}$ & A & B & C & D & E \\
\hline $\begin{array}{l}\text { 11. Tell my family one thing we can do to } \\
\text { stop water pollution. }\end{array}$ & A & B & C & D & E \\
\hline $\begin{array}{l}\text { 12. Do something outdoors to help keep our } \\
\text { watersheds cleaner. }\end{array}$ & A & B & C & D & E \\
\hline 13. Spend time outdoors in nature. & A & B & C & D & E \\
\hline
\end{tabular}




\section{Appendix D: Interview Questions for OLWEDU}

SCRIPT: Congratulations you have completed the Oswego Lake Watershed Engineering Design Unit! Thank you for participating in our research to help improve the curriculum for the next set of students. We are curious about your opinions on the unit and related topics. If you feel uncomfortable answering a question just say PASS or SKIP. If you think of something else to add as we go along, we can always go back and add your comments in. Since I can't type as fast as you can talk, I might have to ask you to repeat your comment. Let's begin...

1) When did you first become aware of the term watershed? (in this unit, at school, outdoor school, Tryon Creek Park, or other)

2) How did using the local maps of the watershed and school make the unit more meaningful? Did they help you understand your own sub-watershed better?

3) Looking back, what do you remember most about the Watershed Unit? Explain.

4) What was the most interesting part about the Unit? Why?

5) What part of the project did you find to be the most challenging? Was that good or bad?

6) Which stormwater solution did your group focus on? How well do you think the solution would work at your school?

7) Where have you noticed rain garden-type structures in your community or neighborhood? Do you have any at your house?

8) Who did you talk with outside of school about stormwater, engineering or anything else about what you were doing in the Unit? (a friend, a relative, or someone else?)

9) How did learning about the EDP make you think about how humans solve problems?

10) In what ways, if any, did studying about stormwater issues make you think any differently about where you live?

11) Would you be willing to be part of a club that promotes watershed health and stormwater solutions? Otherwise, when might you use something that you learned in the curriculum?

12) Any final thoughts about how we could make the OLWEDU a better learning experience? 
Potential Responses for Interview Questions for OLWEDU

1) When did you first become aware of the term watershed? (in this unit, at school, outdoor school, Tryon Creek Park, or other)

- They talked about watersheds at Sandy River Outdoor School

- In fifth grade we went to Tryon Creek and learned about watersheds.

- This was the first time I had ever heard of a watershed.

- We studied about watersheds in our landforms unit.

2) How did using the local maps of the watershed and school make the unit more meaningful? Did they help you understand your own sub-watershed better?

- It was cool to see maps of the school.

- I never really thought of where the rain goes after it comes down.

- I am starting to look for drainage areas as we drive around town.

- Not really, I have a hard time reading maps.

3) Looking back, what do you remember most about the Watershed Unit? Explain.

- It was fun to have the challenge of finding solutions that would work at our school

- All of the math, like having to figure out the area and the volume of water.

- Learning to use a PUGH chart!

- Being able to use what we learned in a real project.

4) What was the most interesting part about the Unit? Why?

- I liked going outside and looking for pervious and impervious surfaces.

- It was cool to be able to test our solution using a computer program.

- Working in teams

- I didn't, it was too long.

5) What part of the project did you find to be the most challenging? Was that good or bad?

- It was hard to figure out the exact area and volume of our site.

- The PUGH chart was frustrating.

- Deciding which stormwater solution to use.

- We had a hard time deciding which plants to use in our rain garden.

6) Which stormwater solution did your group focus on? How well do you think the solution would have worked at your school?

- We chose a rain garden. It would work, but kids might throw trash in it.

- We chose a green roof, but it might be too big and heavy to work.

7) Where have you noticed rain garden-type structures in your community or neighborhood? Do you have any at your house?

- I see them in the middle of the street in town.

- We have a rain barrel at home.

- The high school parking lot has some bioswales. 
8) Who did you talk with outside of school about stormwater, engineering or anything else about what you were doing in the Unit? (a friend, a relative, or someone else?)

- My parents and I talked about them.

- My friend from another class and I talk about the possibility of having one at school.

- The neighbors have a rain garden.

- No I haven't.

9) How did learning about the EDP make you think about how humans solve problems?

- It is cool to think of myself as being an engineer, since I like to solve problems.

- It seems like a lot of work to go through all those steps.

- I understand more of what it takes to find a solution to a problem.

10) In what ways, if any, did studying about stormwater issues make you think any differently about where you live?

- I think about where the rain goes now.

- I am more aware of pervious and impervious surfaces.

- It didn't really change how I think of stormwater any differently.

- I think about how I might pollute the watershed.

11) Would you be willing to be part of a club that promotes watershed health and stormwater solutions? Otherwise, when might you use something that you learned in the curriculum?

- I don't know about being part of a club, but it would be cool to see some here at school.

- I'd like to try some of the stormwater solutions at home.

- Yes, it would be cool to come up with stormwater solutions in the community.

- It depends on what we would be doing.

12) Any final thoughts about how we could make the OLWEDU a better learning experience?

- It would be great if we could actually have a contest and do one or two at school.

- It is awfully long and confusing. It would be helpful to have more examples.

- Get different maps that are easier to read. 


\section{Appendix E}

\section{Focal NeXt Generation Science Standards \& Performance Expectations}

For Objective 1: "Explain what a watershed is and how it functions"

Standard from NGSS: MS-ESS2 Earth's Systems

Performance Expectation: MS-ESS2-4. Develop a model to describe the cycling of water through Earth's systems driven by energy from the sun and the force of gravity. [Clarification Statement: Emphasis is on the ways water changes its state as it moves through the multiple pathways of the hydrologic cycle. Examples of models can be conceptual or physical.] [Assessment Boundary: A quantitative understanding of the latent heats of vaporization and fusion is not assessed.]

For Objective 2: "Describe impervious surfaces and connect their impact to the watershed" Standard from NGSS: MS-ESS3 Earth and Human Activity

Performance Expectation: MS-ESS3-2. Analyze and interpret data on natural hazards to forecast future catastrophic events and inform the development of technologies to mitigate their effects. [Clarification Statement: Emphasis is on how some natural hazards, such as volcanic eruptions and severe weather, are preceded by phenomena that allow for reliable predictions, but others, such as earthquakes, occur suddenly and with no notice, and thus are not yet predictable. Examples of natural hazards can be taken from interior processes (such as earthquakes and volcanic eruptions), surface processes (such as mass wasting and tsunamis), or severe weather events (such as hurricanes, tornadoes, and floods). Examples of data can include the locations, magnitudes, and frequencies of the natural hazards. Examples of technologies can be global (such as satellite systems to monitor hurricanes or forest fires) or local (such as building basements in tornado-prone regions or reservoirs to mitigate droughts).]

Performance Expectation: MS-ESS3-3. Apply scientific principles to design a method for monitoring and minimizing a human impact on the environment. [Clarification Statement: Examples of the design process include examining human environmental impacts, assessing the kinds of solutions that are feasible, and designing and evaluating solutions that could reduce that impact. Examples of human impacts can include water usage (such as the withdrawal of water from streams and aquifers or the construction of dams and levees), land usage (such as urban development, agriculture, or the removal of wetlands), and pollution (such as of the air, water, or land).

For Objective 3: "Perform the Engineering Design Process"

\section{Standard from NGSS: MS-ETS1 Engineering Design}

Performance Expectation: MS-ETS1-1. Define the criteria and constraints of a design problem with sufficient precision to ensure a successful solution, taking into account relevant scientific principles and potential impacts on people and the natural environment that may limit possible solutions.

Performance Expectation: MS-ETS1-2. Evaluate competing design solutions using a systematic process to determine how well they meet the criteria and constraints of the problem.

Performance Expectation: MS-ETS1-3. Analyze data from tests to determine similarities and differences among several design solutions to identify the best characteristics of each that can be combined into a new solution to better meet the criteria for success.

Performance Expectation: MS-ETS1-4. Develop a model to generate data for iterative testing and modification of a proposed object, tool, or process such that an optimal design can be achieved.

\section{Other NeXt Generation Performance EXPeCtations}

Standard from NGSS: MS-LS2 Ecosystems: Interactions, Energy, and Dynamics

Performance Expectation: MS-LS2-5. Evaluate competing design solutions for maintaining biodiversity and ecosystem services.* [Clarification Statement: Examples of ecosystem services could include water purification, nutrient recycling, and prevention of soil erosion. Examples of design solution constraints could include scientific, economic, and social considerations.]

\section{Standard from NGSS: MS-ESS2 Earth's Systems}

Performance Expectation: MS-ESS2-2. Construct an explanation based on evidence for how geoscience processes have changed Earth's surface at varying time and spatial scales. [Clarification Statement: Emphasis is on how processes change Earth's surface at time and spatial scales that can be large (such as slow plate motions or the uplift of large mountain ranges) or small (such as rapid landslides or microscopic geochemical reactions), and how many geoscience processes (such as earthquakes, volcanoes, and meteor impacts) usually behave gradually but are punctuated by catastrophic events. Examples of geoscience processes include surface weathering and deposition by the movements of water, ice, and wind. 


\section{Appendix F}

Data Correlations Table for the OLWSEDU 2014-2015

The table below is set up to show the categories of columns and their relationship to the dependent variables (i.e. topics under investigation). The first column is aligned with the default Excel identifiers. The second column explains the instruments, gives total scores, and breaks down each question by number. The remaining columns are divided by the topics under consideration: Watershed literacy WSL; Human impacts on Stormwater HIS; Pro-environmental Attitude PEA; Place-based education PBE; Science, Technology, Engineering, and Math STEM. (The X in a column identifies a tie-in with the topic.)

Key to symbols: $*=$ missing data or not applicable; $\mathrm{X}=$ correlation; $\mathrm{Y}=$ yes; $\mathrm{N}=$ no; $1-30=$ points or score; $A-E=1-5$, (no hierarchy in Pre/Posttest, hierarchy in EAS);

\section{Key research question:}

To what extent does the Owl Lake Watershed and Stormwater Engineering Design Unit (OLWSEDU) increase the students' watershed literacy (WSL), knowledge of human impacts on stormwater (HIS), and promote pro-environmental attitudes (PEA)?

How does using a Place-based (PBE), Engineering Design (STEM) focused curriculum increase the relevancy and impact of the curriculum?

\begin{tabular}{|c|c|c|c|c|c|c|}
\hline Column & Instrument details & WSL & HIS & PEA & PBE & STEM \\
\hline A & Student ID Number: Teacher, Period, Individual & & & & & \\
\hline B & $\begin{array}{l}\text { Permission slip }=\mathrm{P}, \text { Additional Interview }=\mathrm{I}(\mathrm{ID} \# \\
\text { highlighted) }\end{array}$ & & & & & \\
\hline $\mathrm{C}$ & Instrument 3: Interview (INT) $\mathrm{Yes}=\mathrm{Y}, \mathrm{No}=\mathrm{N}$ & $\mathrm{X}$ & $\mathrm{X}$ & $\bar{X}$ & $\mathrm{X}$ & $\mathrm{X}$ \\
\hline $\mathrm{D}$ & $\begin{array}{l}\text { Instrument 2: Knowledge Questionnaire (CKQ) } \\
\text { (2a) and Attitude Survey (EAS) (2b) } \\
\text { Yes }=\mathrm{Y}, \mathrm{No}_{\mathrm{o}}=\mathrm{N}\end{array}$ & $\mathrm{X}$ & $\mathrm{X}$ & $\mathrm{X}$ & $\mathrm{X}$ & $(\mathrm{X})$ \\
\hline $\mathrm{E}$ & $\begin{array}{l}\text { Instrument 1: Pre-test(1a)-Posttest (1b) total Score } \\
\mathrm{n}=18\end{array}$ & $\mathrm{X}$ & $\mathrm{X}$ & & $\mathrm{X}$ & $\mathrm{X}$ \\
\hline $\mathrm{F}$ & Instrument 1a: Pretest $($ Pre) score $=\mathrm{n} / 18$ & $\mathrm{X}$ & $\mathrm{X}$ & & $\mathrm{X}$ & $\mathrm{X}$ \\
\hline G & Instrument 1b: Posttest (Post) score $=\mathrm{n} / 18$ & $\mathrm{X}$ & $\mathrm{X}$ & & $\mathrm{X}$ & $\mathrm{X}$ \\
\hline $\mathrm{H}$ & $\begin{array}{l}\text { Quest 1-E (Pre and Post Test Question 1, correct } \\
\text { answer =E) }\end{array}$ & NA & & & & \\
\hline I & $\begin{array}{l}\text { Pre 1-E (Pre Test Question 1, student's answer } \\
\text { correct }=1 \text {, incorrect }=0 \text { ) }\end{array}$ & $\mathrm{X}$ & & & & \\
\hline $\mathrm{J}$ & $\begin{array}{l}\text { Post 1-E (Posttest Question 1, student's answer } \\
\text { correct }=1 \text {, incorrect }=0 \text { ) }\end{array}$ & $\mathrm{X}$ & & & & \\
\hline $\mathrm{K}$ & $\begin{array}{l}\text { Quest } 2 \text {-D (Pre and Post Test Question 2, correct } \\
\text { answer=D ) }\end{array}$ & NA & & & & \\
\hline
\end{tabular}




\begin{tabular}{|c|c|c|c|c|c|c|}
\hline $\mathrm{L}$ & $\begin{array}{l}\text { Pre } 2 \text { - D (Pre Test Question 2, student correct = 1, } \\
\text { incorrect }=0 \text { ) }\end{array}$ & $X$ & & & & $X$ \\
\hline $\mathrm{M}$ & $\begin{array}{l}\text { Post } 2-\mathrm{D}(\text { Post Test Question 2, student correct }= \\
1, \text { incorrect }=0)\end{array}$ & $X$ & & & & $X$ \\
\hline $\mathrm{N}$ & $\begin{array}{l}\text { Quest } 3 \text {-D (Pre and Post Test Question 1, correct } \\
\text { answer =D) }\end{array}$ & NA & & & & \\
\hline $\mathrm{O}$ & $\begin{array}{l}\text { Pre 3- D (Pre Test Question 1, student's answer } \\
\text { correct }=1 \text {, incorrect }=0 \text { ) }\end{array}$ & $X$ & & & & $\mathrm{X}$ \\
\hline $\mathrm{P}$ & $\begin{array}{l}\text { Post } 3 \text { - D (Posttest Question 1, student's answer } \\
\text { correct = 1, incorrect }=0 \text { ) }\end{array}$ & $X$ & & & & $X$ \\
\hline Q & $\begin{array}{l}\text { Quest } 4-\mathrm{C} \text { (Pre and Post Test Question 1, correct } \\
\text { answer =C) }\end{array}$ & NA & & & & \\
\hline $\mathrm{R}$ & $\begin{array}{l}\text { Pre 4-C (Pre Test Question 1, student's answer } \\
\text { correct }=1 \text {, incorrect }=0 \text { ) }\end{array}$ & $X$ & & & & $X$ \\
\hline$S$ & $\begin{array}{l}\text { Post 4-C (Posttest Question 1, student's answer } \\
\text { correct }=1 \text {, incorrect }=0 \text { ) }\end{array}$ & $X$ & & & & $X$ \\
\hline $\mathrm{T}$ & $\begin{array}{l}\text { Quest } 5-\mathrm{C} \text { (Pre and Post Test Question 1, correct } \\
\text { answer =C) }\end{array}$ & NA & & & & \\
\hline $\mathrm{U}$ & $\begin{array}{l}\text { Pre 5-C (Pre Test Question 1, student's answer } \\
\text { correct }=1 \text {, incorrect }=0)\end{array}$ & $X$ & $X$ & $X$ & & $X$ \\
\hline V & $\begin{array}{l}\text { Post 5-C (Posttest Question 1, student's answer } \\
\text { correct }=1 \text {, incorrect }=0 \text { ) }\end{array}$ & $X$ & $X$ & $X$ & & $X$ \\
\hline W & $\begin{array}{l}\text { Quest } 6 \text { - B (Pre and Post Test Question 1, correct } \\
\text { answer =B) }\end{array}$ & NA & & & & \\
\hline$X$ & $\begin{array}{l}\text { Pre 6-B (Pre Test Question 1, student's answer } \\
\text { correct }=1 \text {, incorrect }=0 \text { ) }\end{array}$ & $X$ & & & $X$ & $X$ \\
\hline $\mathrm{Y}$ & $\begin{array}{l}\text { Post 6-B (Posttest Question 1, student's answer } \\
\text { correct }=1 \text {, incorrect }=0 \text { ) }\end{array}$ & $X$ & & & $X$ & $X$ \\
\hline Z & $\begin{array}{l}\text { Quest } 7 \text { - D (Pre and Post Test Question 1, correct } \\
\text { answer =D) }\end{array}$ & NA & & & & \\
\hline AA & Pre 7-D (Pre Test Question 1, student's answer) & $\mathrm{X}$ & & & $\mathrm{X}$ & $\mathrm{X}$ \\
\hline $\mathrm{AB}$ & Post 7-D (Posttest Question 1, student's answer) & $\mathrm{X}$ & & & $\mathrm{X}$ & $\mathrm{X}$ \\
\hline $\mathrm{AC}$ & $\begin{array}{l}\text { Quest } 8-\mathrm{C} \text { (Pre and Post Test Question 1, correct } \\
\text { answer =C) }\end{array}$ & NA & & & & \\
\hline $\mathrm{AD}$ & Pre 8-C (Pre Test Question 1, student’s answer) & $\mathrm{X}$ & & & $\mathrm{X}$ & $\mathrm{X}$ \\
\hline $\mathrm{AE}$ & Post 8-C (Posttest Question 8, student's answer) & $\mathrm{X}$ & & & $\mathrm{X}$ & $\mathrm{X}$ \\
\hline $\mathrm{AF}$ & $\begin{array}{l}\text { Quest } 9-\mathrm{E} \text { (Pre and Post Test Question 1, correct } \\
\text { answer =E) }\end{array}$ & NA & & & & \\
\hline AG & Pre 9-E (Pre Test Question 1, student's answer) & $\mathrm{X}$ & & & & $\mathrm{X}$ \\
\hline $\mathrm{AH}$ & Post 9-E (Posttest Question 1, student's answer) & $\mathrm{X}$ & & & & $\mathrm{X}$ \\
\hline AI & Post Subtotal of WSL \#1-9 & $\mathrm{X}$ & & & & \\
\hline $\mathrm{AJ}$ & $\begin{array}{l}\text { Quest } 10-\text { E (Pre \& Post Test Question 1, correct } \\
\text { answer =E) }\end{array}$ & NA & & & & \\
\hline $\mathrm{AK}$ & Pre 10-E (Pre Test Question 1, student's answer) & $\mathrm{X}$ & $\mathrm{X}$ & & & $\mathrm{X}$ \\
\hline $\mathrm{AL}$ & Post 10-E (Posttest Question 1, student's answer) & $\mathrm{X}$ & $\mathrm{X}$ & & & $\mathrm{X}$ \\
\hline $\mathrm{AM}$ & $\begin{array}{l}\text { Quest 11- E (Pre and Post Test Question 1, correct } \\
\text { answer =E) }\end{array}$ & NA & & & & \\
\hline AN & Pre 11-E (Pre Test Question 1, student's answer) & $\mathrm{X}$ & $\mathrm{X}$ & & $\mathrm{X}$ & $\mathrm{X}$ \\
\hline $\mathrm{AO}$ & Post 11-E (Posttest Question 1, student's answer) & $\mathrm{X}$ & $\mathrm{X}$ & & $\mathrm{X}$ & $\mathrm{X}$ \\
\hline AP & $\begin{array}{l}\text { Quest } 12-\mathrm{A}(\text { Pre and Post Test Question 1, } \\
\text { correct answer =A) }\end{array}$ & NA & & & & \\
\hline
\end{tabular}




\begin{tabular}{|c|c|c|c|c|c|c|}
\hline AQ & Pre 12-A (Pre Test Question 1, student's answer) & $\mathrm{X}$ & $\mathrm{X}$ & & & $\mathrm{X}$ \\
\hline AR & Post 12-A (Posttest Question 1, student's answer) & $\mathrm{X}$ & $\mathrm{X}$ & & & $\mathrm{X}$ \\
\hline AS & Post Subtotal of HIS \#10-12 & $\mathrm{X}$ & $\mathrm{X}$ & & & \\
\hline AT & $\begin{array}{l}\text { Quest } 13-\mathrm{E} \text { (Pre and Post Test Question 1, } \\
\text { correct answer =E) }\end{array}$ & NA & & & & \\
\hline AU & Pre 13-E (Pre Test Question 1, student's answer) & & $\mathrm{X}$ & & & $\mathrm{X}$ \\
\hline AV & Post 13-E (Posttest Question 1, student's answer) & & $\mathrm{X}$ & & & $\mathrm{X}$ \\
\hline $\mathrm{AW}$ & $\begin{array}{l}\text { Quest } 14-\text { B (Pre and Post Test Question 1, } \\
\text { correct answer =B) }\end{array}$ & NA & & & & \\
\hline AX & Pre 14-B (Pre Test Question 1, student's answer) & & $(\mathrm{X})$ & & & $\mathrm{X}$ \\
\hline AY & Post 14-B (Posttest Question 1, student's answer) & & $(\mathrm{X})$ & & & $\mathrm{X}$ \\
\hline $\mathrm{AZ}$ & $\begin{array}{l}\text { Quest } 15-\mathrm{C}(\text { Pre and Post Test Question 1, } \\
\text { correct answer =C) }\end{array}$ & NA & & & & \\
\hline BA & Pre 15-C (Pre Test Question 1, student's answer) & & $(\mathrm{X})$ & & & $\mathrm{X}$ \\
\hline BB & Post 15-C (Posttest Question 1, student's answer) & & $(\mathrm{X})$ & & & $\mathrm{X}$ \\
\hline BC & $\begin{array}{l}\text { Quest } 16-\mathrm{A} \text { (Pre \& Post Test Question 1, correct } \\
\text { answer =A) }\end{array}$ & NA & & & & \\
\hline $\mathrm{BD}$ & Pre 16-A (Pre Test Question 1, student's answer) & & $(\mathrm{X})$ & & & $\mathrm{X}$ \\
\hline $\mathrm{BE}$ & Post 16-A (Posttest Question 1, student's answer) & & $(\mathrm{X})$ & & & $\mathrm{X}$ \\
\hline $\mathrm{BF}$ & $\begin{array}{l}\text { Quest } 17-\text { A (Pre \& Post Test Question 1, correct } \\
\text { answer =A) }\end{array}$ & NA & & & & \\
\hline BG & Pre 17-A (Pre Test Question 1, student's answer) & & $(\mathrm{X})$ & & & $\mathrm{X}$ \\
\hline $\mathrm{BH}$ & Post 17-A (Posttest Question 1, student's answer) & & $(\mathrm{X})$ & & & $\mathrm{X}$ \\
\hline BI & $\begin{array}{l}\text { Quest } 18 \text { - B (Pre \& Post Test Question 1, correct } \\
\text { answer =B) }\end{array}$ & NA & & & & \\
\hline BJ & Pre 18-B (Pre Test Question 1, student's answer) & & & & & $\mathrm{X}$ \\
\hline BK & Post 18-B (Posttest Question 1, student's answer) & & & & & $\mathrm{X}$ \\
\hline $\mathrm{BL}$ & Post subtotal of STEM \#s13-18 & & & & & $\mathrm{X}$ \\
\hline BM & $\begin{array}{l}\text { Posttest and CKQ together } \\
\text { (subset, } \mathrm{n}=42,42 / 359)\end{array}$ & $X$ & $X$ & $X$ & $X$ & $X$ \\
\hline $\mathrm{BN}$ & $\begin{array}{l}\text { Constructed Knowledge Questionnaire }(\mathrm{CKQ} / 2 \mathrm{a}) \\
\text { total possible points } n=30\end{array}$ & NA & & & & \\
\hline BO & $\begin{array}{l}\text { Constructed Knowledge Questionnaire (CKQ/ 2a) } \\
\text { total possible given } \mathrm{n} / 30\end{array}$ & $\mathrm{X}$ & $\mathrm{X}$ & & $X$ & $X$ \\
\hline BP & $\begin{array}{l}\text { CKQ\# } 1, \mathrm{n}=6 \\
\text { (Question } 1,6 \text { pts allowed) }\end{array}$ & NA & & & & \\
\hline BQ & CKQ\# 1 (n/6 points received) & $\mathrm{X}$ & & & & $\mathrm{X}$ \\
\hline BR & $\begin{array}{l}\text { CKQ 2, n=12 } \\
\text { (Question 2, } 12 \text { pts allowed) }\end{array}$ & NA & & & $\mathrm{X}$ & \\
\hline BS & CKQ 2 (n/12points received) & $\mathrm{X}$ & & & $\mathrm{X}$ & $\mathrm{X}$ \\
\hline BT & $\begin{array}{l}\text { CKQ\# 3, } \mathrm{n}=2 \\
\text { (Question 3, 2pts allowed) }\end{array}$ & NA & & & & \\
\hline $\mathrm{BU}$ & CKQ\# 3 (n/2 points received) & $\mathrm{X}$ & & & $\mathrm{X}$ & $\mathrm{X}$ \\
\hline $\mathrm{BV}$ & CKQ Subtotal of WSL \#s 1-3 & $\mathrm{X}$ & & & $\mathrm{X}$ & \\
\hline BW & $\begin{array}{l}\text { CKQ\# 4, } \mathrm{n}=2 \\
\text { (Question 4, 2pts allowed) }\end{array}$ & NA & & & & \\
\hline $\mathrm{BX}$ & CKQ\# 4 (n/2 points received) & $\mathrm{X}$ & $\mathrm{X}$ & & & $\mathrm{X}$ \\
\hline BY & $\begin{array}{l}\text { CKQ\# 5, n= } 4 \\
\text { (Question 5, 4pts allowed) }\end{array}$ & NA & & & & \\
\hline $\mathrm{BZ}$ & CKQ\# 5 (n/4 points received) & $\mathrm{X}$ & $\mathrm{X}$ & & & $\mathrm{X}$ \\
\hline
\end{tabular}




\begin{tabular}{|c|c|c|c|c|c|c|}
\hline $\mathrm{CA}$ & $\begin{array}{l}\text { CKQ\# 6, } \mathrm{n}=2 \\
\text { (Question 6, 2 pts allowed) }\end{array}$ & NA & & & & \\
\hline $\mathrm{CB}$ & CKQ\# 6 (n/2 points received) & $\mathrm{X}$ & $\mathrm{X}$ & $(\mathrm{X})$ & $\mathrm{X}$ & $\mathrm{X}$ \\
\hline $\mathrm{CC}$ & CKQ Subtotal of HIS \#s4-6 & $\mathrm{X}$ & $\mathrm{X}$ & & & \\
\hline $\mathrm{CD}$ & $\begin{array}{l}\text { CKQ\# 7, } \mathrm{n}=2 \\
\text { (Question 1, 2pts allowed) }\end{array}$ & NA & & & & \\
\hline $\mathrm{CE}$ & CKQ\# 7 (n/2 points received) & & $\mathrm{X}$ & & $\mathrm{X}$ & $\mathrm{X}$ \\
\hline $\mathrm{CF}$ & CKQ Subtotal of STEM \#7 & & $\mathrm{X}$ & & $\mathrm{X}$ & $\mathrm{X}$ \\
\hline CG & $\begin{array}{l}\text { Environ. Attitude Survey (EAS/ 2b) } \\
\text { \#1 Keep rivers clean, } \\
\text { Before the unit }\end{array}$ & $\mathrm{X}$ & & $\mathrm{X}$ & & \\
\hline $\mathrm{CH}$ & EAS \#1 After the unit & $\mathrm{X}$ & & $\mathrm{X}$ & & \\
\hline $\mathrm{CI}$ & $\begin{array}{l}\text { EAS \#1 Change (Change Codes, Positive }=+1-5 \text {, } \\
\text { Negative }=-1-5, \text { No Change }=O\end{array}$ & $\mathrm{X}$ & & $\mathrm{X}$ & & \\
\hline CJ & EAS \#2 Protect watershed for drinking, Before & $\mathrm{X}$ & & $\mathrm{X}$ & & \\
\hline CK & EAS \#2 After & $\mathrm{X}$ & & $\mathrm{X}$ & & \\
\hline CL & EAS \#2 Amount of Change in WSL & $\mathrm{X}$ & & $\mathrm{X}$ & & \\
\hline $\mathrm{CM}$ & EAS \#3 Personal responsibility, Before & & & $\mathrm{X}$ & & \\
\hline $\mathrm{CN}$ & EAS \#3 After & & & $\mathrm{X}$ & & \\
\hline $\mathrm{CO}$ & EAS \#3 Change in PEA & & & $\mathrm{X}$ & & \\
\hline $\mathrm{CP}$ & EAS \#4 Impervious surfaces, Before & $\mathrm{X}$ & $\mathrm{X}$ & $\mathrm{X}$ & & $\mathrm{X}$ \\
\hline CQ & EAS \#4 After & $\mathrm{X}$ & $\mathrm{X}$ & $\mathrm{X}$ & & $\mathrm{X}$ \\
\hline $\mathrm{CR}$ & EAS \#4 Change in HIS & $\mathrm{X}$ & $\mathrm{X}$ & $\mathrm{X}$ & & $\mathrm{X}$ \\
\hline $\mathrm{CS}$ & EAS \#5 Local government, Before & $\mathrm{X}$ & & & $\mathrm{X}$ & \\
\hline CT & EAS \#5 After & $\mathrm{X}$ & & & $\mathrm{X}$ & \\
\hline $\mathrm{CU}$ & EAS \#5 Change in PBE & $\mathrm{X}$ & & & $\mathrm{X}$ & \\
\hline $\mathrm{CV}$ & EAS \#6 Work on project, Before & & $\mathrm{X}$ & $\mathrm{X}$ & $\mathrm{X}$ & \\
\hline $\mathrm{CW}$ & EAS \#6 After & & $\mathrm{X}$ & $\mathrm{X}$ & $\mathrm{X}$ & \\
\hline CX & EAS \#6 Change in PEA/PBE & & $\mathrm{X}$ & $\mathrm{X}$ & $\mathrm{X}$ & \\
\hline CY & EAS \#7 Make watershed cleaner, Before & $\mathrm{X}$ & $\mathrm{X}$ & $\mathrm{X}$ & $\mathrm{X}$ & \\
\hline $\mathrm{CZ}$ & EAS \#7 After & $\mathrm{X}$ & $\mathrm{X}$ & $\mathrm{X}$ & $\mathrm{X}$ & \\
\hline DA & EAS \#7 Change in HIS & $\mathrm{X}$ & $\mathrm{X}$ & $\mathrm{X}$ & $\mathrm{X}$ & \\
\hline DB & EAS total Before, $n / 35$ & $\mathrm{X}$ & $\mathrm{X}$ & $\mathrm{X}$ & $\mathrm{X}$ & \\
\hline $\mathrm{DC}$ & EAS total After, n/35 & $\mathrm{X}$ & $\mathrm{X}$ & $\mathrm{X}$ & $\mathrm{X}$ & \\
\hline DD & EAS total Change, $\mathrm{n} / 5$ & $\mathrm{X}$ & $\mathrm{X}$ & $\mathrm{X}$ & $\mathrm{X}$ & \\
\hline $\mathrm{DE}$ & EAS \#8 Change one thing, Future & $\mathrm{X}$ & $\mathrm{X}$ & $\mathrm{X}$ & $\mathrm{X}$ & \\
\hline DF & EAS \#9 Tell others, Future & $\mathrm{X}$ & $\mathrm{X}$ & $\mathrm{X}$ & $\mathrm{X}$ & \\
\hline DG & EAS \#10 Volunteer to help, Future & $\mathrm{X}$ & $\mathrm{X}$ & $\mathrm{X}$ & $\mathrm{X}$ & \\
\hline DH & EAS \#11 Tell my family, Future & $\mathrm{X}$ & $\mathrm{X}$ & $\mathrm{X}$ & $\mathrm{X}$ & \\
\hline DI & EAS \#12 Help keep watersheds cleaner, Future & $\mathrm{X}$ & $\mathrm{X}$ & $\mathrm{X}$ & $\mathrm{X}$ & \\
\hline DJ & EAS \# 13 Spend more time outdoors, Future & $\mathrm{X}$ & $\mathrm{X}$ & $\mathrm{X}$ & $\mathrm{X}$ & \\
\hline DK & EAS total Future & & & & & \\
\hline DL & Interview notes: (WSL)Watershed literacy & $\mathrm{X}$ & & & & \\
\hline DM & Interview notes: (HIS)Human Impacts & & $\mathrm{X}$ & & & \\
\hline DN & $\begin{array}{l}\text { Interview notes: (PEA)Pro-environmental attitudes } \\
\text { or behaviors }\end{array}$ & & & $\mathrm{X}$ & & \\
\hline DO & Interview notes: (PBE)Place-based education & & & & $\mathrm{X}$ & \\
\hline DP & $\begin{array}{l}\text { Interview notes: STEM Science, Technology, } \\
\text { Engineering, and Math }\end{array}$ & & & & & $\mathrm{X}$ \\
\hline
\end{tabular}




\section{Research questions below:}

\section{Key research question:}

To what extent does the Owl Lake Watershed and Stormwater Engineering Design Unit (OLWSEDU) increase the students' watershed literacy (WSL), knowledge of human impacts on stormwater (HIS), and promote pro-environmental attitudes (PEA)?

How does using a Place-based (PBE), Engineering Design (STEM) focused curriculum increase the relevancy and impact of the curriculum?

\section{List of embedded questions and hypotheses:}

1. Was there a significant increase in overall watershed literacy as shown by the students' cumulative scores between the Pre-test and the Posttest?

Null hypothesis 1: there is no relationship between the Pretest (column F) and Posttest (column G).

2. Is there a relationship between the students' cumulative scores on the Posttest and their total scores on the Constructed knowledge questionnaire (CKQ)? Do students that do well on the Posttest also do well on the CKQ?

Null hypothesis 2: there is no relationship between ___ Posttest (column G) and CKQ (column BO).

3. Is there a correlation between the students' Posttest scores for the Objective 1, Watershed literacy (WSL) and the students' scores on the watershed literacy portion of the CKQ?

Null hypothesis 3: there is no relationship between ___ Posttest (column AI) and CKQ (column BV)

4. Is there a correlation between the students' Posttest scores for Objective 2, Human impacts HIS and the scores on the impervious surfaces section of the CKQ? Null hypothesis 4: there is no relationship between Posttest (column AS) and CKQ (column CC)

5. Are there any correlations between the students' Posttest scores for Objective 3, Engineering Design Process EDP and the scores on the EDP portion of the CKQ? Null hypothesis 5: there is no relationship between __ Posttest (column BL) and CKQ (column CF)

6a. With regards to the student's Pro-environmental Attitude (PEA) before, was there a significant increase in their PEA after having completed the OLWSEDU unit? 
Null hypothesis 6: there is no relationship between EAS Before (column DB) and EAS After (column DC) (Would it make sense to do the three-way with DD?)

6b. Whisker plot analysis of Before, After, and Change for each of the following PEA subsections: EAS1. CG, CH, CI (WSL); EAS2. CJ, CK, CL (WSL); EAS3. CM, CN, CO (PEA); EAS4. CP, CQ, CR (HIS); EAS5.CS, CT, CV (PBE); EAS6. CV, CW, CX (PBE); EAS7. CY, CZ, DA (HIS) (I am wondering how to incorporate my questions about Future intentions into this analysis, perhaps a Before, After, Future instead of Change? Does that work? I will examine the questions more closely and get back to you.)

7. Is there a correlation among students who have a higher level of inclusive (STEM) watershed literacy and who exhibit an increased pro-environmental tendency? Null hypothesis 7: there is no relationship between high scores Posttest AND CKQ (column BM) and EAS intent to act in the Future (column DK)

8. Is there a correlation among students who have a lower level of inclusive (STEM) watershed literacy have an increased pro-environmental tendency? Null hypothesis 8: there is no relationship between low scores (column BM) and intent to act in the Future (column DK)

9. Place based questions: Is there a correlation between reading local maps and knowing ones' watershed address? Do students who can read local maps do as well on naming their watershed address?

Null hypothesis 9: there is no relationship between ___ Posttest question \#6 (column Y) and __ CKQ question \# 2 (column BS)

10. Is there a significant relationship between students' perception of personal responsibility and their intent to act upon this sense of duty? Null hypothesis 10: there is no relationship between PEA question \#4 (column CK) and EAS question \#8 (column DE) 
Appendix G: Excel Quick Analysis snapshot

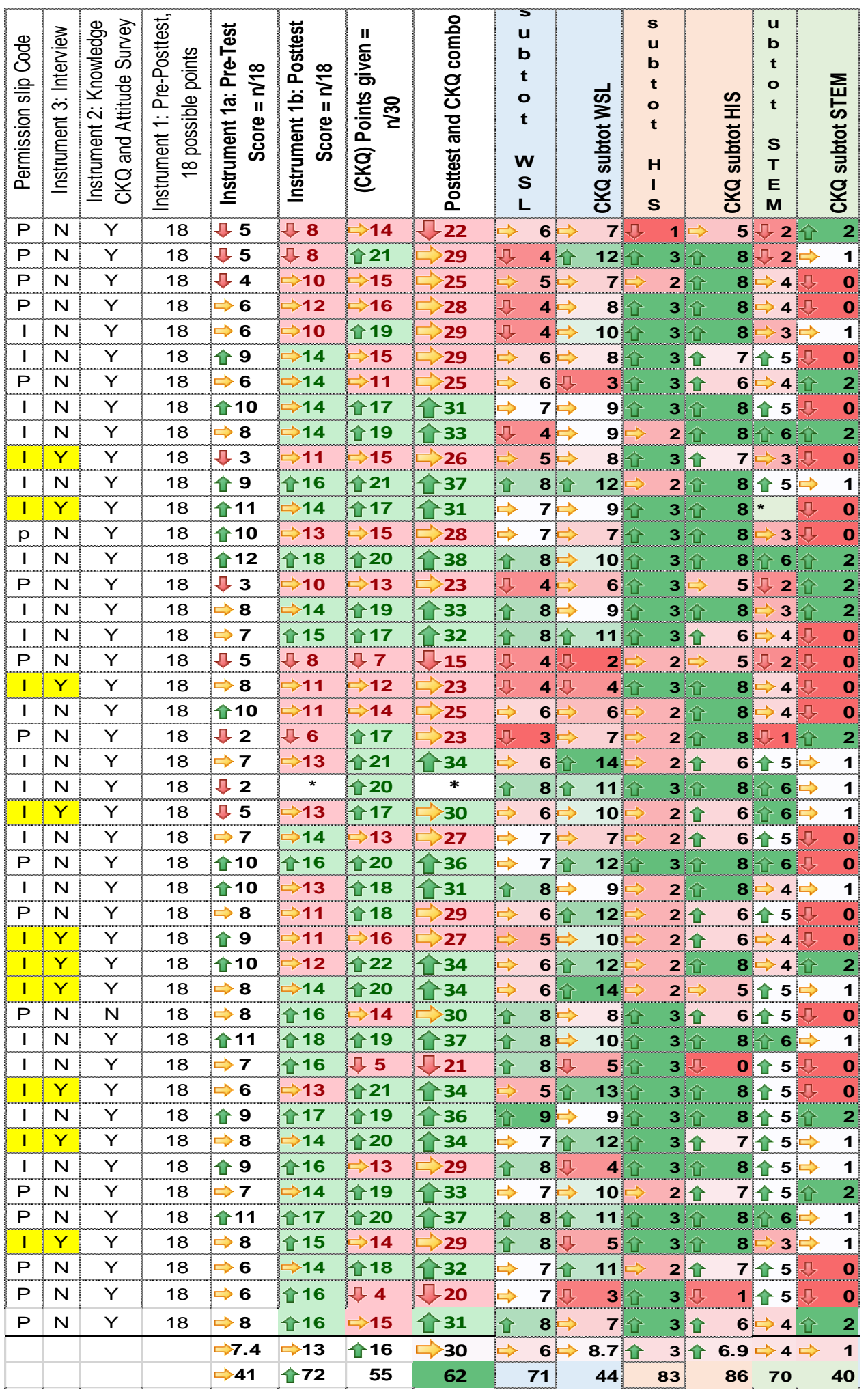


Appendix H: Human Subject Protocols and Consent forms

Research and Strategic Partnerships

Post Office Box 751 (RSP) 503-725-2227 tel

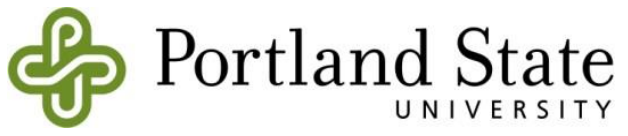

Human Subjects Research Review Committee

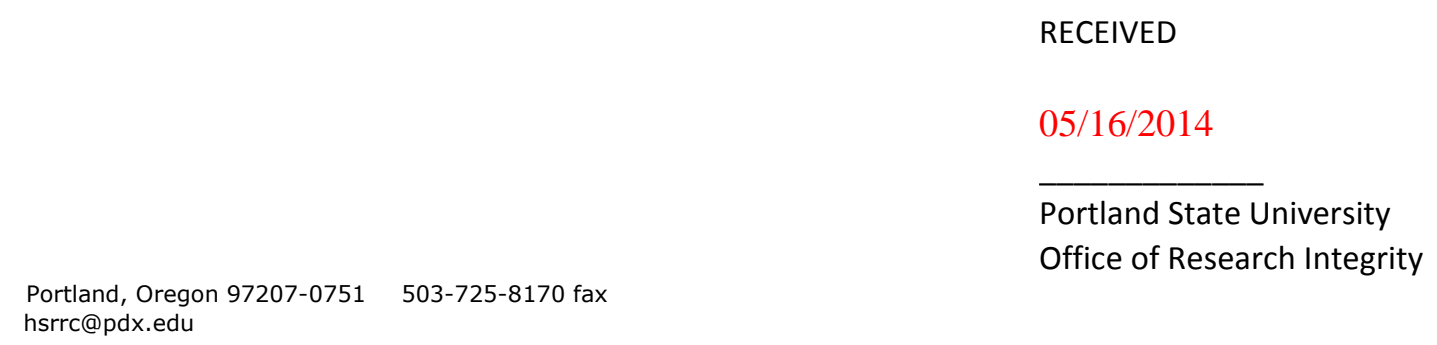

\title{
Amendment of IRB Protocol Form
}

IRB Number: _ 132580

Title: Solving Local Watershed Problems: A measurement of student success with the engineering design.

Funding Agency:_Oswego Lake Watershed Council

PIAF \#

\author{
Principal Investigator: Stephanie \\ Wagner Student Investigator: Riley \\ Meinershagen \\ Department: Center for Science Education \\ Emails: stwagner@pdx.edu \\ meinershagen@gmail.com
}


Phones: 503-803-7708

503-320-6685

Please send all documents electronically to HSRRC@pdx.edu. Hard copies are not accepted.

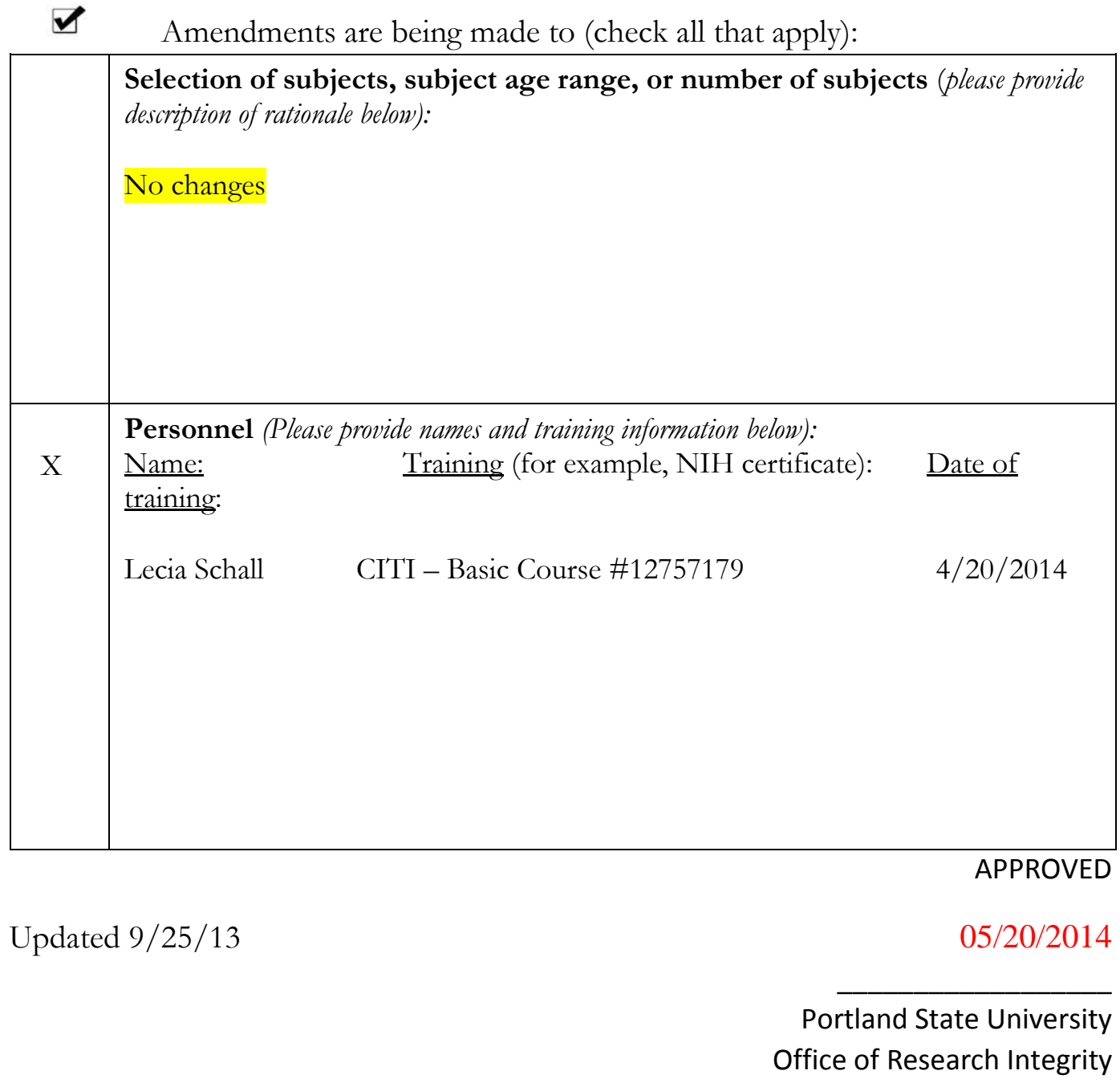

RECEIVED

$05 / 16 / 2014$

Portland State University 


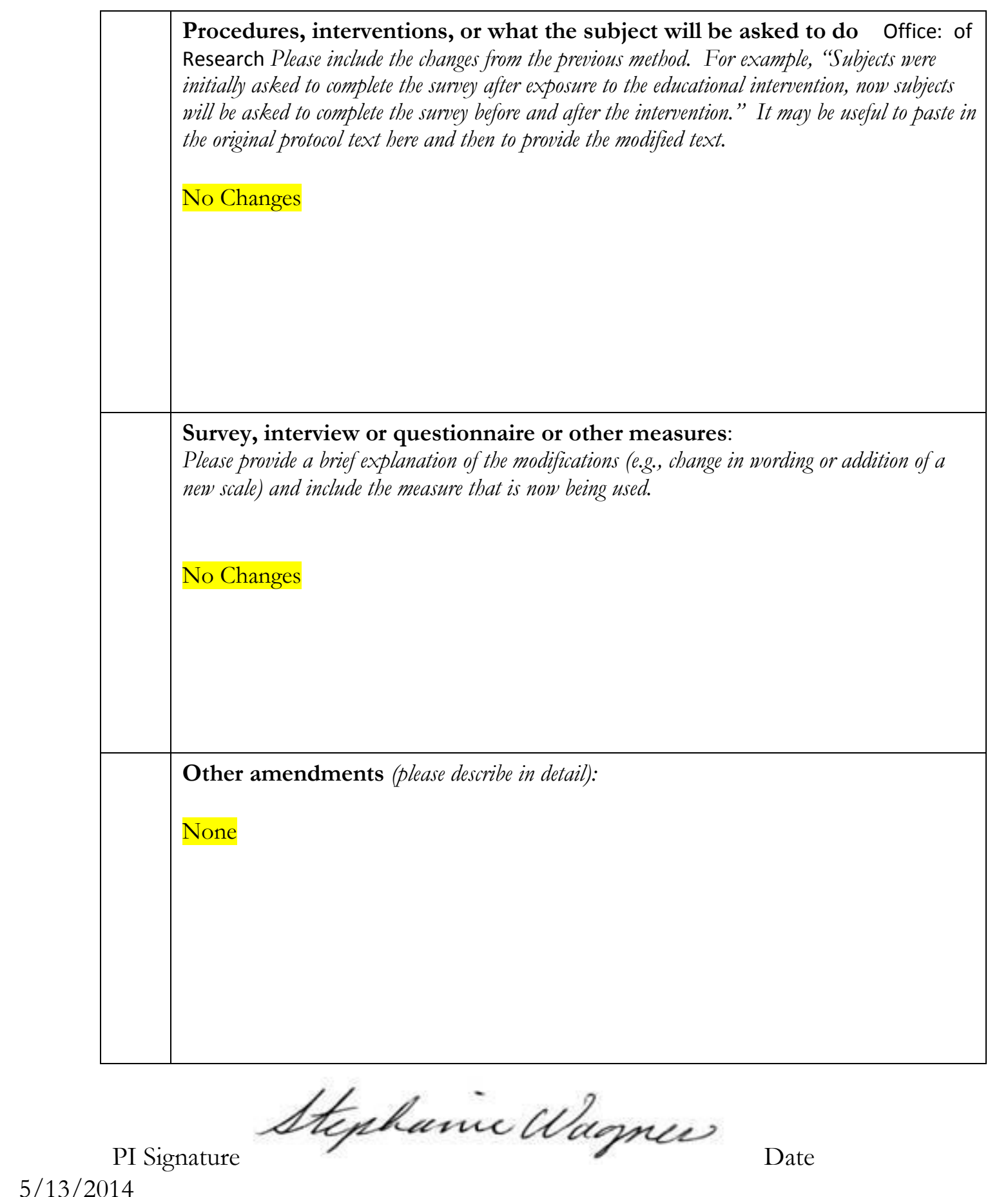

